Aus der Abteilung Prothetik

(Komm. Direktor: PD Dr. med. dent. N. Gersdorff)

im Zentrum Zahn-, Mund- und Kieferheilkunde

der Medizinischen Fakultät der Universität Göttingen

\title{
Untersuchung von osteoarthrotisch geschädigten Kiefergelenken an geeigneten Knockout-Maus-Modellen
}

\section{INAUGURAL - DISSERTATION}

\author{
zur Erlangung des Doktorgrades \\ für Zahnheilkunde \\ der Medizinischen Fakultät \\ der Georg-August-Universität zu Göttingen
}

\author{
vorgelegt von \\ Hetal Gajjar \\ aus \\ Karlsruhe
}

Göttingen 2011 
Dekan:

I. Berichterstatter:

II. Berichterstatter/in:

III. Berichterstatter/in:

Tag der mündlichen Prüfung:
Prof. Dr. med. C. Frömmel

Prof. Dr. med. N. Miosge

Priv.-Doz. Dr. med. dent. R. Gruber

Prof. Dr. med. M. Oppermann

03.07.2012 
Meiner Familie 


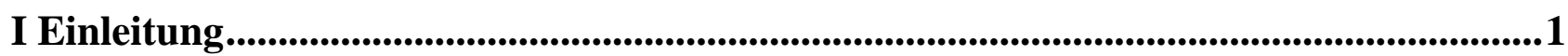

I.1 Einführung in das Thema ................................................................................................................ 1

I.2 Anatomie des Kiefergelenks.............................................................................................................3

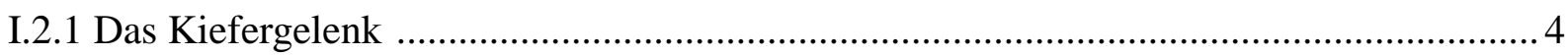

I.2.2 Kondylus (Processus condylaris mandibulae) .......................................................... 4

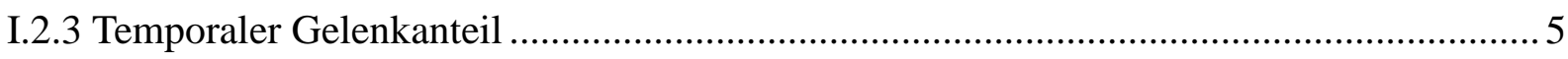

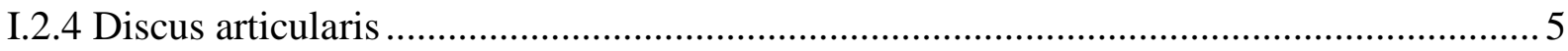

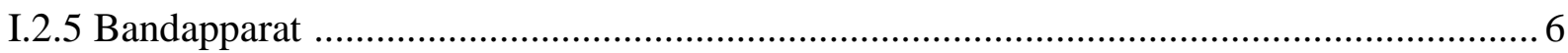

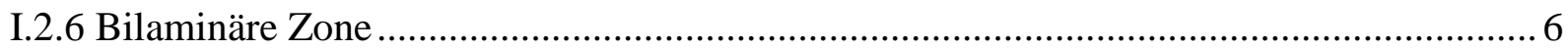

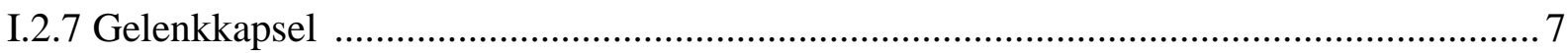

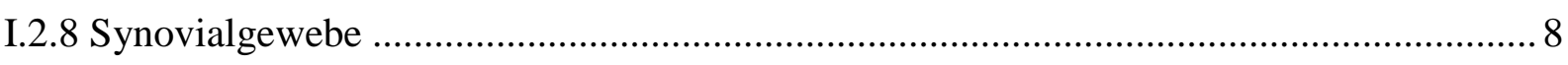

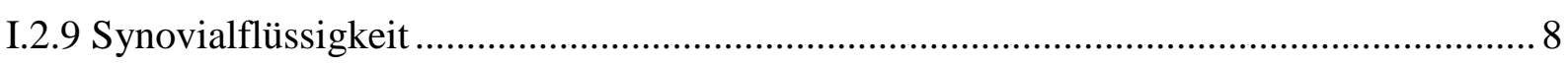

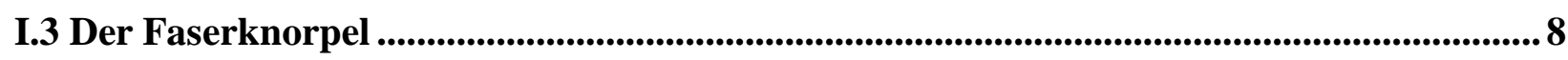

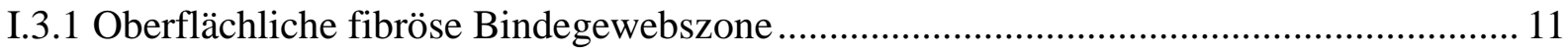

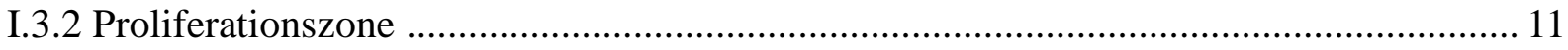

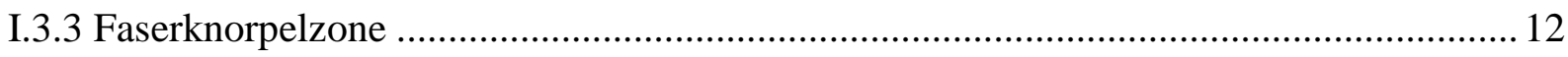

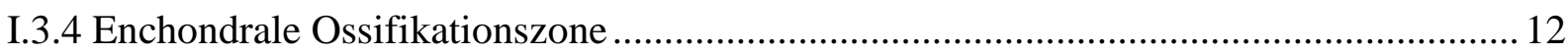

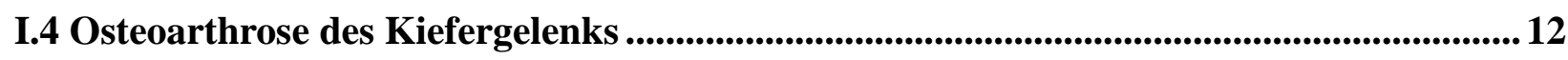

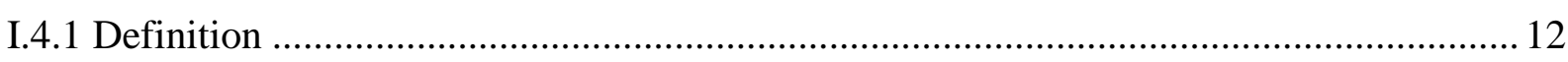

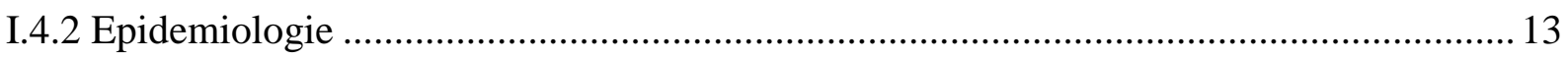

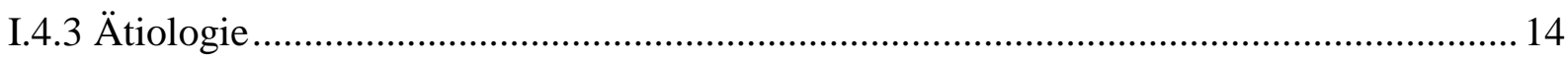

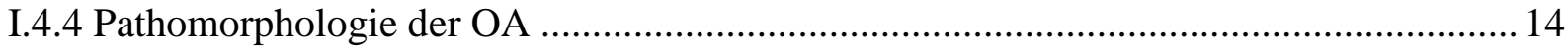

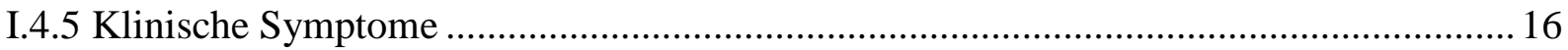

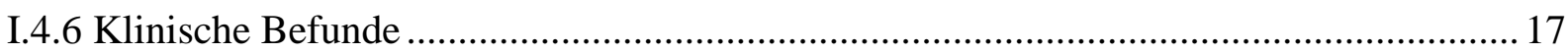

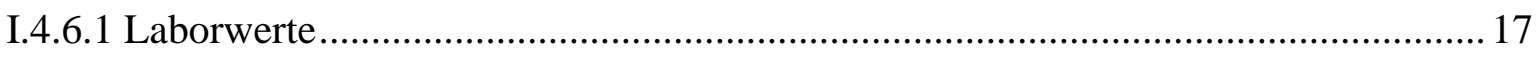

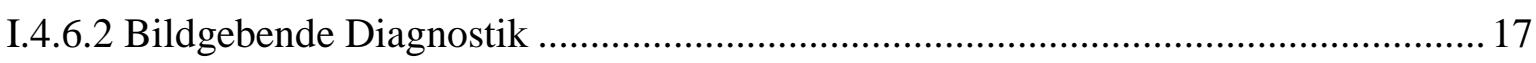

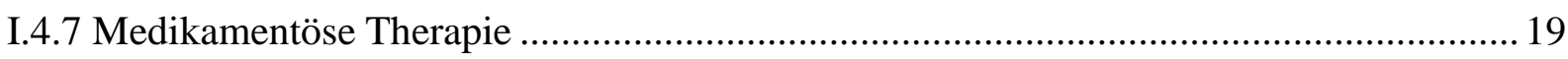

I.5 Maus-Modelle zur Untersuchung der OA ..........................................................................20

I.5.1 Institute-for-Cancer-Research-Caesarean-Derived-1 (ICR-CD1)-Maus-Modell............ 20

I.5.2 Naval-Medical-Research-Institute (NMRI)-Maus-Modell ........................................ 21

I.5.3 Nidogen-2-Knockout (KO)-Maus-Modell ............................................................... 22

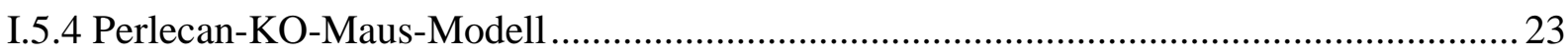

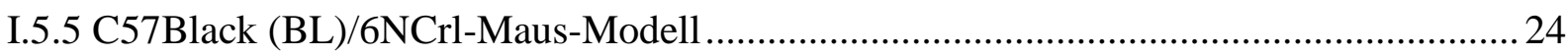




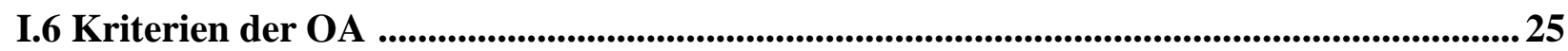

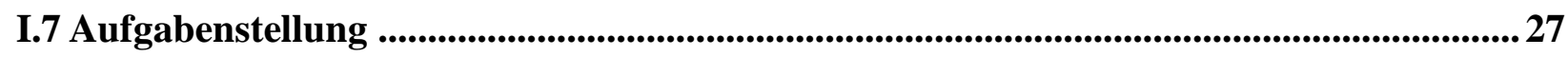

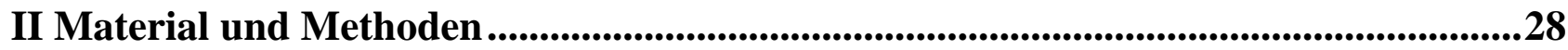

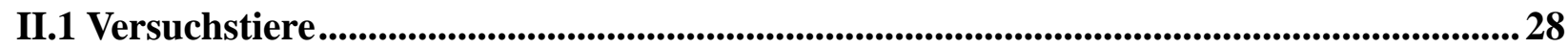

II.2 Präparation ...........................................................................................................................................28

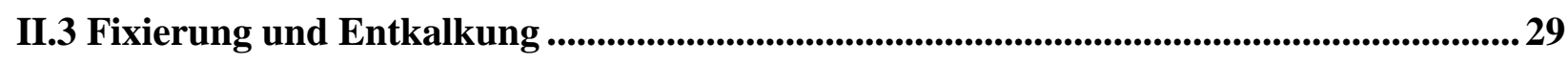

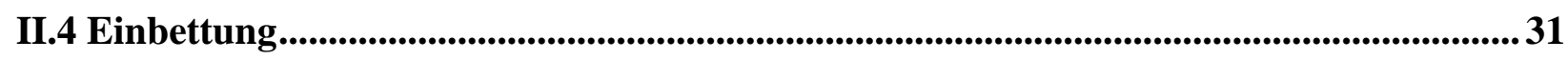

II.5 Anfertigung der Gewebeschnitte.............................................................................................. 32

II.6 Histologische Färbungen .................................................................................................................... 32

II.6.1 Prinzip der Hämatoxylin-Eosin-Färbung ..................................................................... 33

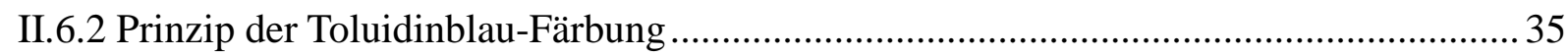

II.7 Lichtmikroskopie, Fotografie und Digitalisierung der Gewebeschnitte ...........................36

II.8 Verwendete Reagenzien, Verbrauchsmaterialien und Geräte .......................................37

III Ergebnisse .......................................................................................................................40

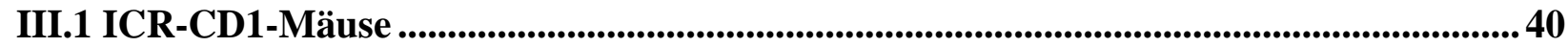

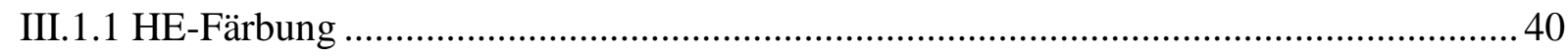

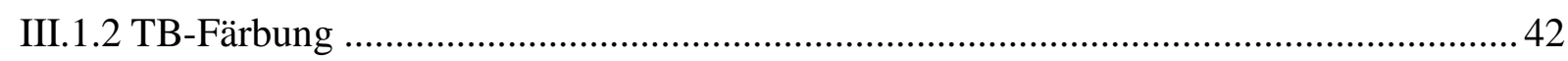

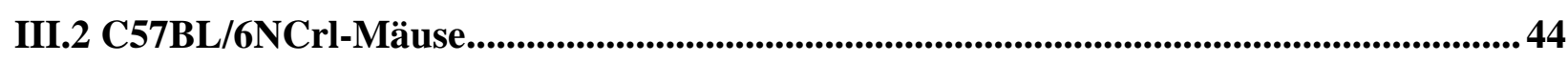

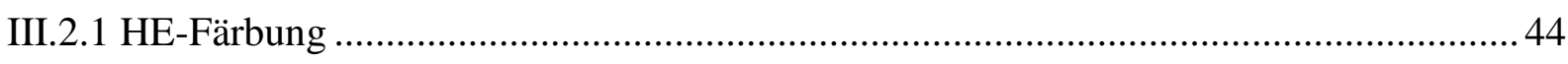

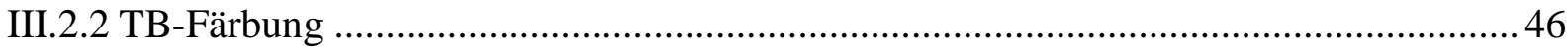

III.3 NMRI-Mäuse ................................................................................................................................................. 48

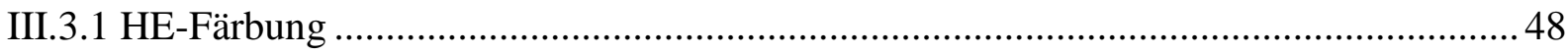

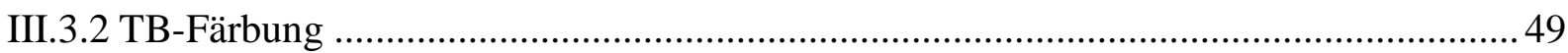

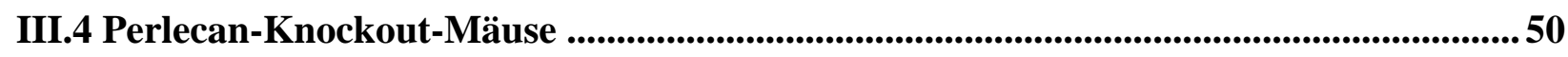

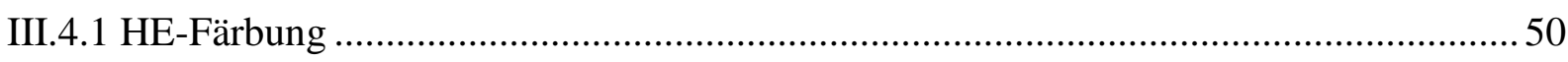

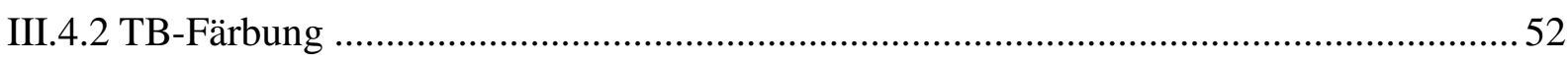

III.5 Nidogen-2-Knockout-Mäuse.........................................................................................................5 53

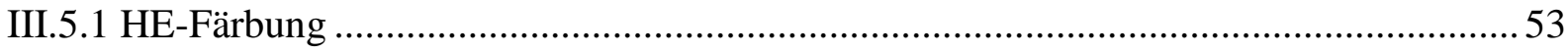

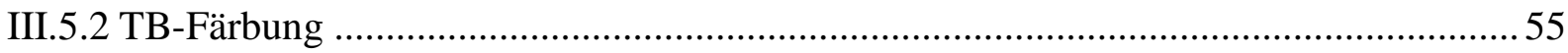

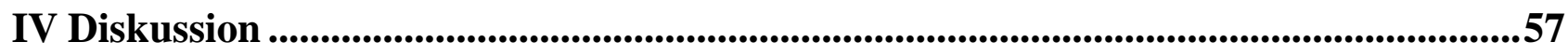

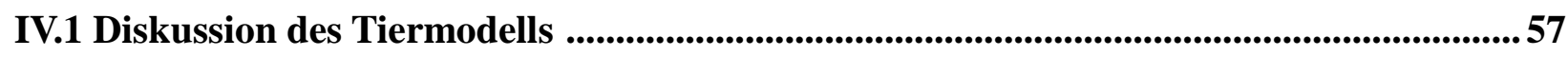

IV.2 Diskussion der verschiedenen Maus-Modelle zur Kiefergelenksosteoarthrose...............58

IV.3 Diskussion der Ergebnisse ....................................................................................................................61

V Zusammenfassung .........................................................................................................66

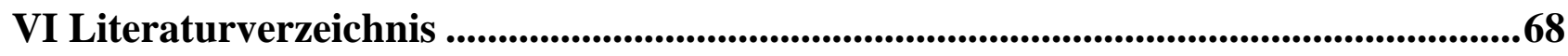




\section{Einleitung}

\section{I.1 Einführung in das Thema}

Das Kiefergelenk ist das meist genutzte Gelenk des Körpers (http://www.gzfa.de). Es besteht aus verschiedenen Komponenten, die den Funktionsablauf des Gelenks ermöglichen. 1949 wurde das Kiefergelenk als ein echtes, zusammengesetztes Gelenk beschrieben, das aus einem kaudal liegenden Drehgelenk besteht, welches gegen eine darüber liegende Gelenkfläche gleitet (Sicher 1949). Zusätzliche Komponenten des Kiefergelenks verbinden über seitlich begleitende Bänder den Diskus articularis mit dem Kondylus (Sicher 1951). Die häufigste Erkrankung des Kiefergelenks ist die Osteoarthrose (Blackwood 1963; Stanson und Baker 1976). Die Osteoarthrose (OA) ist die häufigste Form der Arthrose und ist ein führender Grund für eine chronische Invalidität, die größtenteils durch die Beteiligung der Knie oder der Hüfte bedingt ist (Moskowitz et al. 2007). Der Begriff der Arthrose beschreibt die Abnutzungserscheinung der gelenkbildenden Einheiten. Dieser Vorgang stellt eine Reaktion des Körpers auf unterschiedliche Reize auf das erkrankte Organ dar. Man differenziert dabei zwischen der (Osteo-)Arthritis, die primär durch entzündliche immunologische Reize begleitet wird, und der (Osteo-)Arthrose, die ätiologisch ein multifaktorielles Zusammenspiel darstellt (Knahr und Pinggera 2001). Die OA ist klinisch gesehen ein heterogener Zustand mit nicht vollständig geklärter Genese. Das menschliche Gelenk entwickelt häufig degenerative OA-Läsionen. Dabei ist der Gelenkknorpel ein hochspezialisiertes Verbindungsgewebe, welches die Enden der Knochen und der Gelenkgrube überzieht. Dieses Gewebe ermöglicht harmonische Bewegungen und erleichtert die gleichmäßige Kraftübertragung und -verteilung durch das Abfedern des unterhalb des Knorpels liegenden subchondralen Knochens. Die mechanischen Eigenschaften des Gelenkgewebes ermöglichen eine großflächige Bewegung und eine hervorragende Schmierung unter gleichzeitig minimaler Friktion. Die physikalischen und biologischen Eigenschaften basieren auf einer bestimmten chemischen Zusammensetzung sowie der metabolischen Aktivität des Gelenkgewebes. Eine von vielen einmaligen Eigenheiten des Gelenkknorpels besteht darin, dass es weder Blutgefäße, Nervenfasern noch Lymphgefäße enthält. Dadurch fehlen direkte neuronale Signale, die eine Schädigung der 
Gelenkfläche signalisieren würden (Kuettner 1992). Es wird angenommen, dass 10-40 \% der 18 bis 45-jährigen Menschen Symptome oder Zeichen einer kraniomandibulären Dysfunktion (CMD) haben, von denen wiederum etwa $10 \%$ eine OA im Kiefergelenk aufweisen (Wadhwa et al. 2005). Allerdings kann die Diagnose einer Kiefergelenksarthrose erst in sehr späten Stadien der Erkrankung gestellt werden, wodurch die Anzahl der an Kiefergelenksarthrose erkrankten Menschen durchaus höher sein kann (Wadhwa et al. 2005).

Osteoarthrotische Veränderungen durchlaufen unterschiedliche Stadien (Blackwood 1963), sie sind im Allgemeinen lokalisiert und dehnen sich selten über die gesamte Gelenkoberfläche aus (Zarb und Carlsson 1985). Sie können sowohl die Gelenkflächen als auch die in Nachbarschaft angrenzenden Knochen und das Stützgewebe befallen. Letztendlich manifestiert sich die $\mathrm{OA}$ aus morphologischen, biochemischen, molekularen und biomechanischen Veränderungen seitens der Zellen und der Matrix. Diese Veränderungen können zur Erweichung, Fibrillation, Ulzeration, Knorpelverlust, Sklerosierung, Verknöcherung des subchondralen Knochens, Osteopyhtenbildung und zur subchondralen Zystenbildung führen (Moskowitz et al. 2007). Livne et al. (1997) beschreiben ebenfalls Veränderungen des Knorpel- und Knochengewebes, die sich auf der Oberfläche des Gelenkgewebes abzeichnen. Die visuell charakteristischen Anzeichen einer OA sind durch abgetragene Flächen, Fibrillationen und Osteophytenbildungen gekennzeichnet (Blumenfeld et al. 2000). Mit diesen degenerativen Veränderungen sind Schmerzen, Struktur- und Formveränderungen sowie Bewegungseinschränkungen verbunden. Im Anschluss können die Veränderungen in tiefer liegende Zonen des Knorpelgewebes penetrieren und im Ernstfall zur kompletten Zerstörung führen (Bendele et al. 1989, Mankin 1982). Die Zerstörung des Knorpels im Prozess der OA wurde 1987 von Bora und Miller dem Umbau der extrazellulären Matrix als Reaktion eines anfänglichen Missverhältnisses zwischen erhöhter Belastung und verminderter Reaktion der Chondrozyten zugeschrieben. Obwohl im OA-Knorpelgewebe über eine erhöhte Syntheserate der Chondrozyten berichtet wurde, welche allgemein als Reparaturversuch angenommen werden kann, wird die Syntheserate von der Degeneration des Knorpels übertroffen (Ehrlich et al. 1986). Knahr und Pinggera (2001) sprechen von einem „point of no return“, bei dem zwischen mechanischer Beanspruchung und knorpliger Beanspruchbarkeit ein biologischer Punkt im Reparationsmechanismus überschritten wird. Die daraus resultierenden Schäden des Gelenks führen sekundär zu einer Zerstörung weiterer Gelenkanteile infolge der Überlastung (Knahr und Pinggera 2001). Trotz bestehender 
Reparaturmechanismen, die im Kiefergelenk beobachtet wurden (Sarnat 1991), gibt es keine vollständige Geweberegeneration im Sinne einer Wiederherstellung des zerstörten und verloren gegangenen Gewebes. Aktuelle OA-Therapien lindern lediglich die Symptome, führen jedoch zu keiner vollständigen Heilung (Moskowitz et al. 2007). Um zukünftig eine Heilung der OA herbeizuführen, müssten die ätiologischen Faktoren, die zur Pathogenese führen, genauer untersucht werden. Um Untersuchungen voranzutreiben, sind geeignete Tiermodelle notwendig. Allerdings existieren derzeit nur sehr wenige Tiermodelle, bei denen von einer nicht-induzierten, natürlichen Kiefergelenks-OA berichtet worden ist (Wadhwa et al. 2005). Für die bessere Darstellung der Arbeitshypothese dieser Arbeit wird die Einleitung in die folgenden fünf Teile gegliedert: Anatomie des Kiefergelenks, der Faserknorpel, die Osteoarthrose des Kiefergelenks, Maus-Modelle zur Untersuchung der OA und Kriterien der OA. Als erstes werden die detaillierten anatomischen Verhältnisse des Kiefergelenks vorgestellt.

\section{I.2 Anatomie des Kiefergelenks}

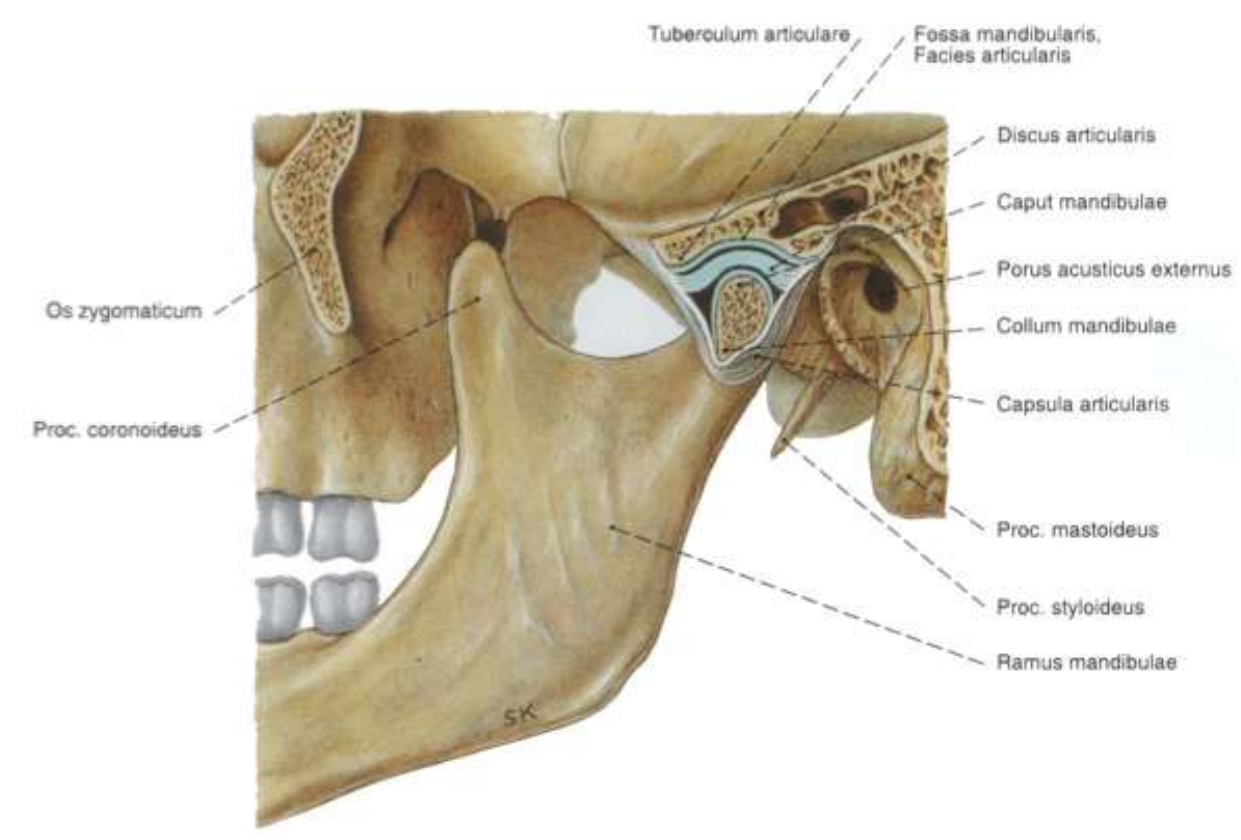

Abbildung 1: Das Kiefergelenk, aus Putz und Pabst (2006), Seite 63. 


\section{I.2.1 Das Kiefergelenk}

Das Kiefergelenk (Articulatio temporomandibularis) ist eine gelenkige Verbindung zwischen dem Schläfenbein (Os temporale) und dem Unterkiefer (Corpus mandibulae). Der Unterkiefer ist ein parabelförmiger kompakter Knochenkörper, der von seiner Horizontalebene beidseitig im Bereich der Kieferwinkel (Angulus mandibulae) in einen rechten und linken vertikal aufsteigenden Unterkieferast (Ramus mandibulae) übergeht. Nach kranial enden die beiden Unterkieferäste in einen jeweils anterior liegenden Fortsatz (Processus coronoideus) und einen posterior liegenden Fortsatz (Processus condylaris). Während der Processus coronoideus den Muskelansatz für den Musculus (M.) temporalis darstellt, dient der Processus condylaris der eigentlichen Gelenkfunktion. Der Muskelfortsatz und der Gelenkfortsatz sind beidseitig durch bogenförmige Vertiefungen (Incissurae mandibulae) voneinander getrennt.

\section{I.2.2 Kondylus (Processus condylaris mandibulae)}

Dem Gelenkfortsatz (Processus condylaris) des Unterkiefers liegt auf beiden Seiten der Gelenkkopf (Caput mandibulae) oben auf. Beide Kondylen sind von frontal betrachtet leicht schräg nach außen angeordnet, so dass zwei die Oberfläche der Gelenkfläche tangierenden Horizontalachsen einen stumpfen Winkel von etwa $150^{\circ}$ bis $165^{\circ}$ ergeben. Der menschliche Kondylus hat eine walzen- bis ellipsen-artige Form und eine breitere Ausdehnung in mediallateraler Richtung als in antero-posteriorer Richtung. Gemessen an humanem Sektionsmaterial ermittelten Öberg et al. eine durchschnittliche Breite von $20 \mathrm{~mm}$ in medial-laterale Richtung zu 10 mm Länge in antero-posteriorer Richtung (Öberg et al. 1971). Allerdings unterliegen die Messungen einer beträchtlichen Variation, die sich von Individuum zu Individuum unterscheiden. Nur selten sind beide Gelenkköpfchen symmetrisch in Bezug auf ihre Achsstellung und Größe. In beide Größenangaben wurden die Weichgewebe mit einberechnet. Die artikulierende Oberfläche des Kondylus ist mit Faserknorpel überzogen. Die Gelenkfortsätze des Unterkiefers liegen in der Gelenkgrube des Schläfenbeins. 


\section{I.2.3 Temporaler Gelenkanteil}

Die Gelenkgrube (Fossa mandibularis) ist kaudal der seitlichen Schläfenbeinschuppe (Pars squamosa os temporale) lokalisiert. Die Fossa mandibularis ist eine konkave Vertiefung, die unmittelbar vor dem äußeren Gehörgang liegt. Nach anterior geht diese konkave Vertiefung in einen konvexen Wulst über, den man als Gelenkknöchelchen (Tuberculum articulare) bezeichnet. Nach posterior wird die Fossa mandibularis vom Tuberculum glenoidale begrenzt. Dadurch entsteht im Sagittalschnitt von anterior nach posterior ein „S“-förmiger Verlauf von dem Tuberculum articulare, der Fossa mandibularis und dem Tuberculum glenoidale. Der vordere Anteil der Gelenkgrube und die Rückfläche des Gelenkknöchelchens sind mit blutgefäßlosem Faserknorpel überzogen. Der dorsale Anteil der Fossa mandibularis ist mit derbem Bindegewebe bedeckt. Die Gelenkoberfläche der Fossa mandibularis besitzt größtenteils eine ovale Form und ist mit ca. $23 \mathrm{~mm}$ in medial-lateraler Richtung breiter als mit ca. $19 \mathrm{~mm}$ in antero-posteriorer Richtung (Öberg et al. 1971). Zwischen den beiden Gelenkflächen des Processus condylaris und der Fossa mandibularis ist die Zwischengelenkscheibe (Discus articularis) lokalisiert.

\section{I.2.4 Discus articularis}

Der Discus articularis ist eine Bindegewebsscheibe, die auf dem Kiefergelenkköpfchen aufsitzt und den Unterkiefer beweglich mit dem temporalen Gelenkanteil in der Fossa mandibularis verbindet. Der Diskus hat eine ovoide Form und ist bikonkav. Er wird in eine Pars anterior, Pars medialis und Pars posterior unterteilt (Rees 1954). Die Pars medialis stellt mit ca. 1,1 mm die dünnste Stelle des Diskus dar, wobei die Dicke nach anterior (ca. $2 \mathrm{~mm}$ ) und posterior (ca. 2,8 mm) deutlich zunimmt (Hansson et al. 1977). Der Diskus besteht anterior aus einem Übergang von straffem parallelfaserigen Bindegewebe zu Faserknorpel. Die dünnere Pars medialis besteht aus Faserknorpel, wobei die Pars posterior wieder einen Übergang zwischen Faserknorpel und straffem kollagenen Bindegewebe darstellt. Das posteriore Gewebe des Diskus setzt sich als bilaminäre Zone fort. Der Diskus ist bis auf seine Randbezirke weder vaskularisiert noch innerviert. Eine sich durch den Diskus ergebende Besonderheit für das Kiefergelenk ist, dass es im Unterschied zu allen anderen Gelenken 
keinen direkten Kontakt der beiden Artikulationsflächen zulässt und sie vollständig in eine obere diskotemporale und eine untere diskomandibuläre Gelenkkammer teilt (Rees 1954). Ringsherum ist der Diskus über Bänder fest mit der Gelenkkapsel verwachsen und sitzt bei geschlossenem Mund dem Kondylus kappenartig auf.

\section{I.2.5 Bandapparat}

Der Bandapparat des Kiefergelenks sorgt dafür, dass der Diskus nach jeder Unterkieferbewegung wieder in seine ursprüngliche Lage zurückkehrt und verstärkt zusätzlich die Gelenkkapsel. Der Diskus ist über ein mediales Band (Ligamentum mediale) und ein laterales Band (Ligamentum laterale) am Kondylus befestigt. Lig. laterale und Lig. mediale bestehen aus straffem Bindegewebe. Anterior inseriert die Sehne des oberen M. pterygoideus lateralis durch den vorderen Anteil der Kapsel hindurch an den Diskus und an den Kondylus. An den posterioren Teil des Diskus schließt sich ein nervenfaserreiches, lockeres Bindegewebe an, welches als bilaminäre Zone bezeichnet wird.

\section{I.2.6 Bilaminäre Zone}

Die bilaminäre Zone wird durch den posterioren Anteil des Discus articularis gebildet (Zenker 1956; Boering 1979) und ist besonders stark vaskularisiert und innerviert. Diese Zone besteht aus zwei übereinander liegenden Faserschichten. Die obere Schicht (Stratum superius) enthält hauptsächlich elastische Fasern. Diese Fasern verlaufen nach kranial, durchziehen den knorpligen und knöchernen Gehörgang (Meatus acusticus) und sind mit ihm fest verwachsen (Delaire und De Olivera 1979). Die unten liegende Schicht (Stratum inferius) besteht überwiegend aus kollagenen Fasern (Takisawa et al. 1982; Meyenberg et al. 1986; Scapino 1991), welche nach kaudal verlaufen und an die posteriore Fläche des Kondylus inserieren (Limbdom 1960; Tillmann 1987). Zwischen diesen beiden Schichten entsteht eine lockere Bindegewebszone, die reich an elastischen Fasern, Fettzellen, Blutgefäßen und Nervenfasern ist (Mahan 1983). Die bilaminäre Zone verschmilzt mit dem posterioren Anteil der Gelenkkapsel. 


\section{I.2.7 Gelenkkapsel}

Die Gelenkkapsel (Capsula articularis) entspringt am Rand der Fossa mandibularis und umschließt trichterförmig die Gelenkoberfläche des temporalen Anteils, den Kondylus und den dazwischen liegenden Diskus. Die Kapsel wird in einen ventralen, medialen, dorsalen und lateralen Anteil unterteilt. Sie besteht überwiegend aus lockerem Bindegewebe, wird aber von zahlreichen kollagenen Faserbündeln verstärkt. Der ventrale Anteil stellt den lockersten, der dorsale Kapselanteil stellt den dicksten und kräftigsten Teil dar (Johansson und Isberg 1991; Koritzer et al. 1992). Sie wird von Blutgefäßen und Nervenfasern nutritiv und sensibel versorgt. Die Gelenkkapsel besteht aus zwei aneinander angrenzenden Schichten: der äußeren fibrösen Schicht (Membrana fibrosa) und der inneren, am Gelenkspalt angrenzenden Synovialgewebsschicht (Membrana synovialis) (Takisawa et al. 1982, Savalle 1988). Die äußere Membrana fibrosa besteht aus kollagenen Faserbündeln, die in kranio-kaudaler Richung verlaufen (Rees 1954). Die an der Innenseite lokalisierte Membrana synovialis setzt sich aus lockerem vaskularisierten Bindegewebe und Synovialgewebe zusammen (Huth und Bellmann 1976).

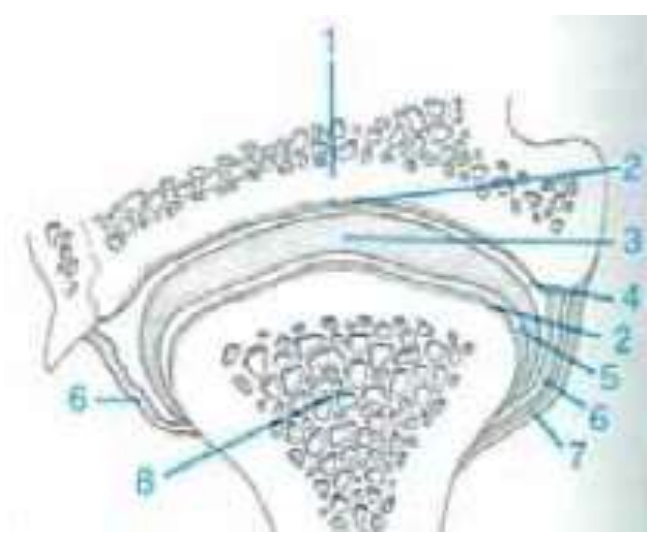

Abbildung 2: Frontalschnitt durch das Kiefergelenk, entnommen aus Gühring/Barth, (1992), Seite 110.

1. Gelenkgrube; 2. Gelenkknorpel; 3. Discus articularis;

4. diskotemporaler Gelenkspalt; 5. diskomandibulärer Gelenkspalt;

6. Gelenkkapsel; 7. Bandapparat; 8. Kondylus 


\section{I.2.8 Synovialgewebe}

Das Synovialgewebe, das an der Innenseite der Gelenkkapsel lokalisiert ist, besteht wiederum aus zwei Schichten. Die an dem Gelenkspalt angrenzende Schicht (Intima) ist zellreich und gut vaskularisiert im Gegensatz zur äußeren, an die Kapsel grenzenden Schicht (Subintima). Die Intima produziert und sezerniert Synovialflüssigkeit.

\section{I.2.9 Synovialflüssigkeit}

Die Synovialflüssigkeit ist ein zellarmes Plasmadialysat, welches reich an PolysaccharidProtein-Komplexen und hyaluronsäurehaltigen Proteoglykanen ist. Das Volumen der Synovialflüssigkeit beträgt ca. $1 \mathrm{ml}$. Eine wichtige Funktion dieser Flüssigkeit ist die optimale Lubrikation und Dämpfung der Gelenkanteile. Durch die Lubrikation wird die Reibung und der damit verbundene Verschleiß reduziert. Da die Knorpeloberflächen des Kondylus, Diskus und des temporalen Gelenkanteils avaskularisiert sind, werden sie über Diffusion von der Synovialflüssigkeit ernährt. Die Synovialflüssigkeit hat damit auch eine nutritive Funktion. In gleichem Maße dient die Synovialflüssigkeit auch dem Abtransport von Abbauprodukten, die aus dem Gelenkspalt entfernt werden sollen. Zusätzlich sind die in der Flüssigkeit enthaltenen Makrophagen und Histeozyten dank deren phagozytären Eigenschaften in der Lage, durch Abnutzung und Zerreißung entstandene Gewebsteile zu entfernen (Zarb und Carlsson 1985).

\section{I.3 Der Faserknorpel}

Im Kiefergelenk sind die artikulierenden Flächen mit Faserknorpel statt mit hyalinem Knorpel überzogen (Benjamin und Ralphs 2004), wodurch sich das Kiefergelenk von allen übrigen Gelenken unterscheidet. Faserknorpel ist dem straffen Bindegewebe sehr ähnlich. Durch die zahlreichen, stark verflochtenen kollagenen Faserbündel erreicht Faserknorpel eine hohe Festigkeit. Im Faserknorpel lagern sich Chondrozyten in kleinen Gruppen an. Die Grundsubstanz besteht aus weniger Matrixbestandteilen als bei hyalinem Knorpel, ist jedoch durch einen höheren Anteil an Kollagenfasern vom Typ I gekennzeichnet. Der Knorpel des 
Kiefergelenks enthält größtenteils Kollagen Typ I. Im Gegensatz dazu kommt Typ-IIKollagen nur in der Matrix hypertropher und reifender Zellen vor (Mizoguchi et al. 1990, Mizoguchi et al. 1992). Durch den höheren Anteil an Kollagen Typ I ist Faserknorpel widerstandsfähiger gegen Kompressionskräfte (Mills et al. 1994a, Mills et al. 1994b). Zusätzlich besteht er zu ca. $40 \%$ aus Kollagenfasern vom Typ II (Mow et al. 1992). Glykosaminoglykane und elastische Fasern sind im Faserknorpel reduziert (Hansson et al. 1977). Dadurch ist Faserknorpel weniger elastisch als hyaliner Knorpel und hat einen geringeren Wassergehalt. Unphysiologische Belastungen oder reduzierte funktionelle Bewegungen des Gelenks beanspruchen den Knorpel und verändern den Kollagentyp von Typ II zu Typ I (Karaharju-Suvanto et al. 1996).

Die Histologie des Kondylus und des temporalen Gelenkanteils haben eine einheitliche Gemeinsamkeit hinsichtlich der Gewebsschichtung. Jedoch variieren sie in Ausdehnung, Dicke und Zusammensetzung der Schichten der beiden Gelenkanteile, wodurch sie voneinander unterschieden werden können. Die Oberfläche des Kiefergelenks besteht aus verschiedenen histologischen Zonen, die sowohl aus knorpeligen als auch aus knöchernen Schichten zusammengesetzt ist. Die Dicke der verschiedenen Zellzonen verringert sich, wenn sich die Wachstumsfunktion des Kondylus zur Gelenkfunktion umändert. Dies geschieht etwa ab dem Alter von drei Wochen mit dem Durchbruch der Molaren (Durkin et al. 1973; Vinkka 1982; Livne et al. 1990). Der Literatur konnte keine einheitliche Anzahl und Nomenklatur bezüglich der Schichtung entnommen werden, da sich die Namen und die Anzahl der Schichten von Autor zu Autor unterscheiden. Zarb und Carlsson (1985) differenzieren beispielsweise sechs Schichten, wobei sie jeweils die „Schicht der undifferenzierten Mesenchymzellen“ und die „Übergangsschicht“ einzeln betrachten und den Knochen in „Kompakta“ und „Spongiosa“ unterteilen. Berg et al. (2000) hingegen zählen vier Schichten, da sie die Schicht der ,undifferenzierten Mesenchymzellen“ mit der „Übergangsschicht“ zur „Proliferationszone“ und die Knochenschichten zu einer „Ossifikationszone“ zusammenfassen. 
In dieser Arbeit wurde folgende Nomenklatur für die Unterteilung von vier Schichten des Kondylus verwendet. Da die Schichtung wichtig für die Beschreibung und Klassifizierung der Ergebnisse sein wird, wird sie hier im Einzelnen vorgestellt:

1. Oberflächliche fibröse Bindegewebszone

2. Proliferationszone

3. Faserknorpelzone

4. Enchondrale Ossifikationszone.

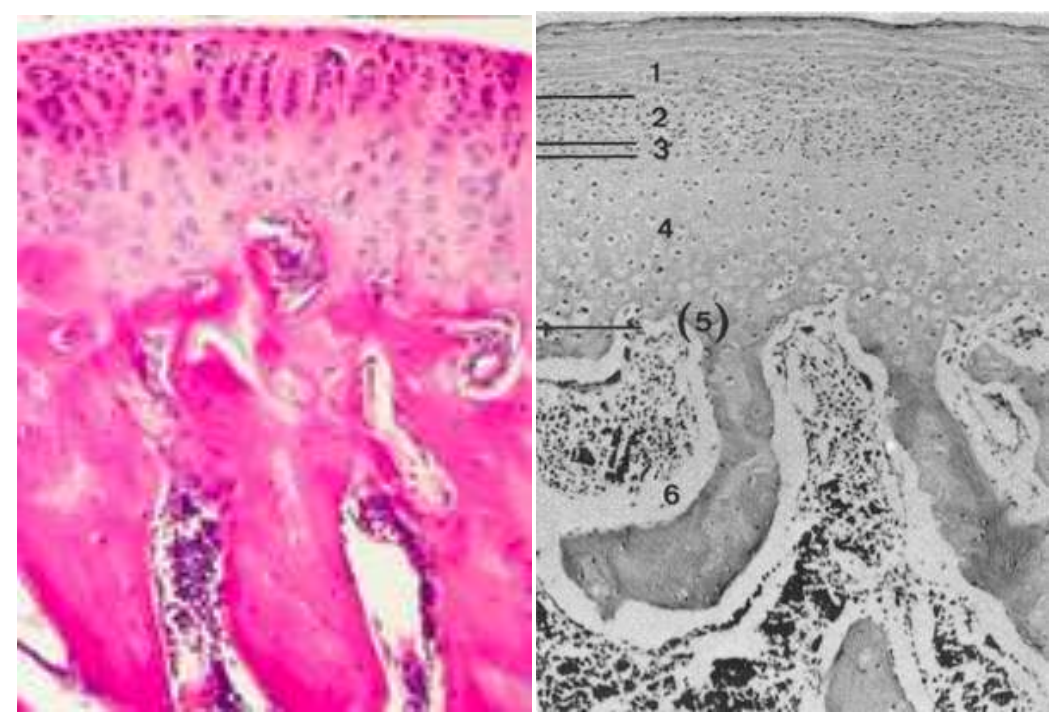

Abbildung 3: Die Gewebsschichtung des Kondylus linkes Bild: Ausschnitt aus einem Kondylus der Maus (Sagittalschnitt) rechtes Bild: entnommen aus Zarb und Carlsson (1985), Seite 126. 1. oberflächliche fibröse Bindegewebszone; 2. Proliferationszone (gebildet aus undifferenziertem Mesenchym und 3. Übergangszone); 4. Faserknorpelzone; 5. Ossifikationszone; 6. Spongiosa 


\section{I.3.1 Oberflächliche fibröse Bindegewebszone}

Die oberflächliche Bindegewebszone, welche die eigentliche Gelenkfläche des Kondylus und der temporalen Gelenkfläche darstellt, besteht aus dichtem, fibrösen Bindegewebe. Die kollagenen Fasern verlaufen entsprechend der funktionellen Belastung im Wesentlichen parallel zur Oberfläche und in antero-posteriorer Richtung. Zwischen den Fasern befinden sich spindelförmige fibroblastenähnliche Zellen mit langgezogenen Zellkernen, die dem Verlauf der Fasern folgen. Diese Schicht ist entsprechend der höheren funktionellen Belastungen superior-anterior am Kondylus und posterior-inferior am Tuberculum articulare verknorpelt (Öberg 1964; Hansson et al. 1977; Öberg 1977). Sie ist nicht zur aktiven Zellproliferation befähigt und kann auf diese Weise während aktiver Umbildungsvorgänge der tieferen Schichten funktionell intakt bleiben (Blackwood 1963).

\section{I.3.2 Proliferationszone}

Die Proliferationszone besteht aus undifferenziertem Mesenchym. Diese Zone bildet zusammen mit der Faserknorpelzone und der Übergangszone (intermediate layer) eine Wachstumszone, die am Kondylus besonders aktiv ist (Zarb und Carlsson 1985). Nur die undifferenzierten Mesenchymzellen sind zeitlebens zur Proliferation und zur Differenzierung befähigt (Blackwood 1966). Diese undifferenzierten Mesenchymzellen sind multipotent und haben die Fähigkeit, sich in tieferen Schichten zu Chondroblasten oder Osteoblasten zu differenzieren. In Zonen des geringeren Wachstums erfolgt die Differenzierung zu Präosteoblasten und Osteoblasten, wohingegen sie sich in Zonen höheren Wachstums zu Prächondrozyten und hypertrophierenden Chondrozyten differenzieren (Öberg 1964; Öberg et al. 1967; Öberg 1977). Sie haben demzufolge das Potenzial, sowohl Knorpel- als auch Knochenmatrix zu produzieren. Die Übergangszone besteht aus den jeweils differenzierten Präosteoblasten, Osteoblasten, Prächondrozyten oder Chondrozyten und haben eine runde bis ovale Form. 


\section{I.3.3 Faserknorpelzone}

Die Faserknorpelzone besteht aus ungeordneten, großblasigen (hypertrophen) Chondroblasten, die mit der Tiefe an Größe zunehmen. Sie hypertrophieren zum Knochen hin und zeigen eine Zunahme ihres intrazellulären Volumens. Die Kerne sind rund und im Verhältnis zur Zellgröße klein. Die Matrix der Chondrozyten verkalkt zunehmend mit der Tiefe und bildet die abschießende Zone der enchondralen Ossifikation.

\section{I.3.4 Enchondrale Ossifikationszone}

In der Zone der enchondralen Ossifikation wird der Knorpel resorbiert und durch spongiösen Knochen ersetzt. Sowohl beim temporalen Knorpel als auch beim Kondylusknorpel führt eine funktionelle Mehrbelastung zu einer progressiven Adaptation mit einer Hypertrophie der Knorpelzellen und einer Anlagerung von Knochenmatrix. Wird die Mehrbelastung unphysiologisch, zeigt auch der Kondylenknorpel regressive Veränderungen.

\section{I.4 Osteoarthrose des Kiefergelenks}

\section{I.4.1 Definition}

Die OA ist primär eine nichtentzündliche degenerative Erkrankung der artikulierenden Gelenke, welche durch Verschleiß, Abnutzungserscheinungen und gleichzeitige Umbildungsvorgänge des subchondralen Knochengewebes charakterisiert ist. Die Änderung der Kontur der Gelenkoberfläche wird somit sowohl von Erosion als auch durch neue Weichgewebsproliferation bestimmt (Sokoloff 1977). Diese Umbauvorgänge können zu pathologischen Formveränderungen der Gelenkkomponenten führen und damit die Funktion beeinträchtigen. Degenerativ veränderte Gelenkoberflächen können vielgestaltig sein und beispielsweise Fibrillationen, Osteophyten, Risse oder Perforationen aufweisen. 
Die OA tritt in einigen Gelenken bei $50 \%$ aller Menschen über 50 Jahren auf und ist damit die häufigste Gelenkerkrankung (Zarb und Carlsson 1985). Sie kann in allen Gelenken, einschließlich des Kiefergelenks, Symptome hervorrufen.

\section{I.4.2 Epidemiologie}

Bei $44 \%$ von einem Kollektiv von 80 symptomfreien Patienten wurden röntgenologische Veränderungen und OA im Kiefergelenk gefunden (Ericson und Lundberg 1967). Blackwood untersuchte an Leichen 400 Kiefergelenke von über 40-jährigen Menschen und fand OAVeränderungen in einer Häufigkeit von 40 \% (Blackwood 1963). In einer weiteren Studie wurden 961 Kiefergelenke mit bildgebenden Diagnoseverfahren untersucht. Dabei hatten 65 Patienten (7\%) OA-Veränderungen im Kiefergelenk. Allerdings traten diese Veränderungen selten vor dem 40. Lebensjahr auf (Stanson und Baker 1976). Madson untersuchte wiederum 192 Kiefergelenke von 96 Patienten anhand von Röntgenaufnahmen und fand bei 13,5 \% OAVeränderungen. Allerdings kam er zu dem Schluss, dass es keine befriedigende Gemeinsamkeit zwischen radiologischen und klinischen Befunden gibt (Madson 1966). Ireland und Toller erkannten, dass „Knack“-Geräusche im Kiefergelenk am häufigsten bei Patienten zwischen dem 15. und dem 25. Lebensjahren auftraten. „Knack“-Geräusche, Bewegungseinschränkungen und Schmerzen waren häufiger bei Patienten zwischen dem 25 . und 35. Lebensjahr, während reibend-zermalende „Knirsch“-Geräusche, Mundöffnungsschmerzen und Palpationsschmerzen erst nach dem 40. Lebensjahr auftraten. Alle diese Symptome stehen im Zusammenhang mit der OA (Ireland 1951; Toller 1974). Die Häufigkeit der OA nimmt bei allen Gelenken, einschließlich des Kiefergelenks, mit dem Alter zu (Blackwood 1963; Moffett et al. 1964; Bollet 1969; Öberg et al. 1971; Kopp 1978). 


\section{I.4.3 Ätiologie}

Die Ursache, die zu einer OA führen, sind bis heute nicht ganz geklärt. Es wird allgemein vermutet, dass lokale und systemische Faktoren eine Rolle für die Entwicklung einer OA spielen (Zarb und Carlsson 1985). Ein bekannter Faktor für die Entstehung einer OA ist eine erhöhte mechanische Belastung des Gelenks (Bollet 1969; Radin et al. 1972; Telhag 1973; Inerot et al. 1978), obwohl eine OA auch in gering belasteten Gelenken, wie z. B. dem Sternoklavikulargelenk, entstehen kann (Zarb und Carlsson 1985).

\section{I.4.4 Pathomorphologie der OA}

Auch über die Entstehung der OA herrscht laut Literatur noch keine eindeutige Einheitlichkeit, was klar macht, dass der Prozess der Krankheit noch nicht geklärt ist. Eine Meinung ist, dass die OA an der Gelenkoberfläche beginnt (Collins 1949; Meachim und Emery 1974; Byers et al. 1976). Radin et al. sind der Meinung, dass auch eine übermäßige Verknöcherung des subchondralen Knochens zu Mikrofrakturen und Rissen der Gelenkoberfläche führt (Radin et al. 1972, 1973). Eine weitere Studie belegt, dass die OA aus der gleichzeitigen Veränderung des subchondralen Knochens und der Gelenkoberfläche entsteht (Telhag 1973).

Betrachtet man die Komponenten des Kiefergelenks getrennt, so wird zu allererst der Discus articularis in OA-Prozesse einbezogen, weil er keine Fähigkeit besitzt, sich umzubauen. Daher können z. B. lang andauernde erhöhte Kompressionskräfte zu Verdünnungen, Zelluntergang und Perforation führen (Zarb und Carlsson 1985). Die Kompressionskräfte werden an die Gelenkoberfläche weitergeleitet. Dadurch können Chondrozyten geschädigt werden und es kommt zur Freisetzung von proteolytischen Enzymen aus den Lysosomen. Diese proteolytischen Enzyme können Bestandteile der extrazellulären Matrix (Proteoglykane) abbauen (Ali und Evans 1973) und die kollagenen Fasern freilegen. Die frühste makroskopisch sichtbare Veränderung seitens der Gelenkoberflächen ist die Fibrillation. Die Oberfläche des Gelenks erscheint bei der Fibrillation matt, statt glänzend (Freeman 1972). Der Grund dieser anfänglichen Veränderungen steht im Zusammenhang mit dem Abbau der Proteoglykane und letztendlich dem Verlust von Glycosaminoglykanen 
(Maroudas et al. 1973, Inerot et al. 1978). Durch den Abbau der Proteoglykane und die mechanische Belastung des Gelenks kommt es zu einem beschleunigten Austritt von in der Matrix gebundenem Wasser. Der dadurch bedingte Wasserverlust der knorpeligen Matrix entzieht dem Knorpel die Eigenschaft, sich bei Deformationen wieder in seine ursprüngliche Form zurückzustellen (Hesse et al. 1990). Der Verlust an Proteoglykanen führt zu einer verminderten Widerstandskraft gegenüber Kompressionskräften, die bei Belastung und Funktion des Gelenkes einwirken (Kempson et al. 1970). Verringert sich also der Gehalt an Proteoglykanen, so wird das Gewebe weicher und anfälliger für Deformationen (Freeman und Kempson 1973). Die aus dem degenerierten Knorpel entlassenen Bestandteile können eine Entzündung der Synovialräume nach sich ziehen. Dabei können wichtige Komponenten der Synovialflüssigkeit, wie zum Beispiel Hyaluronan, nicht mehr gebildet werden. Die daraus resultierende Flüssigkeit im Synovialraum ist weniger viskoelastisch und kann eine optimale Schmierung der artikulierenden Gelenkflächen nicht mehr garantieren (Balazs 1968). Auf die Veränderung der Proteoglykanverteilung folgt die Bildung von Zellklustern (Poole et al. 1991), die anfangs in den oberen Anteilen der Knorpelmatrix zu finden sind und sich im Krankheitsverlauf auch in tiefen Schichten bilden. Zellanordnungen, die sich zu Klustern vereinigen, verfügen über eine höhere Stoffwechselaktivität (Kouri et al. 1996).

Im weiteren Krankheitsverlauf können vertikale Fissuren und Risse an der Gelenkoberfläche entstehen, die sich langfristig in die Tiefe ausdehnen. Dieser Vorgang kann soweit fortschreiten, bis das gesamte Weichgewebe von der Gelenkoberfläche entfernt ist. Die Formveränderung bewirkt, dass die Kompressionskräfte direkt an den subchondralen Knochen weitergegeben werden, der die Kräfte adsorbiert (Radin et al. 1973). Durch die übermäßige Belastung auf das subchondrale Knochengewebe aufgrund des fehlenden Knorpels, können kleinste Ermüdungsbrüche entstehen (Pugh et al. 1974). Als Folge der erhöhten Belastung treten osteolytische Umbauvorgänge auf, die den subchondralen Knochen im Kiefergelenk schädigen (Bean et al. 1977). Durch diese osteolytischen Umbauvorgänge wird der OA-subchondrale Knochen weicher und seine Widerstandsfähigkeit gegenüber Belastungen nimmt weiterhin ab (Lereim et al. 1974). Eine daraus resultierende reaktive Mehrdurchblutung in den peripheren Randzonen des Knochens, die zur Bildung neuen Knochens führt, kann in den Bereichen des Umbaus zu knöchernen Auswüchsen, sogenannten Osteophyten, führen (Jeffery 1973). 
Osteophyten sind ein wichtiger Hinweis für eine degenerative Gelenkerkrankung. Jedoch wird angenommen, dass diese Osteophytenbildung Ausdruck einer Späterscheinung der Erkrankung ist (Gardner 1965). Bei schwereren Zerstörungen treten Knochen-“Zysten“ auf (Zarb und Carlsson 1985).

Die Umbauvorgänge können wiederum zu einer gesteigerten Produktion von Proteoglykanen führen, wodurch eine Verdickung der Weichgewebsbedeckung durch die Bildung von Knorpel erzeugt wird, um das Gewebe widerstandsfähiger gegen Kompressionskräfte zu machen (Hansson et al. 1977). Öberg et al. zeigten anhand von humanen Autopsie-Präparaten des Kiefergelenks, dass die Umbauprozesse häufig im latero-posterioren Bereich des Tuberculum articulare und im latero-anterioren Teil des Kondylus auftraten. An diesen Stellen entstehen vermutlich die höchsten Belastungen (Öberg et al. 1971). Die OA stellt sich im Allgemeinen als lokalisierte Läsion dar und dehnt sich selten über die gesamte Gelenkoberfläche aus. Jedoch ist es nach neuerer Ansicht von Little und Smith offensichtlich, dass in den pathophysiologischen und molekularen Mechanismen der OA alle an der Gelenkfunktion beteiligten Gewebsanteile involviert sind (Little und Smith 2008).

\section{I.4.5 Klinische Symptome}

Die subjektiven Symptome der Kiefergelenksarthrose umfassen Schmerzen im Bereich des Kiefergelenks und der Kaumuskulatur, Geräusche, Steifheit und Mundöffnungsschwierigkeiten. Ebenfalls lassen sich Bewegungseinschränkungen und Schmerzen auf Palpation zu den Symptomen rechnen, sofern sie nicht muskulärer Genese sind. Auf ein relativ spätes Stadium der OA weisen Reibegeräusche bei Bewegung des Kiefergelenks hin (Zarb und Carlsson 1985). Als Reaktion der gestörten Funktion des schmerzhaften OAveränderten Kiefergelenks wird die Kaumuskulatur schwächer (Bollet 1969; Miller et al. 1973). Die Kaukraft bei Patienten mit Kiefergelenksstörungen ist ebenfalls vermindert (Helkimo et al. 1975). 


\section{I.4.6 Klinische Befunde}

Die folgenden Methoden werden der Vollständigkeit halber vorgestellt. Methoden, die keine klinische Relevanz mehr haben, wie z. B. die Arthroskopie des Kiefergelenks, wurden außer Acht gelassen.

\section{I.4.6.1 Laborwerte}

Die Bestimmung der Blutkörperchensenkungsgeschwindigkeit (BSG) ist eine unspezifische Routineuntersuchung, um eine Entzündung zu bestimmen. Die BSG ist bei einer OA normalerweise unauffällig bis leicht erhöht. Während einer aktiven Phase im Verlauf der OA kann die BSG deutlich erhöht sein (Fischel 1975). Eine weitere Möglichkeit bietet die Untersuchung der Synovialflüssigkeit auf verschiedene Zellen und Konzentrationen (Cohen et al. 1975). So kann beispielsweise eine erhöhte Anzahl an bestimmten Blutzellen, zum Beispiel den polymorphkernigen Leukozyten, für eine OA sprechen. Die aus der Synovialflüssigkeit stammende Hyaluronsäure sollte nach der Beimischung von 2-prozentiger Essigsäure ausfallen, jedoch nicht spontan durch Fibrinogen ausfallen. Altman et al. haben nachgewiesen, dass sich in der Synovialflüssigkeit bei OA doppelbrechende Kalziumpyrophosphat-Kristalle nachweisen lassen (Altman et al. 1973).

\section{I.4.6.2 Bildgebende Diagnostik}

Auf konventionellen Röntgenbildern lässt sich die Veränderung der Knorpeloberfläche nicht sehen, da Knorpelgewebe völlig strahlendurchlässig für Röntgenstrahlen ist. In Folge dessen kann nur das Knochenhartgewebe befundet werden. Trotzdem kann man anhand der sekundären Veränderungen einen entsprechenden Schweregrad der OA gut erkennen. Bereits ein verschmälerter Abstand zwischen den temporalen und mandibulären Gelenkanteilen kann für einen Verlust der dazwischen liegenden Weichgewebeanteile sprechen. Allerdings kann eine harmlose Formabweichung des Kiefergelenks nur schwierig von einer OA unterschieden werden (Öberg et al. 1971, Bean et al. 1977). 
Eine Sklerosierung des subchondralen Knochens wurde als diagnostisches Kriterium für eine OA angesehen (Kellgren und Lawrence 1957; Madsen 1966; Martel 1973). Eine solche Aufnahme ist durch Projektion mit posterior-anteriorem Strahlengang durch den Kondylus möglich (Kopp und Rockler 1978). In besonders schweren Fällen der Kiefergelenksosteoarthrose könnten intraossäre Zerstörungen des Kondylus und am Tuberculum articulare festgestellt werden (Lindvall et al. 1976; Bean et al. 1977). Besonders gut lassen sich in Röntgenaufnahmen Osteophyten diagnostizieren. Sie werden am häufigsten an der anterioren Fläche des Kondylus beobachtet (Zarb und Carlsson 1985). Zarb und Carlsson kommen zu der Erkenntnis, dass das Kiefergelenk von einer Vielzahl von Erkrankungen betroffen sein kann. Einige dieser Erkrankungen sind häufig, während andere seltener auftreten. Ein pathologischer Prozess kann häufig der Grund von Schmerzen im Kiefergelenk sein, obwohl das Röntgenbild keine strukturellen Anhaltspunkte dafür bietet. Insofern besteht besonders in den Anfangsstadien kein unmittelbarer Zusammenhang zwischen dem radiologischen Stadium und den klinischen Krankheitszeichen einer OA. Die Behauptung, dass eine Kiefergelenkerkrankung anhand eines Röntgenbefunds ausgeschlossen werden kann, ist unzulässig, da die Frühstadien nicht im Röntgenbild sichtbar sind (Zarb und Carlsson 1985).

Als weitere bildgebende Methode hat die Magnetresonanztomographie (MRT) einen besonders hohen Stellenwert in der Diagnostik der Arthrose eingenommen. Die MRT ist die beste verfügbare bildgebende Technik zur Darstellung von normalem und geschädigtem Knorpel und damit der Goldstandard der Weichgewebediagnostik. Fissuren und Knorpelverschmälerungen bis hin zum völligen Knorpelverlust werden erkennbar (Lang et al. 2000). Dieses computergestützte Bilderzeugungsverfahren ermöglicht es, ganz ohne den Einsatz von Röntgenstrahlen, Schnittbilder von inneren Organen und Geweben zu erstellen. Dabei entstehen detailreiche Sequenzen von Bildern, die die verschiedenen Gewebe aufgrund ihres unterschiedlichen Wassergehaltes hochauflösend darstellen. Auf diese Weise können alle anatomischen Strukturen voneinander differenziert und untersucht werden. Durch die Variation der Untersuchungsparameter und die Verwendung von Kontrastmitteln sind spezielle detaillierte Darstellungen der Gewebe möglich. Wie in vielen Krankheitsbildern spielt der Zeitpunkt der Diagnose für die erfolgreiche Behandlung eine wichtige Rolle. So kann die MRT bei OA schon sehr früh Knorpelveränderungen abbilden, wenn das Röntgenbild noch völlig unauffällig ist. Bei Veränderungen des Gelenkknorpels, der Bänder und der Muskulatur ist also eine MRT einer herkömmlichen Röntgenaufnahme überlegen. 
Ein weiterer möglicher Vorteil der MRT ist, dass punktgenaue konservative Therapien oder eventuell notwendige operative Eingriffe ermöglicht und besser navigiert werden können.

\section{I.4.7 Medikamentöse Therapie}

Kiefergelenks-OA ist oftmals schmerzhafter Natur und kann medikamentös lediglich symptomatisch behandelt werden. Zunächst werden bei starken Schmerzen Analgetika zur medikamentösen Behandlung der Beschwerden eingesetzt. Werden die Schmerzen durch eine zusätzlich entzündliche Komponente begleitet, so werden als Therapiealternative Kombinationen aus schmerzlindernden Analgetika zusammen mit entzündungshemmenden Antiphlogistika verordnet. Die Acetylsalizylsäure (ASS) ist bereits nach einer Menge von 0,5$1 \mathrm{~g}$ analgetisch, und im Bereich von 3-5g antiphlogistisch wirksam (Zarb und Carlsson 1985). Des Weiteren bieten intraartikuläre Injektionen mit Kortikosteroidpräparaten eine weitere Möglichkeit, die Schmerzen zu lindern. Dabei wurde die lindernde Wirkung von Hydrokortison, Prednison und Prednisolon sehr gut bei anhaltenden Schmerzen beschrieben (Carlsson et al. 1970). Die Kortikosteroidpräparate sind vor allem dann indiziert, wenn entzündliche Genesen, wie es zum Beispiel bei einer OA-bedingten Synovitis der Fall ist, diagnostiziert werden. Als klare Nachteile der Therapie mit ASS und Kortikosteroidpräparaten ist die hemmende Wirkung auf die Synthese von Proteoglykanen und Kollagenen zu nennen. Durch die fehlende Synthese werden die körpereigenen Heilungsprozesse gestört (Zarb und Carlsson 1985). Eine weitere Möglichkeit bietet die intraartikuläre Injektion von Hyaluronsäure. Hyaluronsäure kommt in der Synovialflüssigkeit vor und besitzt die Eigenschaft, eine Schutzschicht auf Gelenkoberflächen zu bilden. Dadurch wird eine Degeneration durch proteolytische Substanzen verhindert (Cotta 1973; Balazs 1974). In einer Studie von Helfet konnten verheißungsvolle Resultate an menschlichen Kiefergelenken berichtet werden. Allerdings ist die Injektion von Hyaluronsäure nur in sehr frühen diagnostizierten OA-Stadien hilfreich (Helfet 1974). Regelmäßige Gabe von NatriumHyaluronat in einer Tierstudie bewirkte, dass die Häufigkeit einer OA um 50 \% reduziert war (Wigren et al. 1975). 


\section{I.5 Maus-Modelle zur Untersuchung der OA}

Die im Folgenden aufgeführten Maus-Modelle wurden von mir auf das Auftreten von spontanen, nicht-induzierten OA am Kiefergelenk untersucht. Die genauere Auseinandersetzung der verwendeten Modelle wird im Diskussionsteil mit weiteren relevanten Ergebnissen diskutiert und daher im folgenden Teil lediglich kurz vorgestellt.

\section{I.5.1 Institute-for-Cancer-Research-Caesarean-Derived-1 (ICR-CD1)-Maus-Modell}

Die Mäuse der ICR-CD1-Maus-Kolonie stammen ursprünglich aus der Schweiz. ICR-CD1Mäuse wurden im Krebsforschungsinstitut in Philadelphia eingeführt, von wo aus sie in verschiedenen Laboratorien weitergezüchtet wurden. Diese Gattung wird als universeller Maus-Stamm für die Grundlagenforschung eingesetzt. Die Mäuse des ICR-CD1-Stamms werden bevorzugt für onkologische und pharmakologische Forschungen verwendet. Es handelt sich um einen robusten heterozygoten Stamm. Die ICR-Mäuse sind besonders anfällig für Tumorerkrankungen (http://www.harlaneurope.com).

Silbermann erforschte die Wirkung von Triamcinolon-Diacetat (Kortikosteroide) am Kiefergelenk von ICR-Mäusen und erkannte eine höhere Anfälligkeit dieser Mäuse für induzierte degenerative Veränderungen am Kiefergelenk (Silbermann 1976). Die darauf folgende Studie war seinerzeit die erste dokumentierte Forschungsarbeit überhaupt, in der über degenerative Veränderungen am Kiefergelenk von gealterten Mäusen geforscht und berichtet wurde. Die Ergebnisse von Silbermanns Arbeit zeigten, dass es mit zunehmendem Alter zu einer hohen Rate an spontanen degenerativen Veränderungen am Gelenk kam. Diese altersbedingten spontanen OA-Veränderungen am Kiefergelenk der ICR-Maus wurden bereits ab dem frühen Alter von sieben Monaten festgestellt (Silbermann und Livne 1979). Daher dienen die ICR-CD1-Mäuse in dieser Arbeit als Positivkontrolle, da es bei diesen Mäusen besonders häufig zu spontaner OA kommt. 


\section{I.5.2 Naval-Medical-Research-Institute (NMRI)-Maus-Modell}

Die NMRI-Maus gehört ursprünglich zu einem Maus-Stamm, der ebenso wie der ICR-CD1Stamm in der Schweiz entstanden ist. Später ist der Stamm zu Forschungszwecken in die Vereinigten Staaten von Amerika überführt worden, wo sie als US-Naval-Medical-ResearchInstitute (NMRI)-Mäuse geführt wurden. Von dort aus wurden sie in verschiedenen Laboratorien weitergezüchtet. Diese Gattung wird ebenfalls wie die ICR-Maus als universeller Maus-Stamm zur Erforschung von generellen biologischen, pharmakologischen und toxikologischen Wirkungsmechanismen eingesetzt. NMRI-Mäuse wurden häufig für verhaltensbiologische Tests (Lamberty und Gower 1992), immunologische Untersuchungen, Infektionsstudien und zur Erforschung von spontan auftretenden Erkrankungen verwendet. In zahlreichen Studien wurde von verschiedenen Autoren berichtet, dass NMRI-Mäuse häufig $\mathrm{zu}$ spontanen tumorösen Veränderungen in verschiedenen Organen neigen können (http://www.harlaneurope.com). Murray et al. fanden heraus, dass bestimmte Leukämie-Viren Osteopetrose induzieren können. Durch die Injektion von diesen Tumor erzeugenden Leukämie-Viren wird das Stoffwechselverhalten von Osteoblasten und Osteozyten beeinflusst und führt zu induzierten OA-veränderten Knochengeweben von NMRI-Mäusen (Murray et al. 1986). Es kommt zu Störungen der Zelldifferenzierung und Zellaktivität in den Osteoprogenitorzellen, die daraufhin OA-verändertes Gewebe herstellen (Schmidt et al. 1987). In einer darauf folgenden in-vitro-Studie von Livne et al. wurde an embryonalen Knorpelzellen des Kiefergelenks von MNRI-Mäusen nachgewiesen, dass dieselben Tumor erzeugenden Leukämie-Viren pathologische Skelettveränderungen und Knorpelschäden induzieren können (Livne et al. 1989). In bisherigen Untersuchungen wurden allerdings bislang von keinen spontanen, nicht induzierten OA-Veränderungen am Kiefergelenk der NMRI-Maus berichtet. 


\section{I.5.3 Nidogen-2-Knockout (KO)-Maus-Modell}

Nidogene sind Glykoproteine, die vornehmlich in Basalmembranen vorkommen. Das Glykoprotein Nidogen ist eines von vielen Hauptbestandteilen aller Basalmembranen. Diese Makromoleküle bilden zusammen mit den weiteren Hauptbestandteilen Perlecan, Laminin und Kollagen IV das Grundgerüst jeder Basalmembran (Timpl und Brown 1996), in das weitere spezifische extrazelluläre Matrixmoleküle eingelagert werden. Die Basalmembran ist eine spezialisierte Schicht der extrazellulären Matrix, mit einer Dicke zwischen 50 und 100 nm (Kalluri 2003). Sie ist für eine Reihe wichtiger zellulärer und biologischer Funktionen zuständig, wovon im Rahmen dieser Einleitung nur die wesentlichsten Hauptaufgaben der Basalmembran beschrieben werden.

Zu ihren Aufgaben gehören vor allem die Aufrechterhaltung der Gewebestruktur, Adhäsion von angrenzenden Zellen mit dem umgebenden Bindegewebe und Kompartimentierung des Gewebes; sie kann den Stoffaustausch zwischen den Kompartimenten regeln oder sogar unterbinden. Die Basalmembranen sind verantwortlich für die Kontrolle und Differenzierung des epithelialen Wachstums, da sie eine für das Zellwachstum undurchdringliche Barriere bilden (Timpl und Brown 1996). Eine weitere wichtige Funktion von Basalmembranen besteht darin, dass sie an der Defektheilung von Gewebsverletzungen beteiligt sind (Kefalides et al. 1979). Es wurden bereits zwei Isoformen des Nidogens identifiziert, bei denen man zwischen Nidogen-1 und Nidogen-2 differenziert. Die beiden Isoformen unterscheiden sich hauptsächlich in ihrer Moleküllänge und in der Glykosylierung (Kohfeldt et al. 1998). Beide Nidogene weisen in vitro ein großes Spektrum an Bindungsaffinitäten zu anderen Komponenten der Basalmembran wie Fibulin, Perlecan und Kollagen IV auf (Hopf et al. 2001; Salmivirta et al. 2002; Schymeinsky et al. 2002). Nidogen-2 wird während der Embryonalentwicklung gemeinsam mit Nidogen-1 ubiquitär in allen Basalmembranen exprimiert (Miosge et al. 2002; Gersdorff et al. 2005). 


\section{I.5.4 Perlecan-KO-Maus-Modell}

Das heparansulfat-haltige Proteoglykan Perlecan ist ein weiterer Hauptbestandteil von Basalmembranen (Noonan und Hassel 1993). Perlecan ist der Universalist unter den Proteoglykanen des belasteten, knorpeligen Bindegewebes (Melrose et al. 2008). Proteoglykane werden im Knorpelgewebe von Chondrozyten hergestellt und sind Komplexe, an die große negativ geladene kohlenhydratreiche Ketten gebunden sind. Diese Ketten bezeichnet man als Glykosaminoglykane (Gag); sie sind mit dem zentralen Proteinstrang verbunden. Verbinden sich mehrere Proteoglykane gleicher Art, entsteht ein ProteoglykanMakromolekül wie z. B. Perlecan. Aufgrund der negativ geladenen Seitenketten weisen diese Makromoleküle eine hohe Tendenz auf, Wasser zu binden. Durch diese Eigenschaft wird dem Gewebe eine höhere mechanische Belastbarkeit, kompressiven Deformationen und Scherkräften standzuhalten, verliehen.

Perlecan ist das am häufigsten vorkommende Proteoglykan (Dziadek et al. 1985) und damit das Hauptproteoglykan der extrazellulären Matrix (Melrose et al. 2006). Dieses Proteoglykan spielt eine überaus wichtige Rolle in der extrazellulären Matrix, weil es sie durch Interaktionen mit einer Reihe anderer ECM-Proteine organisiert und stabilisiert (Iozzo 2005; Farach-Carson und Carson 2007; Gomes R et al. 2002; Iozzo 1998; Iozzo et al. 1994).

Das Perlecan Makromolekül setzt sich aus einem 400kDa schweren Kern-Protein und multiplen globulären Domänen (400-450kDa) zusammen. An einem der beiden Enden des Moleküls sind drei Heparansulfatketten angehängt (Paulsson et al. 1987; Noonan et al. 1991; Hassell et al. 1980). Perlecan ist ein wichtiger Bestandteil von Basalmembranen und wird wie die restlichen Bestandteile sehr früh während der Entwicklung synthetisiert (Iozzo et al. 1994). Perlecan kommt aber auch in allen Zonen der Wachstumsplatte während der enchondralen Ossifikation und in Gelenkknorpel vor (SundarRaj et al. 1995). 


\section{I.5.5 C57Black (BL)/6NCrl-Maus-Modell}

Die Gattung der C57BL ist wohl der am häufigsten verwendete Stamm, der zu verschiedenen Forschungszwecken eingesetzt wird. Der Maus-Stamm wird besonders als „background“ für genetische Mutationen verwendet. Die Mäuse zeichnen sich durch eine lange Lebensspanne aus, entwickeln aber im Alter diverse Tumore. Man unterteilt den Hauptstamm der C57BLMaus in viele verschiedene „Unterstämme“. Deswegen ist es wichtig, die genaue Bezeichnung des verwendeten Maus-Stamms zu kennen, mit dem man arbeiten möchte.

Der Name C57Black ist der gebräuchliche Name des C57BL/6 Maus-Stamms. Diese Mäuse stammen ursprünglich alle von einem Anbieter. Mit der Zeit wurden Kolonien des Originalstamms an verschiedene Anbieter weitergeben. Dadurch entstanden neue unterschiedliche Stämme, die zwar alle ursprünglich verwandt sind, sich jedoch genetisch voneinander unterscheiden. Die Mäuse erhalten je nach Anbieter einen oder mehrere Identifikationsbuchstaben nach der in dem Namen der Maus vorkommenden Zahl „6“. In dieser Studie wurden Mäuse der Bezeichnung C57BL/6NCrl von Charles River Laboratories bezogen und untersucht. 


\section{I.6 Kriterien der OA}

Im folgenden Kapitel werden die wichtigsten Anzeichen der OA vorgestellt, die für die Untersuchung und Interpretation der Ergebnisse wichtig waren. Dabei wurden Kriterien verwendet, die bereits von verschiedenen etablierten Autoren angewandt wurden, um eine OA eindeutig zu klassifizieren. Die Ergebnisse dieser Arbeit wurden mit dem von Zarb und Carlsson (1985) beschriebenen Schichtaufbau des Kondylus und der Pathomorphologie des Kiefergelenks verglichen. Zusätzlich wurden die HE gefärbten Kiefergelenkspräparate mithilfe einer modifizierten Klassifizierung nach Mankin et al. (1971) untersucht. Ein weiteres Beurteilungsschema von Collins und McElligott (1960) wurde modifiziert angewandt, um OA Zeichen anhand der Toluidinblau-Färbung untersuchen und bestätigen zu können.

\begin{tabular}{|c|c|c|}
\hline \multirow[t]{8}{*}{ I } & Knorpelstruktur & Score \\
\hline & normal & 0 \\
\hline & Oberflächenunregelmäßigkeiten & 1 \\
\hline & Pannus, Oberflächenunregelmäßigkeiten & 2 \\
\hline & Risse bis in die Proliferationszone & 3 \\
\hline & Risse bis in die Faserknorpelzone & 4 \\
\hline & Risse bis in die Ossifikationszone & 5 \\
\hline & komplette Desorganisation & 6 \\
\hline \multirow[t]{5}{*}{ II } & Beurteilung der Zellen & \\
\hline & Normal & 0 \\
\hline & Diffuse Verteilung, Hyperzellularität & 1 \\
\hline & Zellkluster & 2 \\
\hline & Hypozellularität & 3 \\
\hline \multirow[t]{3}{*}{ III } & Intaktheit der Faserknorpel-Knochengrenze & \\
\hline & Intakt & 0 \\
\hline & Von Blutgefäßen durchkreuzt & 1 \\
\hline
\end{tabular}

Tabelle 1: modifizierter Mankin Score (Mankin et al. 1971, Seite 525). 


\begin{tabular}{|c|c|c|c|}
\hline Grad & Chondrozyten & Knorpelgewebe & Toluidinblau \\
\hline $\mathbf{0}$ & $\begin{array}{l}\text { Gleichmäßige } \\
\text { Chondrozytengröße und } \\
\text { Chondrozytenverteilung }\end{array}$ & $\begin{array}{l}\text { Gleichmäßige Oberfläche, } \\
\text { regelmäßige Anordnung der } \\
\text { Knorpelzonen }\end{array}$ & $\begin{array}{l}\text { Superfiziell kaum } \\
\text { Anfärbung, Knorpelzonen } \\
\text { metachromatisch gefärbt }\end{array}$ \\
\hline 1 & $\begin{array}{l}\text { einzelne kleine } \\
\text { Chondrozytenkluster }\end{array}$ & $\begin{array}{l}\text { Tangentiale Fibrillation der } \\
\text { oberflächlichen, fibrösen } \\
\text { Bindegewebszone (BG), } \\
\text { leichte vertikale Risse } \\
\text { innerhalb dieser BG-Zone }\end{array}$ & $\begin{array}{l}\text { Farblose Fibrillen, } \\
\text { deutliche Färbung } \\
\text { reaktiver Zellkluster }\end{array}$ \\
\hline 2 & $\begin{array}{l}\text { größere } \\
\text { Chondrozytenkluster }\end{array}$ & $\begin{array}{l}\text { Verlust der oberflächlichen } \\
\text { fibrösen BG-Zone, } \\
\text { Risse bis an die } \\
\text { Faserknorpelschicht, } \\
\text { keine Knorpelfreilegung }\end{array}$ & $\begin{array}{l}\text { Zunahme der Färbung der } \\
\text { reaktiven Zellkluster }\end{array}$ \\
\hline 3 & $\begin{array}{l}\text { Zunahme der Anzahl und } \\
\text { der Größe der } \\
\text { Chondrozytenkluster, } \\
\text { Verteilung auch in tiefere } \\
\text { Knorpelschichten }\end{array}$ & $\begin{array}{l}\text { Risse über die } \\
\text { Faserknorpelschicht hinaus, } \\
\text { Knorpelfreilegung, } \\
\text { marginal Osteophyten }\end{array}$ & $\begin{array}{l}\text { Stärkere Zunahme der } \\
\text { reaktiven Zellkluster, } \\
\text { diffuse Färbung um die } \\
\text { Zellkluster }\end{array}$ \\
\hline 4 & $\begin{array}{l}\text { Befunde des } \\
\text { Arthrosegrads } 3\end{array}$ & $\begin{array}{l}\text { Zunahme der bisherigen } \\
\text { Befunde, } \\
\text { kompletter Knorpelverlust, } \\
\text { größere Osteophyten }\end{array}$ & $\begin{array}{l}\text { Weiterhin stärkere } \\
\text { Zunahme der } \\
\text { Farbintensitäten }\end{array}$ \\
\hline
\end{tabular}

Tabelle 2: Kriterien des Arthrosegrads anhand histologischer Befunde nach Collins und McElligott (1960), Seite 319, unter besonderer Berücksichtigung der Toluidinblau-Färbung. 


\section{I.7 Aufgabenstellung}

Bis heute ist die OA nicht heilbar und die zur Pathogenese führenden ätiologischen Faktoren nicht vollständig geklärt. Viele Tiere weisen die gleichen grundlegenden Charakteristika der OA auf, wie sie auch beim Menschen beschrieben sind (Walton 1977). In der derzeitigen Literatur gibt es viele verschiedene Tier-Modelle, die zur Aufschlüsselung der pathologischen Prozesse der OA studiert wurden. Auf der Suche nach neuen wissenschaftlichen Erkenntnissen zur OA wurden in dieser Forschungsarbeit die Kiefergelenke von Mäusen untersucht. Bei Wirbeltieren, die keine Hände entwickelt haben, spielt das Gebiss eine besonders wichtige Rolle für das Überleben. Dadurch unterliegt das Kiefergelenk von Wirbeltieren einer höheren Beanspruchung (Zarb und Carlsson 1985).

Derzeit existieren jedoch nur eine sehr geringe Anzahl von Maus-Modellen, an denen eine natürlich auftretende OA im Kiefergelenk beobachtet worden ist (Wadhwa et al. 2005). In Anlehnung an die Publikation von Wadhwa et al. besteht diese Forschungsarbeit daraus, ein mögliches neues Maus-Modell mit nicht induzierter, natürlich auftretender OA zu finden.

Diese Forschungsarbeit soll Hinweise zu neuen Maus-Modellen liefern, um die OA des Kiefergelenks besser untersuchen zu können. Du Brul war schon 1964 der Meinung, dass das Kiefergelenk in der Evolution allen anderen Gelenken vorausgehe (Du Brul 1964).

Ließen sich neue Erkenntnisse der pathologischen Mechanismen der OA anhand von Forschungsarbeiten am Kiefergelenk besser verstehen, könnte man diese Ergebnisse eventuell auch auf andere Gelenke übertragen. 


\section{Material und Methoden}

\section{II.1 Versuchstiere}

Bei der einen Gruppe der verwendeten Tieren handelt es sich um Mäuse aus dem Tierstall des Max-Planck-Instituts für experimentelle Medizin Göttingen. Im Rahmen dieser Forschungsarbeit wurden genetisch unveränderte Mäuse vom NMRI-Stamm und C57BL/6NCrl-Stamm zusammen mit Nidogen-2-KO-Mäusen und Perlecan-KO-Mäusen untersucht. Als letzte Gruppe der $\mathrm{zu}$ untersuchenden Tiere wurden ICR-CD1-Mäuse verwendet, die käuflich erworben wurden und von Harlan Europe stammten. Die Mäuse wurden bei $21 \pm 2^{\circ}$ C Raumtemperatur (RT) unter Standardbedingungen in Käfigen, mit je 2 bis 3 Tieren, in den tierexperimentellen Einrichtungen des Instituts mit einem 12-StundenLichtrhythmus gehalten. In jedem Käfig befand sich ausreichend viel Wasser und Trockenfutter, zu dem die Tiere unbegrenzten Zugang hatten. Vor Beginn der Experimente wurden die Tiere für circa 24 Stunden in den Versuchsräumen akklimatisiert. Bei den Tieren wurde der Genotyp, das Alter und das Geschlecht festgehalten. Die Tiere wurden euthanasiert und anschließend zur Vermeidung von Kontaminationen mit Meliseptol® (Fa. B. Braun, Melsungen, Deutschland) besprüht.

\section{II.2 Präparation}

Um die Kiefergelenke nicht zu beschädigen, wurden die Köpfe separat vom Körper präpariert. Auf Höhe der mittleren Halswirbel wurden die Köpfe vom restlichen Körper getrennt. Danach wurde die Fellhaut von der Squama occipitale, kranial sagittal nach anterior zum Os nasale, und kaudal sagittal bis zum Hals mit einer Schere durchtrennt. Die Haut wurde stumpf abpräpariert, Organe wie Augen und Ohren wurden ebenfalls entfernt. Das Schädelskelett wurde zusammen mit der Kaumuskulatur dargestellt. Die mastikatorische Muskulatur, besonders die Musculi (Mm.) masseterici laterales, Mm. masseterici mediales, Mm. masseterici superficiales und Mm. temporales wurden belassen, damit sie den Condylus articularis zusammen mit dem Discus articularis in der Fossa articularis fixiert. 
Die Schädelkalotten wurden anschließend median sagittal vom Os nasale entlang der Raphe mediana bis zum Foramen occipitale mit einer scharfen Spitzschere durchgeschnitten. Die Unterkiefer wurden vorsichtig mit einer scharfen Skalpell-Klinge zwischen den beiden unteren Inzisivi an der Symphyse des Unterkiefers durchtrennt.

Nun wurden die linken Schädelhälften zusammen mit den linken Unterkieferhälften von den rechten Schädel- und Unterkieferhälften voneinander getrennt und separat in beschrifteten Kunststoffbechern mit Schraubverschlüssen aufbewahrt. Organe, wie z. B. Gehirn, Bulbus olfactorii und größere Drüsen, wurden zur verbesserten Übersicht und zur besseren Penetrierbarkeit der anschließenden Reagenzienbäder entfernt.

\section{II.3 Fixierung und Entkalkung}

Für jede weitere histologische Aufarbeitung war die Fixierung und Entkalkung der Präparate notwendig. Die gewonnenen Schädelhälften wurden sofort nach der Entnahme jeweils einzeln in beschriftete, sterile Kunststoffröhren (50 ml Reagenz- und Zentrifugenröhre, Sarstedt) zusammen mit $45 \mathrm{ml} 4 \%$ gepufferter Formalinlösung nach Lilie für sechs Stunden bei vier Grad Celsius fixiert. Das Kühlen der Präparate und der Fixierungslösung im Kühlschrank verhinderte eine mögliche Autolyse der unfixierten Gewebsanteile. Auch die Einwirkdauer dieser Lösung muss begrenzt sein, weil die Präparate sonst brüchig sowie schlecht anfärbbar werden und auch quellen können. Für eine ausreichende Fixation muss das Volumen der Formalinlösung mindestens zehn Mal dem Volumen des Gewebes entsprechen. Die Fixierung hat die wichtige Aufgabe, die Gewebsstrukturen zu stabilisieren, den Zellzerfall zu verhindern und die Lagebeziehungen der anatomischen Strukturen zueinander zu erhalten.

Dabei kann man generell physikalisch durch schnelles Einfrieren fixieren, oder alternativ chemisch mittels beispielsweise Formaldehyd. Bei der klassischen Originalrezeptur, die von Lilie beschrieben wurde, handelt es sich um eine Lösung, die nicht neutral gepuffert vorliegt und einen $\mathrm{pH}$-Wert von 7,0 hat. Bei der heute üblichen, modifizierten Rezeptur nach Lilie wird eine neutral gepufferte Lösung erzeugt, deren $\mathrm{pH}-$ Wert bei 7,4 liegt. 
Neutral gepuffertes Formalin ist dem ungepufferten Formalin unbedingt vorzuziehen. In ungepufferten Formalinlösungen kommt es unter Lichteinwirkung zur Oxidation zu Ameisensäure und zu einer damit verbundenen Absenkung des $\mathrm{pH}$-Werts, was sich negativ auf die Qualität des Gewebes auswirken kann (http://www.pathology.unibe.ch).

Die Lösung wird lichtgeschützt in einer braunen Flasche im Kühlschrank aufbewahrt. Insbesondere für das Schneiden mit dem Mikrotom war die anschließende Entkalkung der knöchernen Präparate notwendig. Jedes Präparat wurde für mindestens drei Wochen in 10prozentiger Ameisensäure zur Entkalkung überführt. Jedes Präparat wurde mit $45 \mathrm{ml}$ der Entkalkungslösung versetzt, die täglich gewechselt wurde. Während der gesamten Entkalkungsdauer wurden die Präparate lichtgeschützt aufbewahrt, um eine mögliche Polymerisation des Formaldehyds zu vermeiden. Die Präparate entkalkten bei RT. Nachdem alle Schädelhälften vollständig entkalkt und fixiert waren, wurden sie zum Auswaschen und Dehydrieren für mindestens vier Tage in 70- prozentigem Ethanol eingelegt und bei $4^{\circ} \mathrm{C}$ gelagert. Alle verwandten alkoholischen Verdünnungen erfolgten mit destilliertem Wasser. 


\section{II.4 Einbettung}

Die fixierten und entkalkten Gewebe müssen, bevor man sie in wenige $\mu$ m-dicke Schnitte anfertigen kann, eingebettet werden. Die Einbettung erfolgte mittels Paraffin. Die ParaffinEinbettung stellt eine aufwendigere Bearbeitung der Organe dar, als beispielsweise die der Kryo-Histologie. Der Vorteil der Paraffin-Einbettung ist jedoch die deutlich bessere Strukturerhaltung. Vor dem Einbetten in Paraffin wurden alle Schädelhälften einzeln in beschriftete Kunststoffkassetten (Paraplast X-tra, Fa. Carl Roth) versetzt. Im sofortigen Anschluss folgte das Einbetten nach folgendem Einbettungsprotokoll mithilfe eines Einbettautomaten der Firma Duplex (Processer, Shandon Elliot, Cheshire, England):

\begin{tabular}{|l|l|l|}
\hline \multicolumn{1}{|c|}{ Schritt } & \multicolumn{1}{c|}{ Reagenz } & \multicolumn{1}{c|}{ Zeit } \\
\hline Position 1 & $70 \%$ Ethanol & $3 \mathrm{~h}$ \\
\hline Position 2 & $80 \%$ Ethanol & $1 \mathrm{~h}$ \\
\hline Position 3 & $90 \%$ Ethanol & $1 \mathrm{~h}$ \\
\hline Position 4 & $96 \%$ Ethanol & $1 \mathrm{~h}$ \\
\hline Position 5 & Abs. Ethanol & $2 \mathrm{~h}$ \\
\hline Position 6 & Abs. Ethanol & $\begin{array}{l}2 \mathrm{~h} \mathrm{nur} \mathrm{für} \mathrm{embryonales} \\
\text { Gewebe }\end{array}$ \\
\cline { 2 - 3 } & Isopropylalkohol & $2 \mathrm{~h}$ nur für adultes Gewebe \\
\hline Position 7 & Isopropylalkohol & $1,5 \mathrm{~h}$ \\
\hline Position 8 & Xylol & $30 \mathrm{~min}$ \\
\hline Position 9 & Xylol & $45 \mathrm{~min}$ \\
\hline Position 10 & Xylol & $45 \mathrm{~min}$ \\
\hline Position 11 & Paraplast Plus $\left(52^{\circ} \mathrm{C}\right)$ & $6 \mathrm{~h}$ \\
\hline Position 12 & Paraplast Plus $\left(56^{\circ} \mathrm{C}\right)$ & $7 \mathrm{~h}$ \\
\hline
\end{tabular}

Anschließend wurden alle Gewebestücke mit den jeweiligen Einbettkassetten einzeln in spezielle Edelstahl-Einbett-Schälchen (Fa. Langenbrinck) gelegt und mit Hilfe einer Paraffinausgießstation (Paraffinspender, Fa. Medax) eingebettet. Die Paraffinblöcke wurden einen Tag bei RT ausgehärtet und konnten für die Anfertigung der histologischen Schnittpräparate verwendet werden. 


\section{II.5 Anfertigung der Gewebeschnitte}

Mit Hilfe eines Rotationsmikrotoms (Jung Biocut 2035, Fa. Reichert-Jung) wurden Serienschnitte der gesamten Schädelhälften mit der Dicke von $5 \mu \mathrm{m}$ hergestellt. Die Schnitte wurden in der Median-Sagittal-Ebene durchgeführt. Diese Paraffinschnitte wurden in einer mit erwärmten Aqua dest. befüllten Petrischale auf der Heizplatte maximal entfaltet und gestreckt, um glatt auf einen Objektträger aufgezogen werden zu können. Besonders die Schnittpräparate, die unmittelbar vor, durch und unmittelbar nach dem Kiefergelenk entstanden sind, wurden vorsichtig auf silanisierten Superfrost ${ }^{\circledR}$-Plus-Objektträger (Thermo Scientific, Fa. Menzel, Braunschweig, Deutschland) aufgezogen. Anschließend wurden die Paraffinschnitte für $24 \mathrm{~h}$ in einem Wärmeschrank bei $37^{\circ} \mathrm{C}$ getrocknet.

\section{II.6 Histologische Färbungen}

Als histologische Färbungen zur Beurteilung der Gewebeschnitte wurden die HämatoxylinEosin (HE)-Färbung und die Toluidinblau (TB)-Färbung ausgewählt. Dabei wurde jeweils die eine Hälfte der verwendeten Präparate mit HE gefärbt und die andere Hälfte der Präparate mit TB gefärbt. 


\section{II.6.1 Prinzip der Hämatoxylin-Eosin-Färbung}

Jeder zweite Objektträger mit den fertig getrockneten Gewebeschnitten wurden in einem speziellen Objektträger-Korb eingesetzt. Zur Vorbereitung der Färbung wurden die Objektträger-Körbe zum Entparaffinieren für 15 min in eine Reagenzien-Küvette mit Xylol gehängt. Die Gewebeschnitte wurden in anschließender absteigender Ethanol Konzentration rehydriert und gefärbt. Die Bewässerung, Färbung, anschließende Entwässerung und Fixierung der Präparate wurden mithilfe eines Färbeautomaten (Stainix DiaPath, R.W. Weinkauf Medizintechnik, Forchheim, Deutschland) nach folgendem Protokoll durchgeführt:

\begin{tabular}{|l|l|l|}
\hline \multicolumn{1}{|c|}{ Schritt } & \multicolumn{1}{c|}{ Reagenz } \\
\hline Position 1 & Xylol & $5 \mathrm{~min}$ \\
\hline Position 2 & Xylol & $5 \mathrm{~min}$ \\
\hline Position 3 & Abs. Ethanol & $2 \mathrm{~min}$ \\
\hline Position 4 & $96 \%$ Ethanol & $2 \mathrm{~min}$ \\
\hline Position 5 & $80 \%$ Ethanol & $2 \mathrm{~min}$ \\
\hline Position 6 & $60 \%$ Ethanol & $2 \mathrm{~min}$ \\
\hline Position 7 & Aqua dest. & $2 \mathrm{~min}$ \\
\hline Position 8 & Hämalaun (nach Mayer) & $4 \mathrm{~min}$ \\
\hline Position 9 & Aqua dest. & $1 \mathrm{~min}$ \\
\hline Position 10 & Fließendes Wasser & $15 \mathrm{~min}$ \\
\hline Position 11 & Eosin & $7 \mathrm{~min}$ \\
\hline Position 12 & Aqua dest. & $1 \mathrm{~min}$ \\
\hline Position 13 & $60 \%$ Ethanol & $1 \mathrm{~min}$ \\
\hline Position 14 & $80 \%$ Ethanol & $1 \mathrm{~min}$ \\
\hline Position 15 & $96 \%$ Ethanol & $1 \mathrm{~min}$ \\
\hline Position 16 & Abs. Ethanol & $2 \mathrm{~min}$ \\
\hline Position 17 & Abs. Ethanol & $2 \mathrm{~min}$ \\
\hline Position 18 & Xylol & $3 \mathrm{~min}$ \\
\hline
\end{tabular}


Bei dieser Doppelfärbemethode werden Hämatoxylinlösungen nach Meyer für die Zellkernfärbung und Eosinlösungen für die Zytoplasmafärbung benutzt. Im ersten Schritt werden durch die Hämatoxylinlösung in Position 8 die Zellkerne gefärbt, so dass die Kerne blau bis dunkelviolett erscheinen. Der zweite Färbeschritt dieser Methode beinhaltet die Gegenfärbung in Position 11. Zytoplasma, Kollagen, Erythrozyten und Keratin werden dabei durch das Eosin rot gefärbt. Meyers Hämalaun hat den Vorteil dass es rasch das Gewebe färbt und bei zu langem Einwirken nicht überfärbt. Ein paar Tropfen Essigsäure, die dem Eosin beigemischt werden, sorgen für eine leichte Überfärbung vom Eosin. Dies ist empfehlenswert und verbessert den Färbekontrast, da beim Spülen mit destilliertem Wasser und niedrig konzentriertem Alkohol Farbe verloren geht.

Die HE-Färbung ermöglicht einen mikroskopischen Überblick über die Strukturen des Gewebes und bietet dabei gleichzeitig die Unterscheidung zwischen gesundem, pathologisch-, entzündlich- oder degenerativ-verändertem Gewebe. Auf Grundlage der HE-Färbetechnik können oft Diagnosen gestellt werden, bzw. differenziert werden, welche Spezialfärbungen zur Feintypisierung notwendig ist.

Die gefärbten HE-Präparate wurden im Anschluss mit Deckgläsern (Fa. Roth, Karlsruhe, Deutschland) und Deckmedium (Eukitt ${ }^{\circledR}$, Sigma-Aldrich) fertig gestellt und bei RT getrocknet. 


\section{II.6.2 Prinzip der Toluidinblau-Färbung}

Von den übrigen Präparaten wurde wieder jeder zweite Objektträger zum Entparaffinieren in einen Korb eingesetzt und für 15 min in das Xylol-Bad eingehängt. Die TB-Färbung erfolgte wiederum mit dem bereits zur HE-Färbung vorgestellten Färbeautomat, allerdings mit den für die TB-Färbung nötigen Reagenzien und Zeiteinstellungen. Die Reagenzien und Zeiteinstellungen sind dem folgenden Protokoll zu entnehmen:

\begin{tabular}{|c|c|c|}
\hline Schritt & Reagenz & Zeit \\
\hline Position 1 & Xylol & $5 \mathrm{~min}$ \\
\hline Position 2 & Xylol & $5 \mathrm{~min}$ \\
\hline Position 3 & Abs. Ethanol & $2 \mathrm{~min}$ \\
\hline Position 4 & $96 \%$ Ethanol & $2 \min$ \\
\hline Position 5 & $80 \%$ Ethanol & $2 \min$ \\
\hline Position 6 & $60 \%$ Ethanol & $2 \mathrm{~min}$ \\
\hline Position 7 & Aqua dest. & $2 \min$ \\
\hline Position 8 & 0,04\% Toluidine Blue O & $10 \mathrm{~min}$ \\
\hline Position 9 & Aqua dest. & $2 \min$ \\
\hline Position 10 & Fließendes Wasser & $1 \mathrm{~min}$ \\
\hline Position 11 & $0,1 \%$ Fast Green FCF & $2 \mathrm{~min}$ \\
\hline Position 12 & Fließendes Wasser & $1 \mathrm{~min}$ \\
\hline Position 13 & Aqua dest. & $2 \mathrm{~min}$ \\
\hline Position 14 & $60 \%$ Ethanol & $1 \mathrm{~min}$ \\
\hline Position 15 & $80 \%$ Ethanol & $1 \mathrm{~min}$ \\
\hline Position 16 & $96 \%$ Ethanol & $1 \mathrm{~min}$ \\
\hline Position 17 & Abs. Ethanol & $2 \mathrm{~min}$ \\
\hline Position 18 & Abs. Ethanol & $2 \min$ \\
\hline Position 19 & Xylol & $3 \mathrm{~min}$ \\
\hline
\end{tabular}


Um die Metachromasie eines Gewebeanteils nachzuweisen, werden ausschließlich Thiazinfarbstoffe, wie z. B. dem TB verwendet. Die TB-Färbung stellt ebenfalls eine gute Übersichtsfärbung dar. Hierbei wird das Gewebe kontrastreich blau gefärbt und der Farbstoff diffundiert gut in die Grundsubstanz des Knorpels. Die TB-Färbung ist ein basischer Farbstoff, der selektiv an negativ geladenen Amin- und Sulfatgruppen bindet. Bei mineralisiertem Knochengewebe erscheint das Präparat farblos bis blassblau, während entsprechendes Weichgewebe, wie Knorpelmatrix und Mastzellengranula metachromatisch rot-violett gefärbt werden. So zeigt eine metachromatische rot-violette Färbung in der Knorpelgrundsubstanz die Anwesenheit von hochpolymeren sauren Proteoglykanen, Glykosaminoglykanen und Mukopolysacchariden (Romeis 1989) an. Wirkt das Gewebe des Knorpels blass oder ausgebleicht, so weißt dies den Abfall des Proteoglykangehalts nach (Blumenfeld et al. 2000). Damit ist die TB-Färbung ein Nachweis der im Knorpel vorhandenen Proteoglykanen. Die Gegenfärbung mit Fast Green FCF bewirkt eine kontrastreichere Darstellung des Gewebes durch die türkisfarbene Plasmafärbung.

\section{II.7 Lichtmikroskopie, Fotografie und Digitalisierung der Gewebeschnitte}

Zur Beurteilung und Auswertung der im Rahmen dieser Studie angefertigten histologischen Schnittbilder wurden die fertig angefärbten Präparate unter einem Lichtmikroskop untersucht. Das dabei verwendete Mikroskop (Olympus CX40 PCM, 4x 10x 40x 100x Vergrößerung) war an eine digitale Spiegelreflexkamera (Nicon DX 90) gekoppelt. Um standardisierte Bilder zu erstellen, wurden alle Präparate hintereinander mit ein und der selben Vorrichtung und Einstellung bezüglich der Licht-, Vergrößerungs-, Kontrast-, und Kameraeinstellung angefertigt und gespeichert. Die vergrößerten und abfotografierten histologischen Schnittbilder wurden auf einen Speichermedium gespeichert. Die Auswertung der Bilder erfolgte an einem Bildschirm. 


\section{II.8 Verwendete Reagenzien, Verbrauchsmaterialien und Geräte}

\begin{tabular}{|c|c|}
\hline \multicolumn{2}{|r|}{ Reagenzien } \\
\hline \multicolumn{2}{|c|}{ 4-prozentiges gepufferte Formalinlösung nach Lillie, pH 7,4: } \\
\hline $100 \mathrm{ml}$ & $37 \%$ Formalin, Fa. Merck, Darmstadt, Deutschland \\
\hline $333 \mathrm{ml}$ & 0,3 M Sörensen Puffer \\
\hline $566 \mathrm{ml}$ & Aqua dest. \\
\hline \multicolumn{2}{|c|}{ Sörensen Puffer, pH 7,4 } \\
\hline \multicolumn{2}{|c|}{ Lösung A (Kaliumhydrogenphosphat): } \\
\hline $40,872 \mathrm{~g}$ & $\mathrm{KH}_{2} \mathrm{PO}_{4}$ (Fa. Carl Roth Nr. 3904.1, Karlsruhe, Deutschland) \\
\hline $1000 \mathrm{ml}$ & Aqua dest. $\rightarrow$ bei $4^{\circ} \mathrm{C}$ im Kühlschrank aufbewahren \\
\hline \multicolumn{2}{|c|}{ Lösung B (Di- Natriumhydrogenphosphat): } \\
\hline $42,588 \mathrm{~g}$ & $\mathrm{Na}_{2} \mathrm{HPO}_{4}$ (Fa. Merck Nr.1.06580.1000, Darmstadt, Deutschland) \\
\hline $1000 \mathrm{ml}$ & Aqua dest. $\rightarrow$ bei RT lagern \\
\hline \multicolumn{2}{|c|}{ für fertige 0,3 M Sörensen Puffer 18,2 ml Lsg A mit 81,8 ml Lsg B mischen } \\
\hline \multicolumn{2}{|c|}{ 10-prozentige Ameisensäure: } \\
\hline $900 \mathrm{ml}$ & Aqua dest. \\
\hline $50 \mathrm{~g}$ & Paraformaldehyd, reinst (Fa. Carl Roth Nr. 0335.3, Karlsruhe, D.) \\
\hline $100 \mathrm{ml}$ & Ameisensäure (Fa. Roth Nr. 4724.2 Rotipuran ${ }^{\circledR}>98 \%$, Karlsruhe, D.) \\
\hline \multicolumn{2}{|c|}{$\begin{array}{l}\text { Aqua dest. in lichtgeschützter Flasche bei } 60-70^{\circ} \mathrm{C} \text { und circa vier Stunden mittels } \\
\text { Magnetrührer das Paraformaldehyd auflösen, bis die Lösung klar ist. Anschließend abkühlen } \\
\text { lassen und mit } 100 \mathrm{ml} \text { Ameisensäure vermischen, kühl und dunkel lagern }\end{array}$} \\
\hline \multicolumn{2}{|c|}{ Hämalaun Färbelösung nach Meyer für Hämatoxylin-Eosin-Färbung: } \\
\hline $1 \mathrm{~g}$ & Hämalaun \\
\hline $1000 \mathrm{ml}$ & Aqua dest. \\
\hline $0,2 \mathrm{~g}$ & $\mathrm{NaJO}_{3}$ \\
\hline $50 \mathrm{~g}$ & Kalialaun (Kaliumaluminiumsulfat reinst) \\
\hline $50 \mathrm{~g}$ & Chloraldydrat \\
\hline $1 \mathrm{~g}$ & Zitronensäure \\
\hline
\end{tabular}




\section{Eosin-Lösung:}

\begin{tabular}{|l|l|}
\hline $1 \mathrm{~g}$ & Eosin Y (AppliChem, BioChemica, Darmstadt, Deutschland) \\
\hline $1000 \mathrm{ml}$ & Aqua dest.
\end{tabular}

ein paar Tropfen Essigsäure vor der Färbung dazugeben

Toluidinblau-Färbung:

\begin{tabular}{|l|l|}
\hline $0,04 \%$ & Toluidine Blue O (Sigma Aldrich, Steinheim am Albuch, Deutschland) \\
\hline $100 \mathrm{ml}$ & $0,1 \mathrm{M}$ Natriumacetat Puffer $\mathrm{pH} 4,0$ \\
\hline $3 \mathrm{M}$
\end{tabular}

$3 \mathrm{M}$ Natriumacetat Puffer $\mathrm{pH} 7$ wird bei $4^{\circ} \mathrm{C}$ gelagert, $1: 30$ verdünnt, das heißt $4 \mathrm{ml} 3 \mathrm{M}$ Natriumacetat auf $120 \mathrm{ml}$ Aqua dest. mit $\mathrm{HCl}$ auf $\mathrm{pH}$ 4,0 einstellen

Fast Green FCF:

\begin{tabular}{|l|l|}
\hline $0,1 \mathrm{~g}$ & Fast Green FCF (Sigma Aldrich, Steinheim am Albuch, Deutschland) \\
\hline $100 \mathrm{ml}$ & Aqua dest. \\
\hline
\end{tabular}

\begin{tabular}{|l|l|}
\hline \multicolumn{2}{|c|}{ Verbrauchsmaterialien } \\
\hline 70-prozentiges Ethanol & $\begin{array}{l}\text { Fa. Merck, Ethanol Absolut, Darmstadt, } \\
\text { Deutschland }\end{array}$ \\
\hline Deckgläser & Menzel GmbH, Braunschweig, Deutschland \\
\hline Edelstahl Einbett-Schälchen & Fa. Langenbrinck, Emmendingen, Deutschland \\
\hline Einbettkassetten Kunststoff & Fa. Carl Roth, Karlsruhe, Deutschland \\
\hline Eukitt Eindeckmedium & $\begin{array}{l}\text { Sigma-Aldrich, Steinheim am Albuch, } \\
\text { Deutschland }\end{array}$ \\
\hline Meliseptol ${ }^{2}$ & B. Braun Melsungen AG, Deutschland \\
\hline $\begin{array}{l}\text { Paraplast X-Tra Tissue Embedding } \\
\text { Medium }\end{array}$ & $\begin{array}{l}\text { McCormick Scientific, C. Roth, Karlsruhe, } \\
\text { Deutschland }\end{array}$ \\
\hline Reagenz- und Zentrifugenröhren, 50 ml & Sarstedt, Deutschland \\
\hline Superfrost@-Plus-Objektträger & $\begin{array}{l}\text { Thermo Scientific, Menzel GmbH, Braunschweig, } \\
\text { Deutschland }\end{array}$ \\
\hline Xylol & Fa. Carl Roth, Karlsruhe, Deutschland \\
\hline
\end{tabular}




\begin{tabular}{|c|c|}
\hline \multicolumn{2}{|r|}{ Geräte } \\
\hline digitale Spiegelreflexkamera & Nicon DX 90 \\
\hline Einbettautomat Duplex Processer & Shandon Elliot, Cheshire, England \\
\hline Microtom Blades 218 & $\begin{array}{l}\text { Fa. Reichert-Jung, Leica Microsystems, Nussloch, } \\
\text { Deutschland }\end{array}$ \\
\hline Mikroskop Olympus CX40 PCM & 4x 10x 40x 100x Vergrößerung \\
\hline Mikrotom Jung Biocut 2035 & $\begin{array}{l}\text { Fa. Reichert-Jung, Leica Instruments, Nussloch, } \\
\text { Deutschland }\end{array}$ \\
\hline Paraffinausgießstation & $\begin{array}{l}\text { Paraffinspender, Fa. Medax, Rendsburg, } \\
\text { Deutschland }\end{array}$ \\
\hline
\end{tabular}




\section{Ergebnisse}

\section{III.1 ICR-CD1-Mäuse}

\section{III.1.1 HE-Färbung}

An den Kiefergelenken der ICR-CD1-Mäuse konnten mit Hilfe der HE-Färbung an verschiedenen Bereichen OA-Veränderungen bestätigt werden. An der Knorpeloberfläche lieferten Risse, welche bis an die Zone des Faserknorpels (Übergangszone) reichten, den Beweis für einen OA-geschädigten Knorpel. Die oberflächliche fibröse Bindegewebszone war stark reduziert und nur noch rudimentär antero-superior am Kondylus nachweisbar. Die normalerweise in dieser Schicht liegenden spindelförmigen Fibroblasten-ähnlichen Zellen waren ebenfalls nur in geringer Anzahl antero-superior erkennbar. Die Gelenkoberflächen wiesen Unregelmäßigkeiten auf. In der Faserknorpelzone erkannte man hypertrophe Chondrozyten, die sich lokalisiert zu Zellklustern versammelt hatten. Trotz der typischen OAMerkmale waren die Chondrozyten größtenteils säulenartig angeordnet und wiesen tendenziell eine regelmäßige Verteilung auf. 


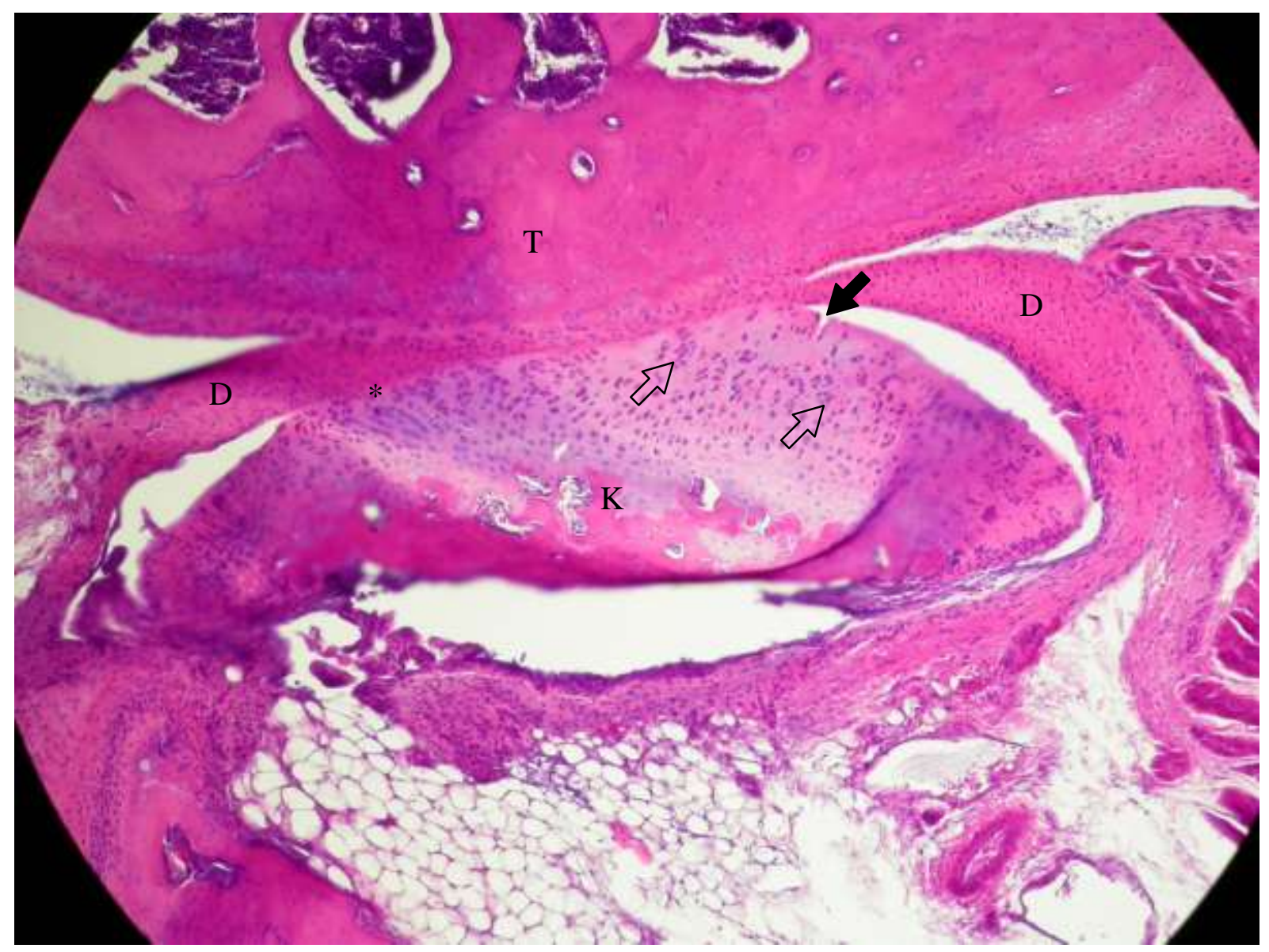

Bild 1: HE gefärbtes Kiefergelenk der ICR-CD1-Maus (x 4)

$\mathrm{T}=$ Temporaler Gelenkanteil; $\mathrm{D}=$ Discus articularis; $\mathrm{K}=$ Kondylus

Schwarzer Pfeil = OA; Transparenter Pfeil = hypertrophe Chondrozyten-Zellkluster * = oberflächliche fibröse Bindegewebszone 


\section{III.1.2 TB-Färbung}

In der Nachweisfärbung für Proteoglykane konnte eine verstärkte Färbung besonders in den inneren Knorpelzonen dargestellt werden. Die Chondrozyten waren von außergewöhnlich viel Matrix umgeben. Ein hoher Proteoglykangehalt konnte zentral am Kondylus, von tieferen Knorpelzonen bis an die Oberfläche durch eine intensive TB-Färbung dargestellt werden, wohin gegen die Intensität an den peripheren Bereichen sowohl in der Tiefe, als auch an der Oberfläche reduziert war. Die intensive Blau-Färbung war besonders perizellulär und an den Zellklustern der Chondrozyten erkennbar. An multiplen Stellen medial des Kondylus konnte man einen extrazellulären proteoglykanreichen Schleier erkennen, der wie aus ausgelaufenen Zellen wirkte und bis an die Oberfläche reichte. In dieser Abbildung waren die Tiefen und Ausdehnungen der oberflächlichen Risse am Kondylus besonders deutlich erkennbar. Die Risse verursachten klaffende Furchen in der Oberfläche und unterbrachen die Kontinuität sowohl am anterioren, als auch am posteriorem Kondylusanteil. 


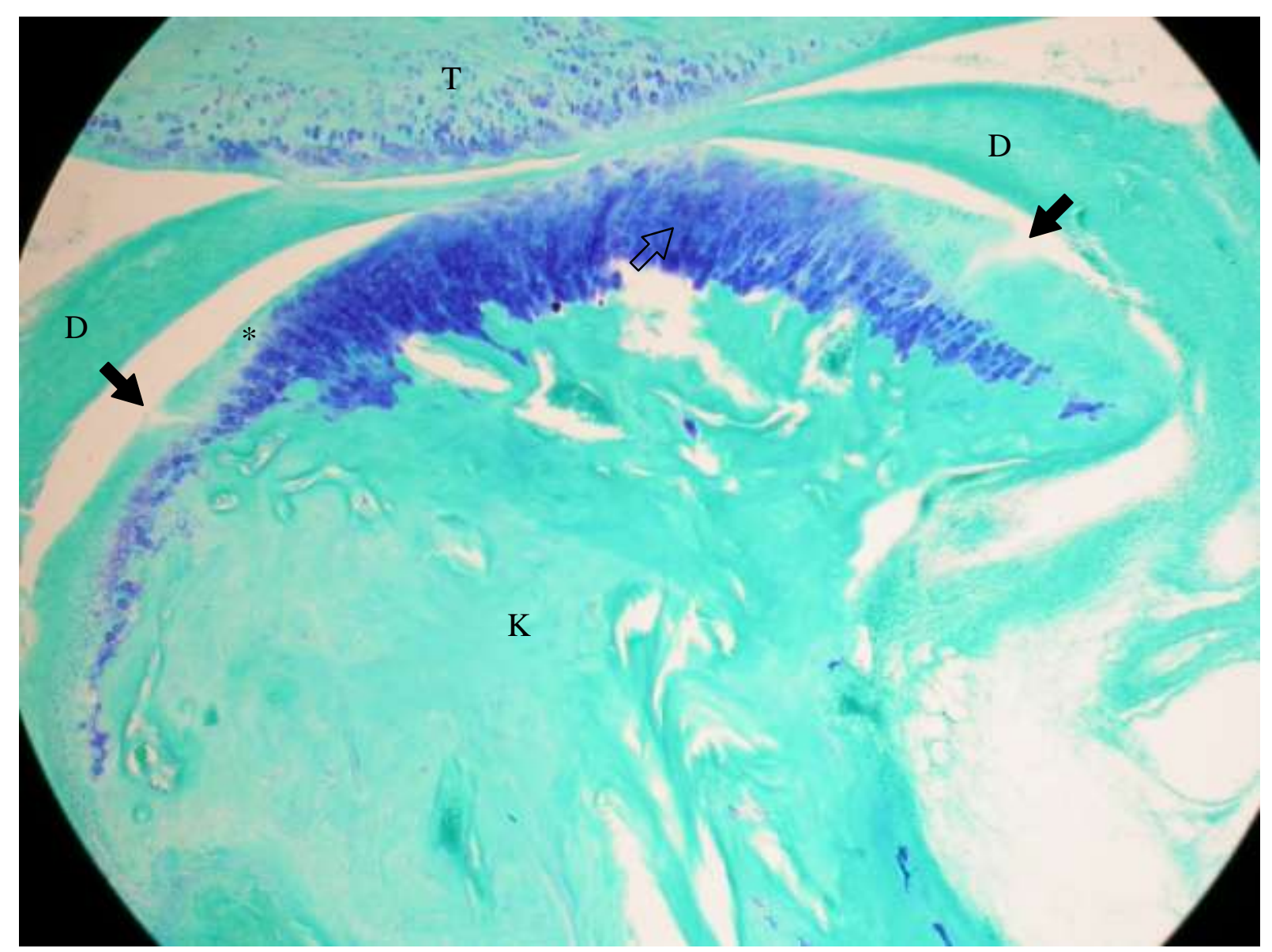

Bild 2: TB gefärbtes Kiefergelenk der ICR-CD1-Maus (x 4)

$\mathrm{T}=$ Temporaler Gelenkanteil; $\mathrm{D}=$ Discus articularis; $\mathrm{K}=$ Kondylus

Schwarzer Pfeil = OA; Transparenter Pfeil $=$ hypertrophe Chondrozyten-Zellkluster * = oberflächliche fibröse Bindegewebszone 


\section{III.2 C57BL/6NCrl-Mäuse}

\section{III.2.1 HE-Färbung}

OA-Veränderungen konnte besonders an den Kiefergelenken der C57BL/6NCrl-Mäusen nachgewiesen werden. In der HE-Färbung erkannte man eindeutig eine unregelmäßige Knorpeloberfläche. An mehreren Stellen ließen sich Fissuren nachweisen, die sogar bis in die Zone des Faserknorpels hinein reichten. Stellenweise konnten partielle Weichgewebsverluste die inneren Schichten des Knorpels freilegen. Diese partiellen Weichgewebssegmente lagen als Bruchstücke frei im Gelenkspalt. Diese sich daraus ergebende superfizielle Ulzeration konnte im medialen Bereich des Kondylus dargestellt werden. Besonders auffällig erschien, dass an den gut erkennbaren OA-Defekten überwiegend Zellkluster anwesend waren und kaum normale Chondrozyten vorzufinden waren. Auch an den Ulzerationsrändern waren nur vereinzelte Chondrozyten, die sich ebenfalls zu Klustern formiert hatten, nachweisbar. Die Grenze zwischen der Faserknorpelschicht und der Knochenschicht war stellenweise durchbrochen. Die stark unregelmäßige Oberfläche, die durch diese OA-Veränderung deformiert wurde, wies des weiteren kleine Sporne auf, die in den Gelenkspalt hinein ragten. Diese Sporne waren ebenfalls arm an normotrophen Chondrozyten und bestanden vorwiegend aus hypertrophen Chondrozytenklustern. Des weiteren konnte man bereits bei vierfacher Vergrößerung große, diffuse Zellkluster erkennen. Diese Zellkluster waren vorwiegend antero-superior und medial im Bereich des Kondylus vorzufinden. Die Verteilung der Chondrozyten war sehr diffus und ebenfalls deutlich nach anterior und medial verlagert. Die Chondrozyten zeigten sich in diesem Bereich ungewöhnlich hypertroph bei gleichzeitiger Hypozellularität, wohingegen sie im posterioren Bereich relativ gleichmäßig in Form und Anzahl waren. 


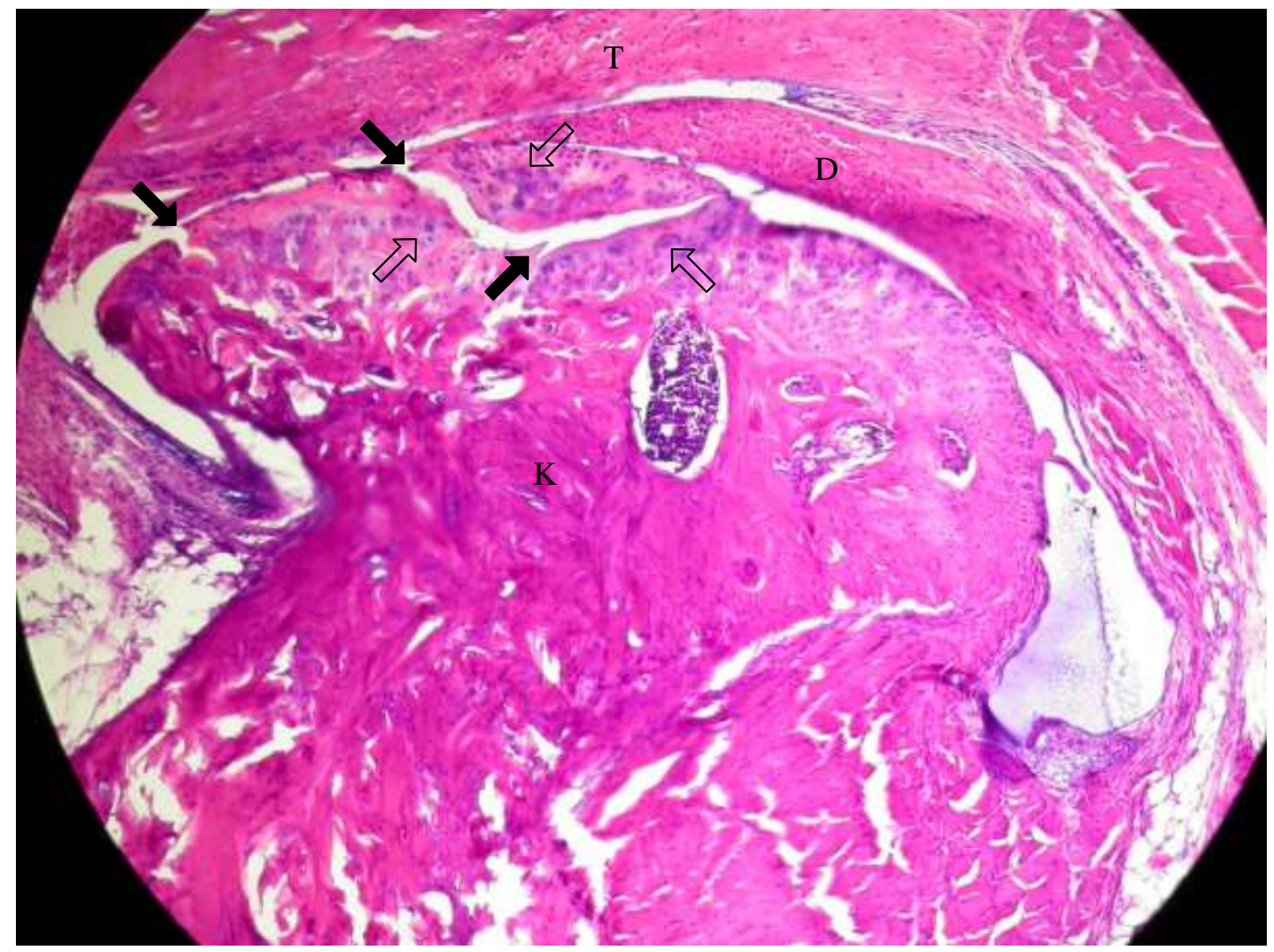

Bild 3: HE gefärbtes Kiefergelenk der C57BL/6NCrl-Maus (x 4)

$\mathrm{T}=$ Temporaler Gelenkanteil; $\mathrm{D}=$ Discus articularis; $\mathrm{K}=$ Kondylus

Schwarzer Pfeil = OA; Transparenter Pfeil $=$ hypertrophe Chondrozyten-Zellkluster 


\section{III.2.2 TB-Färbung}

Die TB-Färbung zeigte unmittelbar an der Oberfläche des antero-superioren Kondylusanteils keine Anfärbbarkeit für Proteoglykane. Im Gegensatz dazu wurden die Chondrozytenkluster der tieferen Schichten besonders stark durch die intensive Blau-Färbung dargestellt. Die Größen und die Farbintensität der Zellkluster weisen auf eine hohe Proteoglykansynthese hin. Die Form der Kluster ist sehr irregulär, die Verteilung und Größe ausgesprochen inhomogen. Eine geordnete säulenartige Anordnung der Chondrozyten konnte nicht nachgewiesen werden. Stattdessen konnte eine komplette Desorganisation der Chondrozyten erwiesen werden. An der Knorpeloberfläche der C57BL/6NCrl-Mäuse lassen sich besonders anterosuperior Chondrozyten freie Bereiche durch die TB-Färbung nachweisen. Durch die OASchädigung ist die Knorpeldicke reduziert, da der Abstand von der Knorpeloberfläche bis zum subchondralen Knochen verringert ist. Des weiteren sind in der Faserknorpelschicht vereinzelt zystenartige Freiräume sichtbar, die nur von wenigen Chondrozyten umgeben sind. 


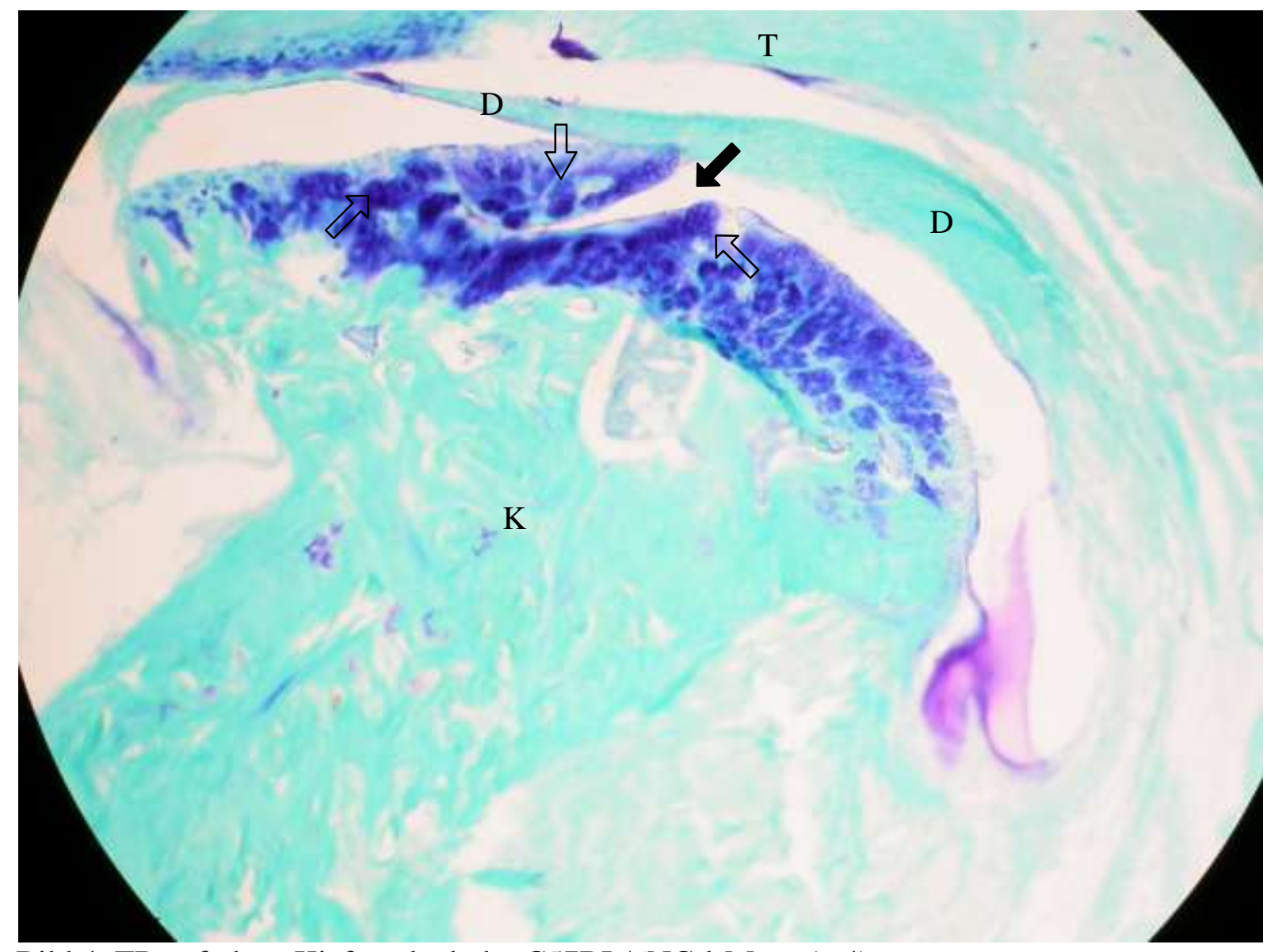

Bild 4: TB gefärbtes Kiefergelenk der C57BL/6NCrl-Maus (x 4)

$\mathrm{T}=$ Temporaler Gelenkanteil; $\mathrm{D}=$ Discus articularis; $\mathrm{K}=$ Kondylus

Schwarzer Pfeil = OA; Transparenter Pfeil $=$ hypertrophe Chondrozyten-Zellkluster 


\section{III.3 NMRI-Mäuse}

\section{III.3.1 HE-Färbung}

An den Kiefergelenken der NMRI-Mäuse konnten keine OA-Veränderungen nachgewiesen werden. Die Knorpeloberfläche des Kondylus stellte sich als regelmäßige und intakte Gelenkstruktur dar. Oberflächlich konnte sogar ein schmaler Saum der fibrösen Bindegewebszone mit fibroblasten-ähnlichen Zellen, die superfiziell von anterior nach posterior verlaufen dargestellt werden. Die Zone des Faserknorpels war geordnet und die Zellverteilung der Chondrozyten regelmäßig. Auch die Zellgröße war der jeweiligen Zone entsprechend.

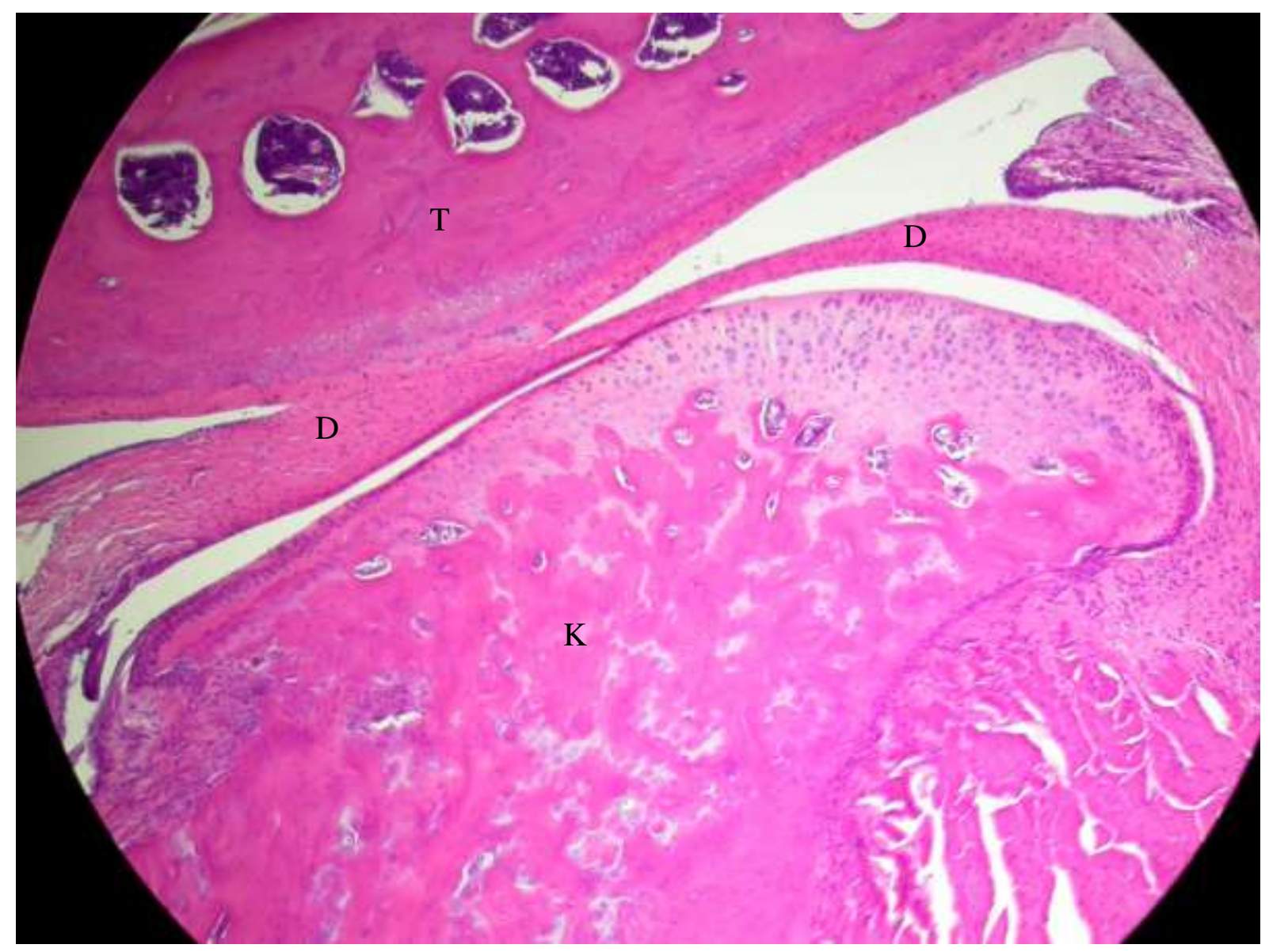

Bild 5: HE gefärbtes Kiefergelenk der NMRI-Maus (x 4)

$\mathrm{T}=$ Temporaler Gelenkanteil $; \mathrm{D}=$ Discus articularis; $\mathrm{K}=$ Kondylus; 


\section{III.3.2 TB-Färbung}

Durch die TB-Färbung konnte ebenfalls keine OA in den Kiefergelenken der NMRI-Mäuse bewiesen werden. Die metachromatische Eigenschaft der Färbung zeigt deutlich, dass die Proteoglykane regelmäßig perizellulär der Chondrozyten vorhanden sind. Die superfizielle Zone konnte nicht angefärbt werden, wohin gegen sich die tieferen Zonen deutlich durch eine regelmäßige Blau-Färbung darstellen ließ. Die Chondrozyten liegen organisiert vor und weisen eine klar erkenntliche säulenartige Anordnung auf.

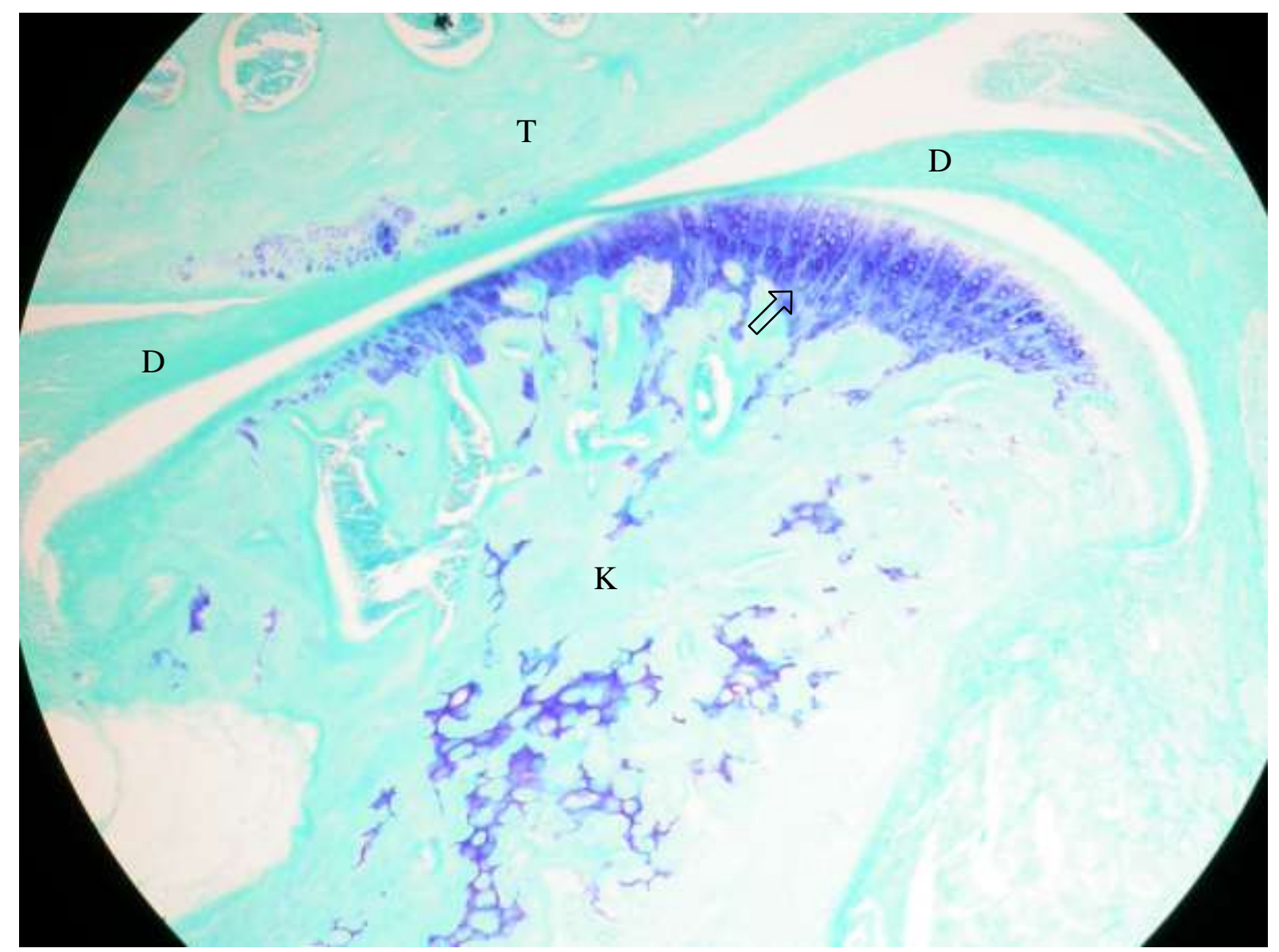

Bild 6: TB gefärbtes Kiefergelenk der NMRI-Maus (x 4)

$\mathrm{T}=$ Temporaler Gelenkanteil; $\mathrm{D}=$ Discus articularis; $\mathrm{K}=$ Kondylus

Transparenter Pfeil = säulenartige Zellorganisation 


\section{III.4 Perlecan-Knockout-Mäuse}

\section{III.4.1 HE-Färbung}

Bei den Perlecan-KO-Mäusen konnten mehrere OA-Veränderungen nachgewiesen werden. Durch die HE-Färbung stellte sich der Kondylus sowohl in Form, als auch in Struktur der Knorpeloberfläche unregelmäßig dar. Bei kleinster Vergrößerung konnte eine irreguläre Form des Kondylus nachgewiesen werden. Der Kondylus wies keine gelenktypische halbrunde oder ovale Oberflächenform auf, sondern eine unregelmäßige gewellte Form. Am medialsuperioren und am postero-superioren Pol des Kondylus konnten hügelartige exophytische Auswüchse dargestellt werden, die $\mathrm{zu}$ den wesentlichen Formveränderungen der Gelenkkopfoberfläche beitragen. Ebenfalls konnten an der Oberfläche des Kondylus feine Risse sichtbar gemacht werden. Die Risse traten generalisiert am antero-superioren Anteil des Kondylus auf. Allerdings waren die Risse nur in den oberflächlichen Knorpelschichten nachweisbar und besaßen nur eine geringe Tiefe. Durch diese multiplen Mikrorisse wirkt die Gelenkoberfläche ausgefranst. Im Bereich der Mikrorisse konnte festgestellt werden, dass sich hauptsächlich hypertrophe Chondrozyten in den Knorpelzonen befanden. Auch inmitten der postero-superioren Auswüchse stellte sich eine erhöhte Chondrozytendichte als auffällig heraus. Allerdings konnte keine auffällige Chondrozytenkonzentration am medial-superioren Auswuchs erkannt werden. Eine säulenartige Ordnung der Chondrozyten war andeutungsweise $\mathrm{zu}$ sehen. Klusterbildungen von Chondrozyten hingegen wurden mittels der HEFärbung nicht gefunden. 


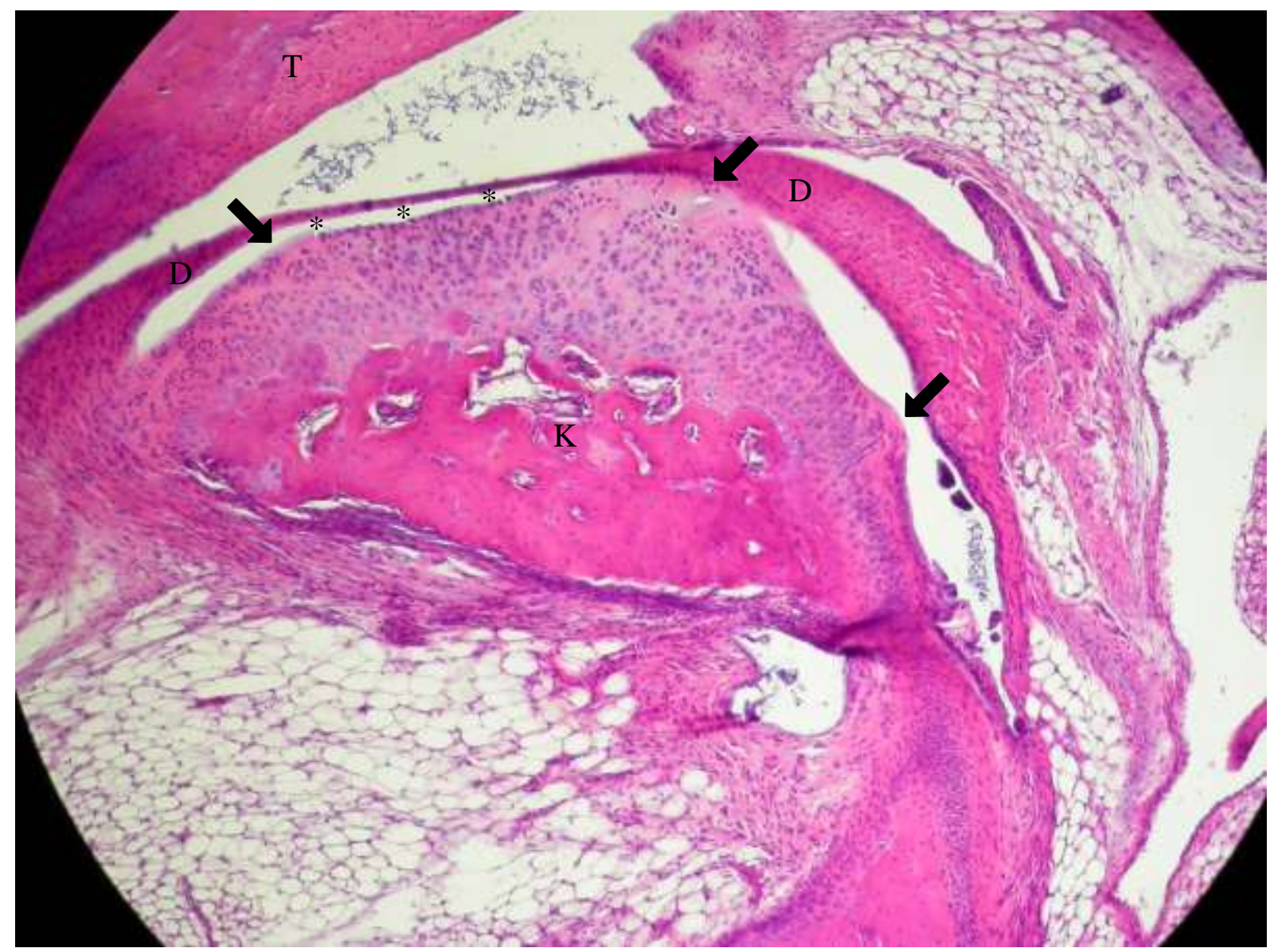

Bild 7: HE gefärbtes Kiefergelenk der Perlecan-KO-Maus (x 4)

$\mathrm{T}=$ Temporaler Gelenkanteil $; \mathrm{D}=$ Discus articularis; $\mathrm{K}=$ Kondylus;

Schwarzer Pfeil = hügelartige exophytische Auswüchse;

* = ausgefranste Oberfläche 


\section{III.4.2 TB-Färbung}

In der Spezialfärbung konnte eine metachromatische Zunahme der Anfärbbarkeit für Proteoglykane in Abhängigkeit der Schichttiefe dargestellt werden. Der geringere Proteoglykangehalt an der Oberfläche stellte sich blass blau dar, während sich der deutlich höhere Gehalt an PG in den tieferen Knorpelschichten in einer intensiven Blau-Färbung hinterlegen ließ. Bei den Perlecan-KO-Mäusen konnte durch die TB-Färbung eine vergleichsweise dicke Knorpelschicht dargestellt werden. Chondrozytenkluster konnten nur vereinzelt und auch nur in der tiefer gelegenen Faserknorpelschicht nachgewiesen werden.

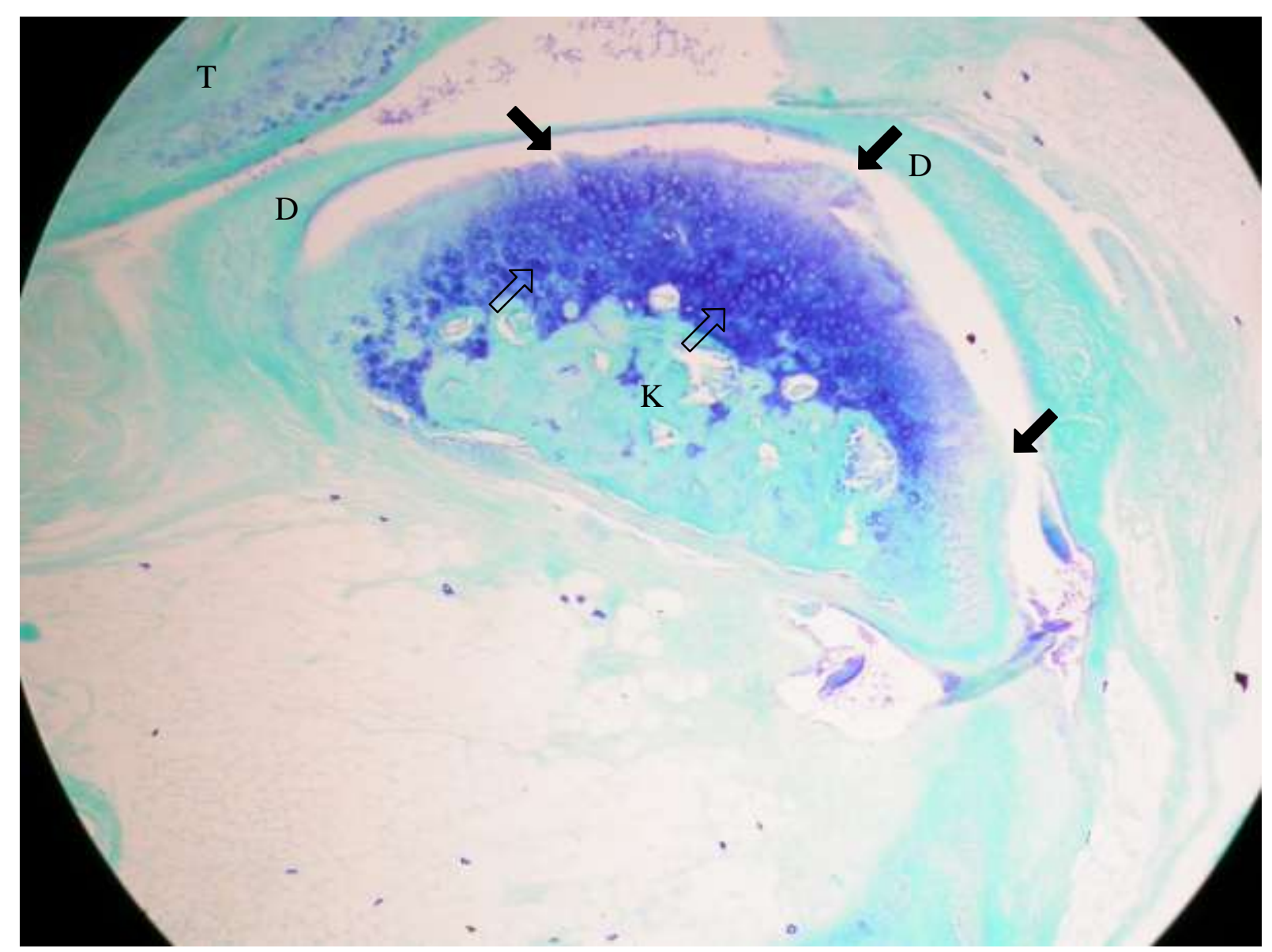

Bild 8: TB gefärbtes Kiefergelenk der Perlecan-KO-Maus (x 4)

$\mathrm{T}=$ Temporaler Gelenkanteil; $\mathrm{D}=$ Discus articularis; $\mathrm{K}=$ Kondylus;

Schwarzer Pfeil = hügelartige exophytische Auswüchse;

Transparenter Pfeil = hypertrophe Chondrozyten-Zellkluster 


\section{III.5 Nidogen-2-Knockout-Mäuse}

\section{III.5.1 HE-Färbung}

Die Nidogen-2-KO-Mäuse lieferten keinen Hinweis für anfängliche oder fortgeschrittene Prozesse der OA am Kiefergelenk. Die Gelenkoberflächen und die Knorpelstrukturen zeigten in der HE-Färbung einen regelmäßigen und harmonischen Verlauf. Es konnte eine größtenteils intakte oberflächliche fibröse Bindegewebszone mit fibroblastenähnlichen Zellen gefunden werden. Des Weiteren zeigte sich die darauffolgende Übergangszone mit relativ gleichmäßig verteilten Chondrozyten, und nahmen mit zunehmender Tiefe an Größe zu. Auffällig war allerdings eine größere Anzahl an großblasigen hypertrophen Chondrozyten, die sich besonders gut in der Zone des Faserknorpels nachweisen ließen. Eine herdartige Ansammlung von Chondrozyten oder Zellklustern waren nicht nachweislich. 


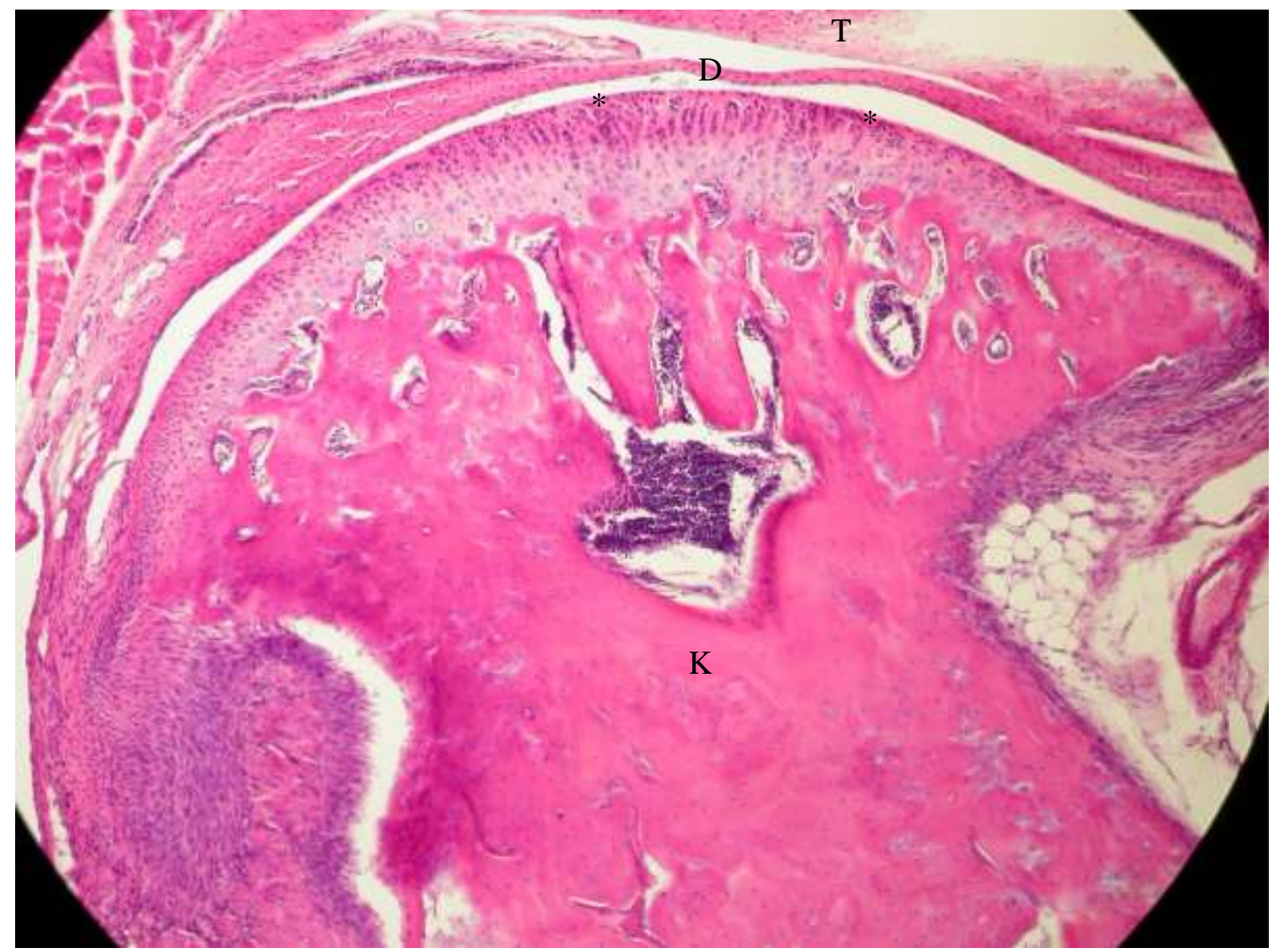

Bild 9: HE gefärbtes Kiefergelenk der Nidogen-2-KO-Maus (x 4)

$\mathrm{T}=$ Temporaler Gelenkanteil; $\mathrm{D}=$ Discus articularis; $\mathrm{K}=$ Kondylus

* = oberflächliche fibröse Bindegewebszone 


\section{III.5.2 TB-Färbung}

Auch die TB-Färbung erbrachte keinen Nachweis einer OA-Schädigung der Kiefergelenkstrukturen. Die Proteoglykane konnten superfiziell kaum angefärbt werden, steigerten jedoch mit zunehmender Tiefe ihre Anfärbbarkeit und Intensität der Blau-Bärbung. Zellkluster konnten auch mithilfe der TB-Färbung nicht nachgewiesen werden. Bei allen Nidogen-2-KOMäusen konnte jedoch eine deutliche antero-superiore Proteoglykanverteilung nachgewiesen werden. Es konnte ebenfalls gezeigt werden, dass sich in der antero-superioren Kondylushälfte ausschließlich relativ kleine, proteoglykanreiche Chondrozyten verteilten, wohingegen in der antero-posterioren Kondylushälfte vorwiegend großblasige, proteoglykanarme Chondrozyten vorkamen. Die großblasigen hypertrophen Chondrozyten der Faserknorpelzone wiesen durch ihre blassblaue Färbung auf einen geringen Proteoglykangehalt hin. Eine leichte, säulenartig Ordnung der Chondrozyten konnte erkannt werden. 


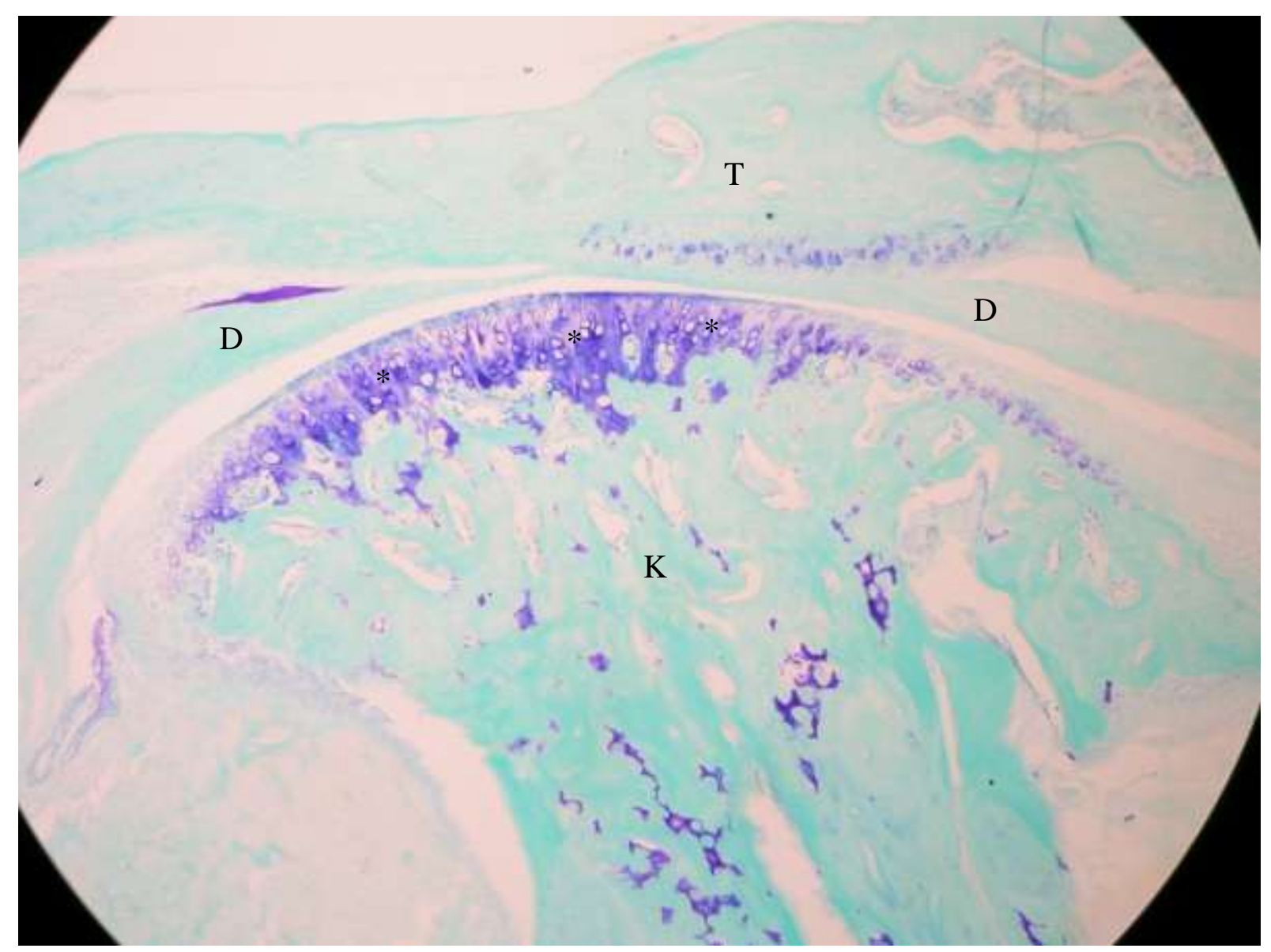

Bild 10: TB gefärbtes Kiefergelenk der Nidogen-2-KO-Maus (x 4)

$\mathrm{T}=$ Temporaler Gelenkanteil $; \mathrm{D}=$ Discus articularis; $\mathrm{K}=$ Kondylus

* = Faserknorpelzone mit großblasigen hypertrophen Chondrozyten 


\section{Diskussion}

\section{IV.1 Diskussion des Tiermodells}

Die Faktoren und Mechanismen, die zu einer OA führen, sind nicht vollends geklärt. Zeitlich gesehen bedarf es einiger Jahre, bis sich die TMJ-OA bei Menschen entwickeln kann. Deswegen sind geeignete Tiermodelle notwendig, die schneller möglichst ähnliche pathologische Veränderungen entwickeln, wie sie auch beim Menschen vorkommen. Grundsätzlich gilt es zu unterscheiden, an welcher Tierart die OA untersucht wurde und wie in diesen Tieren die OA entstanden ist. Bezüglich der Arten wurden von verschiedenen Autoren Kaninchen, Schweine, Ratten, Schafe, Affen und Mäuse untersucht. Für diese Forschungsarbeit erfüllten Mäuse viele der Anforderungen eines idealen Modells zur Untersuchung der OA, die von Little und Smith verfasst wurden (Little und Smith 2008). Auch Livne et al. erkannten die Maus als geeignetes Modell an, da sie besonders in frühen Lebensabschnitten zu OA-Läsionen im Kiefergelenk neigt (Livne et al. 1989). Leider existieren derzeit nur wenige Maus-Modelle, die histologisch auf Anzeichen der TMJ-OA untersucht worden sind. Generell unterscheidet man die induzierte von der nicht-induzierten, natürlich auftretenden OA (Wadhwa et al. 2005). Die induzierte OA im Kiefergelenk kann durch chirurgische Manipulation hervorgerufen werden (Tominaga et al. 2002). Als weitere Möglichkeiten stehen forcierte Mundöffnung (Fujisawa et al. 2003) und die intraartikuläre Injektion von Entzündungsmediatoren zur Verfügung (Harper et al. 2001; Tominaga et al. 2002). Im Gegensatz zu den induzierten Modellen der TMJ-OA bieten die nicht-induzierten, natürlich auftretenden OA-Modelle bedeutende Vorteile. Sie durchlaufen den gesamten Krankheitsprozess und ermöglichen, besonders die anfänglichen Stadien der OA beurteilen zu können. Dadurch, dass sowohl die genetischen als auch die umweltbedingten Faktoren genauer bestimmt und überwacht werden können, behaupten sich die nicht-induzierten Modelle gegenüber den induzierten Modellen. Diese Modelle sind potenziell in der Lage, Erkenntnisse über die molekularen Stoffwechselwege, welche die Degeneration des Kiefergelenks beeinflussen, aufzudecken (Wadhwa et al. 2005). 


\section{IV.2 Diskussion der verschiedenen Maus-Modelle zur Kiefergelenksosteoarthrose}

Obwohl es für OA über 40 verschiedene Maus-Modelle gibt, sind jedoch Modelle für die TMJ-OA sehr rar. In der aktuellen Literatur waren derzeit sechs Maus-Modelle zu entnehmen, an denen eine natürliche, nicht induzierte TMJ-OA beschrieben wurde. Silbermann und Livne entdeckten erstmalig nicht-induzierte, degenerative Veränderungen an Kiefergelenken von ICR-Mäusen (Silbermann und Livne 1979). Dabei wurden männliche ICR-Mäuse unterschiedlichen Alters verwendet und ebenfalls anhand der HE- und Toluidinfärbung histologisch untersucht. Die Ergebnisse deuteten darauf hin, dass die Kiefergelenke der ICRMaus mit zunehmendem Alter Zeichen einer OA entwickeln. Die Knorpeldicke nahm an der Oberfläche ab und schwand zunehmend zu einem halbmondförmigen Band. Oberflächlich angrenzende Chondrozyten nahmen an Zellzahl ab und verteilten sich unregelmäßiger. Die in den tieferen Schichten liegenden hypertrophen Chondrozyten waren von außergewöhnlich viel Matrix umgeben. Der Abstand zwischen der artikulierenden Oberfläche und dem Knochenmarksraum war vermindert. Die meisten Mäuse dieser Studie entwickelten ab einem Alter von sieben Monaten OA Veränderungen im Kiefergelenk. Silbermann und Livne beschrieben in ihrer Studie auch die Anzeichen der beginnenden TMJ-OA. Diese waren dadurch gekennzeichnet, dass sich der Knorpel oberflächlich nicht anfärben ließ. Weiterhin waren Zellanhäufungen von Chondrozyten, die man Kluster nennt, sichtbar. Die Oberflächen erschienen unregelmäßig und zeigten Rissbildungen. In späteren Stadien drangen die Risse bis in tiefere Zonen ein und führten dazu, dass die Gelenkfläche denudiert wurde. Die Studie belegte ebenfalls, dass das Kiefergelenk 12 Monate alter ICR-Mäuse ankylosieren kann (Silbermann und Livne 1979). Auch Moskowitz et al. waren nach Untersuchungen an einigen Maus-Modellen der Auffassung, dass neben Osteophytenbildung und Knorpelschäden die Abnahme der Proteoglykan-Anfärbbarkeit zu den charakteristischen Merkmalen einer fortschreitenden OA zählen (Moskowitz et al. 2007). Diese Erkenntnisse waren Ausgangspunkt für alle weiteren Modelle zur TMJ-OA.

Chen et al. analysierten die Kiefergelenke von zwei verschiedenen Gruppen von Senescence Accelerated Mäusen (SAM), den SAM-P und SAM-R Mäusen. Die Untersuchung erfolgte unter anderem mithilfe der HE- und TB-Färbung. Die OA wurde anhand eines Gradierungsschemas klassifiziert. Die Ergebnisse zeigten bereits nach drei Monaten erste Anzeichen der OA an den SAM-P/3-Mäusen, wobei nach acht Monaten an $50 \%$ und nach 12 
Monaten an $100 \%$ der Mäuse Anzeichen der OA erkennbar waren. Diese SAM-P/3 zählen nach Chen zur Gruppe mit hoher OA-Inzidenz. Die SAM-P/1 und SAM-P/2 zählen zur Gruppe mit mittlerer OA-Inzidenz, wonach die SAM-R/1, SAM-R/2 und SAM-P/6 in der Gruppe der geringen OA-Inzidenz folgen (Chen et al. 1989).

Rintala et al. lieferten 1997 ein weiteres Modell der natürlich auftretenden TMJ-OA. In der Studie wurden heterozygote Mäuse mit Mutationen auf dem Kollagen II a1 Gen (Del1) analysiert. Auf den Menschen übertragen sind verschiedene Mutationen auf dem Kollagen II Gen (COL2A1) bekannt. Der Phänotyp dieser Mutation entwickelt ein weites Spektrum an klinischen Krankheitsbildern, die von OA bis hin $\mathrm{zu}$ perinatal letalen Formen der Achondrogenesis führen (Vikkula et al. 1994). Mutationen auf dem Kollagen II Gen können auch zum Stickler-Syndrom führen, welches Knorpelgewebe schwächt und zur Gruppe der OA zählt (Francomano et al. 1987; Palotie et al. 1989; Ala-Kokko et al. 1990). Mäuse mit dem Kollagen II Gen Defekt entwickelten ebenfalls bereits nach drei Monaten ChondrozytenKluster. Des weiteren wiesen die Kondylen subchondrale Knochenzysten und Risse an den Oberflächen auf. Die Proteoglykane ließen sich besonders perizellulär anfärben. In sechs Monaten alten Del1-Mäusen war die Proteoglykan Anfärbung stark vermindert und kleine Chondrozyten-freie Bereiche wurden beschrieben. An den Kiefergelenken von 15 Monate alten Del1-Mäusen wurden größere Risse, Resorptionen und starke perizelluläre Proteoglykan Anfärbungen der Chondrozyten-Kluster beschrieben (Rintala et al. 1997).

$\mathrm{Xu}$ et al. (2003) erforschten in ihrer Studie ebenfalls Kiefergelenke und Knie genetisch veränderter Mäuse. Diese Mäuse trugen eine Mutation auf dem Gen, welches Informationen für die Alpha-Kette des Kollagen Typ XI (ColXIa1) kodiert. Genetische Mutationen von ColXIa1 führten in Mäusen zu Fehlbildungen des Skelettsystems (Chondrodysplasie, CHO) (Li et al. 1995). Die Ergebnisse zeigten, dass bereits bei drei Monaten alten Mäusen Chondrozyten-Kluster nachweisbar waren. Dies spricht für eine gesteigerte Proliferation der Chondrozyten im frühen Stadium der OA (Mankin und Brandt 1992). Mit sechs Monaten schwand die Anfärbbarkeit für Proteoglykane, wohingegen neun Monate alte Tiere Fibrillationen entlang der Gelenkoberfläche zeigten. Fortgeschrittene Stadien der OA etablierten sich bei diesen Mäusen nicht vor dem neunten Lebensmonat. Dies könnte darauf hinweisen, dass es sich um eine altersbedingte Entwicklung der TMJ-OA handelt (Xu et al. 2003). 
Mateescu et al. stellten fest, dass die Bildung von Mitogen-induzierendem Gen 6 (Mig-6) als Antwort auf mechanische Beanspruchung in OA-Gelenken ansteigt (Mateescu et al. 2005). Zhang et al. ergründeten daraufhin, dass homozygote Mäuse mit Störung des Mig-6 Gens eine OA im Kiefergelenk wie auch in anderen Gelenken entwickelten (Zhang et al. 2005). In dieser Studie wurden sowohl homozygote, als auch heterozygote Mig-6-Mäuse mit gesunden Wildtyp-Mäusen verglichen. Das Resultat zeigte, dass bereits $50 \%$ der Mig-6-Mäuse im embryonalen Stadium verstarben. Die übrigen überlebenden $50 \%$ der homozygote Mig-6Mäuse waren lediglich für sechs Monate überlebensfähig. In diesen sechs Monaten entwickelten nur die homozygoten Mig-6-Mäuse abnormale knöcherne Auswüchse sowohl im Kiefergelenk, als auch in Knie und Extremitäten. Die knöchernen Auswüchse ragten deutlich in den freien Gelenkspalt. Diese sogenannten Osteophyten engten den Gelenkspalt zunehmend ein und führten zu einer Ankylose, woran die Mäuse aufgrund unmöglicher Nahrungsaufnahme letztendlich verstarben. Auch die typischen histologischen Veränderungen, wie erhöhte Proteoglykan-Färbung in den inneren Zonen den Knorpels, Oberflächenveränderung des Knorpels, subchondrale Zystenbildung, Zellhyperplasie und Missorganisation der Chondrozyten, wurden beschrieben. Heterozygote Mig-6-Mäuse und die gesunden Wildtyp-Mäuse zeigten hingegen keine pathologischen Veränderungen (Zhang et al. 2005).

Wadhwa et al. (2005) untersuchten ein weiteres Maus-Modell, das durch einen genetischen Doppelknockout OA im Kiefergelenk entwickelte. Dabei wurden heterozygote Mäuse generiert, welchen die zwei extrazelluläre Matrixbestandteile Biglykan (BGN) und Fibromodulin (FMOD) fehlten. BGN und FMOD sind beides Proteoglykane und ubiquitäre Bestandteile in sowohl skelettalen Geweben als auch im Bindegewebe (Iozzo 1997; Hocking et al. 1998; Ameye und Young 2002; Wadhwa et al. 2004). Die BGN/FMODDoppelknockout-Mäuse wurden histologisch auf OA-Zeichen untersucht. Ferner untersuchten Wadhwa et al. den Apoptose-Grad und veränderte Kollagen II Synthese des Kondylusgewebes. Die BGN/FMOD-Doppelknockout-Mäuse zeigten eine doppelt so hohe Apoptoserate von Knorpelzellen verglichen zu normalen Kontrollmäusen. Auch die Kollagen II Synthese der genetisch veränderten Mäuse verlagert sich zunehmend mit dem Alter von den tieferen Kondylusschichten an die Oberfläche. Erste mikroskopische Anzeichen der TMJ-OA, die mit der Bildung von Chondrozytenklustern einherging, ließen sich bei der BGN/FMODDoppelknockout-Maus nach sechs Monaten feststellen. Nach 18 Monaten war die Oberfläche 
des Kondylus zerklüftet und fast vollständig zerstört (Wadhwa et al. 2005).

$\mathrm{Hu}$ et al. deckten ein weiteres Maus-Modell auf, welche durch genetische Ausschaltung des Kollagen IX Gens (Col9a1) eine OA im Kiefergelenk und im Kniegelenk entwickelten. In den Kiefergelenken von drei Monate alten homozygoten Col9a1-KO-Mäusen deckte die Studie einen gesteigerten Proteoglykangehalt auf, der als lokaler Reparaturversuch interpretiert werden kann. Nach dem 6. Monat wurde allerdings über eine Abnahme der Anfärbbarkeit für Proteoglykane berichtet. Neun Monate alte Col9a1-KO-Mäuse wiesen zu dem geringeren Proteoglykangehalt zusätzlich Fibrillationen und hochgradige Zerstörungen an der Gelenkoberfläche des Kiefergelenks auf (Hu et al. 2006).

\section{IV.3 Diskussion der Ergebnisse}

\section{ICR-CD1-Mäuse}

In dieser Arbeit wurde nach neuen geeigneten Maus-Modellen gesucht, die bevorzugt eine TMJ-OA ausbilden. Dabei konnten meine Ergebnisse zu den ICR-CD1-Mäusen mit den bereits 1979 veröffentlichten Ergebnisse von Silbermann und Livne verglichen und teilweise bestätigt werden. Die Ergebnisse von Silbermann und Livne zeigten, dass es in den Kiefergelenken der ICR-CD1-Mäuse zu einer Reduktion der Oberflächenschicht und der Zellzahl kam (Silbermann und Livne 1979). Zusätzlich fanden sie auch weitere anfängliche Zeichen der OA, wie reduzierte Anfärbbarkeit, hypertrophe Chondrozyten und Klusterbildung. Als eindeutigstes Zeichen entdeckten Silbermann und Livne tiefe Rissbildungen im Faserknorpel des Kondylus (Silbermann und Livne 1979). Die Ergebnisse dieser Arbeit decken sich mit den von Silbermann und Livne veröffentlichten Ergebnissen insoweit, dass die oberflächliche fibröse Bindegewebszone reduziert war. Eine geringere Anzahl an Fibroblasten ähnlichen Zellen konnte ebenfalls bestätigt werden. Die reduzierte Anfärbbarkeit an der Oberfläche und die Tendenz zur Klusterbildung in tieferen Zonen lieferten mithilfe der TB-Färbung übereinstimmende Ergebnisse. Die Risse in der Oberfläche konnten ebenfalls nachgewiesen werden und decken sich somit mit den von Silbermann und Livne beschriebenen Anzeichen der OA im Kiefergelenk der ICR-CD1-Mäuse. Es konnten gemeinsame Ergebnisse der beiden Studien gefunden und somit als reproduzierbar gewertet werden. Ankylotische Gelenkflächen und Osteophytenbildungen, die in der Studie von 
Silbermann und Livne beschrieben wurden, konnten in dieser Studie nicht bestätigt werden. Als Grund wäre anzunehmen, dass der Pool an untersuchten ICR-CD1-Mäusen zu gering war, als dass eine Ankylose oder Osteophytenbildung zu erwarten wäre. Osteophyten sind Merkmale von besonders späten Stadien der OA (Gardner 1965).

Darüber hinaus wurden über diese Erscheinungsformen der OA nur sehr selten berichtet. Die Erkenntnisse über die degenerativen Veränderungen an den Kiefergelenken der ICR-CD1Mäuse verdeutlichen, dass TMJ-OA zwar anscheinend zufällig auftritt, dieser Maus-Typ jedoch ein geeignetes Modell zur Darstellung und Untersuchung der OA im Kiefergelenk ist.

\section{C57BL/6Crl-Mäuse}

In einer Reihe diverser Forschungsarbeiten wurden Kniegelenke und Fußgelenke der C57BLMäuse hinsichtlich einer OA untersucht. Mäuse der Gattung C57BL sind adäquate Tiermodelle zur Untersuchung der OA und damit wichtig für die humane OA-Forschung (Yamamoto et al. 2005). Bereits 1960 wurde die C57BL-Maus von Silberberg und Silberberg als Erstes beschrieben. Sie erkannten eine gewisse Inzidienz für OA-Defekte an den Kniegelenken der C57BL-Maus (Silberberg und Silberberg 1960). Eine genetische Mutation mit rezessivem Erbgang sorgt dafür, dass diese Gattung besonders anfällig für OA-Läsionen ist. Die OA entwickelt sich in diesen Mäusen spontan während der Vergreisung und nimmt fortschreitend mit dem Alter an pathomorphologischem Grad zu. Dabei entstehen zahlreiche Gemeinsamkeiten zwischen der humanen Pathogenese und der Pathogenese des Tiermodells (Yamamoto et al. 2005). Okabe konnte 1989 anhand lichtmikroskopischer Untersuchungen ebenfalls bestätigen, dass die C57BL-Maus ein geeignetes Modell der OA darstellt (Okabe 1989). Jedoch hat sich in vergangenen Studien ebenfalls gezeigt, dass OA-Veränderungen nicht zwangsläufig ausschließlich durch physiologisches Altern verursacht werden, sondern in Kombination mit anderen Faktoren vermutet werden muss (Yamamoto et al. 2005). Es ist ebenfalls bekannt, dass das Auftreten, das Fortschreiten und das jeweilige von der OA beeinflusste Gelenk der Maus mit den verschiedenen Gattungen variiert (Sokoloff und Habermann 1958; Sokoloff 1959; Sokoloff et al. 1962). So untersuchten Yamamoto et al. in ihrer Studie C57BL-Mäuse auf OA-Zeichen und verwendeten C57BL/6J-Mäuse als Kontrollmäuse (Yamamoto et al. 2005). Die hier untersuchten C57BL/6Crl-Mäuse wiesen eindeutige Zeichen der TMJ-OA auf. Strukturell konnten tiefere Rissbildungen und partielle Weichgewebsverluste in der Oberflächenschicht nachgewiesen werden. Superfizielle 
Ulzerationen und aus der Kontinuität des Kiefergelenks hervorstehende Gewebesporne bekräftigen die OA-Befunde. Dabei können diese über die Knorpeloberfläche herausstehenden Fasern kalzifizieren und zu Osteophyten werden (Gardner 1965). Auf zellulärer Ebene konnten ebenfalls belegende Erkenntnisse für eine OA festgestellt werden.

Hypozellularität und die mäßige Färbbarkeit der Oberfläche weisen auf eine gestörte Zellaktivität hin. Die deutliche Klusterbildung der Chondrozyten konnte besonders mittels der TB-Färbung dargestellt werden.

\section{Perlecan-KO-Mäuse}

Über die präzisen Mechanismen, die zur Ausbildung und zum Verlauf der OA führen können, herrschen weiterhin viele Unklarheiten. Jedoch häufen sich zunehmend wissenschaftliche Nachweise, die darauf hindeuten, dass in manchen Fällen bereits eine einzelne Genmutation der prädisponierende Faktor für die Entstehung der OA sein kann (Xu et al. 2003). Es ist bekannt, dass viele verschiedene Gene für die Knorpelentwicklung und -degeneration entscheidend sind. Es wird angenommen, dass mechanische Beanspruchung zu einem gesteigerten Expressionsmuster bestimmter Gene führt. Diese Gene scheinen ausschlaggebend für Zellwachstum, Durchblutung und Ossifikation zu sein (Carter et al. 2004). Das Perlecan-Gen der Maus und das humane Perlecan-Gen (HSPG2-Gen) kodieren die Informationen für das Perlecan-Protein. Perlecan wurde als gut untersuchter Hauptbestandteil des Knorpels (French et al. 1999) zusammen mit Nidogen-2 (Salmivirta et al. 2002) in sich entwickelndem Knorpel nachgewiesen. Die Studie von Kvist et al. bestätigte anhand immunhistochemischer Nachweismethoden, dass Perlecan und Nidogen-2 perizellulär im Knorpelgewebe vorkommen und basalmembranartig die Chondrozyten flächenhaft umgeben (Kvist et al. 2008). Perlecan nimmt zudem eine Schlüsselrolle in der Chondrogenese ein (Gomes RR et al. 2004; Yang et al. 2006). In Studien von Tesche und Miosge wurde die Expression von Perlecan im Spätstadium der OA in humanem Knorpel untersucht. Dabei wurde mithilfe der quantitativen Immunogold-Methode und der ,in-situ-Hybridisierung“ der Gehalt an Perlecan mRNA in vivo bestimmt (Tesche und Miosge 2004; Tesche und Miosge 2005). Eine „real-time polymerase chain reaction“ (RT-PCR) wurde durchgeführt, um die Perlecan Expression in nativem Knorpel mit der von isolierten und kultivierten Chondrozyten zu untersuchen. Die Ergebnisse der Studien zeigten, dass es zu einem Anstieg um $45 \%$ an Perlecan mRNA in OA-Knorpel kam. Der höchste Gehalt an Perlecan konnte in der 
perizellulären und interterritorialen Matrix im Spätstadium der OA histologisch nachgewiesen werden. Dadurch kann die Rolle von Perlecan in Verbindung mit der Pathogenese der OA im Spätstadium gebracht werden. Folglich kann der erhöhte Gehalt an Perlecan und Perlecan mRNA im OA-Gewebe auch als ein Reparaturversuch der an den osteoarthrotischen Knorpeldefekt angrenzenden Chondrozyten gewertet werden (Tesche und Miosge 2004; Tesche und Miosge 2005). Dass Perlecan für die Skelettentwicklung und Gefäßentwicklung eine wichtige Rolle einnimmt, wurde anhand von Perlecan-KO-Mausmodellen beispielhaft erläutert. Studien zeigten, dass das Fehlen von Perlecan generalisierte vaskuläre und muskuloskelettale Veränderungen und verkürzte Wachstumsfugen der langen Röhrenknochen entfaltet. Der gestörte Prozess der enchondralen Ossifikation führt $\mathrm{zu}$ Kleinwuchs und schwerwiegenden Chondrodysplasien (Arikawa-Hirasawa et al. 1999; Arikawa-Hirasawa et al. 2001). Mutationen des humanen Perlecan-Gens konnten sowohl in der Dyssegmentalen Dysplasie vom Silvermann-Handmaker Typ (Arikawa-Hirasawa et al. 1999; ArikawaHirasawa et al. 2001), als auch im Schwartz-Jampel-Syndrom (SJS) nachgewiesen werden (Nicole et al. 2000). Das SJS ist eine nicht-letale, autosomal-rezessiv vererbte Erkrankung, die einen progressiven Krankheitsverlauf hat. Außerdem verursacht das SJS unter anderem erkennbare Besonderheiten in den Gesichtszügen, verminderten Wachstum, verkürzte Röhrenknochen, verformte Hüftstrukturen, Hühnerbrust und andere skelettalen Defekte (Aberfeld et al. 1965; Giedion et al. 1997; Spranger et al. 2000). Die phänotypischen Auswirkungen des SJS sind das Ergebnis von reduziertem Perlecan (Arikawa-Hirasawa et al. 2002). Bezüglich der TMJ-OA bei Perlecan-KO-Mäusen finden sich in meiner Studie interessante Ergebnisse. Der Kondylus der Perlecan-KO-Mäuse zeigte eine beulenartige, irreguläre Form auf und multiple Rissbildungen auf der Oberflächenschicht waren auffindbar. In der Nachweisfärbung für Proteoglykane gab die besonders deutliche Abnahme der Metachromasie Auskunft über eine reduzierte Stoffwechselaktivität an der Oberfläche des Kiefergelenks. Mit zunehmender Tiefe des Kondylusknorpels konnte hingegen eine deutliche Intensität der Toluidinblau-Färbung illustriert werden, was wiederum eine höhere Stoffwechselaktivität und einen größeren Protoglykangehalt in diesen Zellschichten widerspiegelt. Wenige, jedoch ebenfalls für gestörte Zellaktivitäten sprechende Chondrozytenkluster konnten besonders in tieferen Schichten des Knorpels dargestellt werden. 


\section{Nidogen-2-KO-Mäuse}

Hier erwiesen sich die Nidogen-2-KO-Mäuse nicht als geeignetes Modell zur Untersuchung einer TMJ-OA. Kvist et al. konnten Nidogene im Gelenkknorpel der Maus nachweisen (Kvist et al. 2008). In jüngsten Untersuchungen unserer Forschungsabteilung konnte erstmals nachgewiesen werden, dass Nidogen-2 nur schwach perizellulär in gesundem humanem Knorpelgewebe von Knien vertreten ist, jedoch erhöht in OA-geschädigtem Knorpel im Bereich der Chrondrozytenkluster lokalisierbar ist (Kruegel et al. 2008). Dem OAgeschädigten Knorpel wurde von verschiedenen Autoren ein Regenerationspotential nachgewiesen, das durch erhöhte Expression verschiedener extrazellulärer Matrixmoleküle begründbar ist (Aigner und McKenna 2002, Sandell und Aigner 2001, Tesche und Miosge 2005). Die besonders hohe Expression von Nidogen-2 in humanen OA-Defekten könnte als Regenerationsversuch angesehen werden. Daher lag in Hinblick auf die offensichtlich wichtige Rolle des Nidogen-2 im Prozess der OA ein Augenmerk auf den Ergebnissen der Kiefergelenkspräparate der Nidogen-2-KO-Mäuse. Obwohl Nidogen-2 eine besondere Rolle im Prozess der OA einzunehmen scheint, konnten jedoch zumindest an den Kiefergelenken der Nidogen-2-KO-Mäuse keine histologischen Zeichen der OA nachgewiesen werden. Grund hierfür könnte vielleicht eine kompensatorisch erhöhte Expression von Nidogen-1 sein. Vorangegangene Studien erlauben diese These, da es z. B. bei Nidogen-1-KO-Mäusen bewiesenermaßen $\mathrm{zu}$ einer kompensatorischen Hochregulation von Nidogen-2 kommt (Murshed et al. 2000; Miosge et al. 2002). Allerdings ist nicht vollständig auszuschließen, dass Nidogen-2-KO-Mäuse nicht eine OA in anderen Gelenken entwickeln können. 


\section{Zusammenfassung}

Die Osteoarthrose (OA) ist eine nichtentzündliche, degenerative Erkrankung artikulierender Gelenke und stellt die häufigste Erkrankung des meist frequentierten Gelenks des menschlichen Körpers, dem Kiefergelenk, dar. Trotz jahrelanger Forschungsarbeiten herrschen über den genaueren Prozess der OA, die von Schmerzen über Struktur- und Formveränderungen bis hin zur Bewegungseinschränkung führt, noch einige Unklarheiten. Um wichtige Erkenntnisse aufdecken zu können, die zum Verständnis der Pathogenese der OA beitragen könnten, wurden in dieser Arbeit geeignete Maus-Modelle auf histologischer Ebene auf das Auftreten von nicht-induzierter, natürlicher Kiefergelenks-OA (TMJ-OA) untersucht. Dabei wurden Serienschnitte von den Kiefergelenken von ICR-CD1-Mäusen, C57BL/6NCrl-Mäusen, NMRI-Mäusen, Perlecan-KO-Mäusen und Nidogen-2-KO-Mäusen angefertigt und anschließend auf mikroskopischer Ebene mithilfe der Hämatoxylin-EosinFärbung und der Toluidin-Färbemethodik untersucht. Um die Zeichen der TMJ-OA eindeutig einstufen zu können, wurde eine modifizierte Mankin-Klassifizierung und das Beurteilungsschema nach Collins und McElligott verwendet.

In den Forschungsergebnissen konnten bereits nachgewiesene Ergebnisse von Silbermann und Livne (1979) bestätigt werden, dass ICR-CD1-Mäuse repräsentative Maus-Modelle zur Illustration und Erforschung der TMJ-OA sind. Die untersuchten Tiere der NMRI-Gattung und die Perlecan-KO-Mäuse zeigten keinerlei Anzeichen einer Kiefergelenks-OA. Allerdings konnten sowohl bei den C57BL/6NCrl-Mäusen als auch bei den Perlecan-KO-Mäusen eindeutige Zeichen der OA an den Kiefergelenken nachgewiesen werden.

Abschließend lässt sich festhalten, dass auch heute noch die Faktoren und Mechanismen, die zu einer OA führen, noch nicht vollständig geklärt sind. Allerdings haben die Ergebnisse dieser Arbeit gezeigt, dass die Wahrscheinlichkeit einer TMJ-OA bei einigen der untersuchten Maus-Stämme erhöht sind, jedoch kein Modell dabei war, bei dem immer eine OA auftritt. Es bedarf gegenwärtig über den Rahmen dieser Arbeit hinaus weiterer Forschung, um anknüpfende wichtige Erkenntnisse über die OA bei C57BL/6Crl-Mäusen und Perlecan-KOMäusen zu erfahren. 
In zukünftigen Forschungsarbeiten könnte der Zeitpunkt der frühesten mikroskopischen Anzeichen sowie Progredienz und Verlauf der TMJ-OA bei den C57BL/6Crl- und PerlecanKO-Mäusen untersucht und aufgedeckt werden. 


\title{
VI Literaturverzeichnis
}

\author{
Aberfeld DC, Hinterbuchner LP, Schneider M (1965): \\ Myotonia, dwarfism, diffuse bone disease and unusual ocular and facial abnormalities (a new \\ syndrome). \\ Brain $\underline{88}, 313-22$
}

Aigner T, McKenna L (2002):

Molecular pathology and pathobiology of osteoarthritic cartilage.

Cell Mol Life Sci $\underline{59}$, 5-18

\section{Ala-Kokko L, Baldwin CT, Moskowitz RW, Prockop DJ (1990):}

Single base mutation in the type II procollagen gene (COL2A1) as a cause of primary osteoarthritis associated with a mild chondrodysplasia.

Proc Natl Acad Sci U S A $\underline{87}, 6565-8$

Ali SY, Evans L (1973):

Enzymic degradation of cartilage in osteoarthritis.

Fed Proc 32, 1494-8

\section{Altman RD, Muniz OE, Pita JC, Howell DS (1973):}

Articular chondrocalcinosis. Microanalysis of pyrophosphate (PPi) in synovial fluid and plasma.

Arthritis Rheum $\underline{16}, 171-8$

\section{Ameye L, Young MF (2002):}

Mice deficient in small leucine-rich proteoglycans: novel in vivo models for osteoporosis, osteoarthritis, Ehlers-Danlos syndrome, muscular dystrophy, and corneal diseases.

Glycobiology $\underline{12}, 107-16$ 


\section{Arikawa-Hirasawa E, Watanabe H, Takami H, Hassell JR, Yamada Y (1999):}

Perlecan is essential for cartilage and cephalic development.

Nat Genet $\underline{23}, 354-8$

\section{Arikawa-Hirasawa E, Wilcox WR, Le AH, Silverman N, Govindraj P, Hassell JR,} Yamada Y (2001):

Dyssegmental dysplasia, Silverman-Handmaker type, is caused by functional null mutations of the perlecan gene.

Nat Genet 27, 431-4

\section{Arikawa-Hirasawa E, Le AH, Nishino I, Nonaka I, Ho NC, Francomano CA, Govindraj}

\section{P, Hassell JR, Devaney JM, Spranger J (2002):}

Structural and functional mutations of the perlecan gene cause Schwartz-Jampel syndrome, with myotonic myopathy and chondrodysplasia.

Am J Hum Genet 70, 1368-75

\section{Balazs EA (1968):}

Viscoelastic properties of hyaluronic acid and biological lubrication.

Univ Mich Med Cent J 1968, 255-9

\section{Balazs EA:}

The physical properties of snovial fluid and the special role of hyaluronic acid.

In: Helfet, A. (ed.) Disorders of the knee. J.B. Lippincott Co., Philadelphia 1974, 63-75

\section{Bean LR, Omnell KA, Öberg T (1977):}

Comparison between radiologic observations and macroscopic tissue changes in temporomandibular joints.

Dentomaxillofac Radiol $\underline{6}$, 90-106 


\section{Bendele AM, White SL, Hulman JF (1989):}

Osteoarthrosis in guinea pigs: histopathologic and scanning electron microscopic features.Lab Anim Sci 39, 115-21

\section{Benjamin M, Ralphs JR (2004):}

Biology of fibrocartilage cells.

Int Rev Cytol 233, 1-45

\section{Berg R, Diedrich P, Haunfelder D:}

Kieferorthopädie II, Praxis der Zahnheilkunde.

Bd. 11, Urban \& Fischer/Elsevier GmbH, München 2000, 50-51

\section{Blackwood HJJ (1963):}

Arthritis of the mandibular joint.

Br. Dent. J $\underline{115}, 317$

\section{Blackwood HJJ (1966):}

Adaptive changes in the mandibular joints with function.

Dent Clin North Am 1966, 559-66

\section{Blumenfeld I, Gaspar R, Laufer D, Livne E (2000):}

Enhancement of toluidine blue staining by transforming growth factor-beta, insulin-like growth factor and growth hormone in the temporomandibular joint of aged mice.

Cells Tissues Organs 167, 121-9

\section{Boering G (1979):}

Anatomical and physiological considerations regarding the temporomandibular joint.

Int Dent J 29, 245-51 


\section{Bollet AJ (1969):}

An essay on the biology of osteoarthritis.

Arthritis Rheum $\underline{12}, 152-63$

\section{Bora FW Jr, Miller G (1987):}

Joint physiology, cartilage metabolism, and the etiology of osteoarthritis.

Hand Clin $\underline{3}, 325-36$

\section{Byers PD, Contepomi CA, Farkas TA (1976):}

Post-mortem study of the hip joint. II. Histological basis for limited and progressive cartilage alterations.

Ann Rheum Dis $\underline{35}, 114-21$

\section{Carlsson GE, Ekberg T, Öberg T (1970):}

Intra-articular injection of drugs in patients with functional disorders of temporomandibular joint.

Arsb Goteb Tandlak Sallsk $\underline{1970}, 25-38$

\section{Carter DR, Beaupré GS, Wong M, Smith RL, Andriacchi TP, Schurman DJ (2004):}

The mechanobiology of articular cartilage development and degeneration.

Clin Orthop Relat Res $\underline{427}$, 69-77

\section{Chen WH, Hosokawa M, Tsuboyama T, Ono T, Iizuka T, Takeda T (1989):}

Age-related changes in the temporomandibular joint of the senescence accelerated mouse.

SAM-P/3 as a new murine model of degenerative joint disease.

Am J Pathol 135, 379-8

\section{Cohen AS, Brandt KD, Krey PR:}

Synovial fluid. In: Cohen AS (ed.) Laboratory diagnostic procedures in the rheumatic diseases. 2nd ed. Little, Brown \& Co., Boston 1975, 74-115, 221 


\section{Collins DH:}

The Pathology of articular and spinal disease.

Arnold, London 1949, 74-115

\section{Collins DH, McElligott TF (1960):}

Sulphate (35SO4) uptake by chondrocytes in relation to histological changes in osteoarthritic human articular cartilage.

Ann Rheum Dis $\underline{19}, 318-30$

\section{Cotta H (1973):}

Pathogenesis of gonarthrosis.

Z Orthop Ihre Grenzgeb 111, 490-4

\section{Delaire J, De Olivera Y (1979):}

Le procezus retroartikulare ou tuberkule retromandibulaire du squelette cranien chez I' homme.

Acta Anat 104, 211-219

\section{Du Brul EL:}

Evolution of the temporomandibular joint. In: The Temporomandibular Joint.

2nd ed. Ed. Sarnat, B. G. Charles C. Thomas, Springfield/IL 1964, 3-27

\section{Durkin JF, Heeley JD, Irving JT (1973):}

The cartilage of the mandibular condyle.

Oral Sci Rev 2, 29-99

\section{Dziadek M, Fujiwara S, Paulsson M, Timpl R (1985):}

Immunological characterization of basement membrane types of heparan sulfate proteoglycan.

EMBO J $\underline{4}, 905-12$ 


\section{Ehrlich MG, Armstrong AL, Treadwell BV, Mankin HJ (1986):}

Degradative enzyme systems in cartilage.

Clin Orthop Relat Res 213, 62-8

\section{Ericson S, Lundberg M (1967):}

Alterations in the temporomandibular joint at various stages of rheumatoid arthritis.

Acta Rheumatol Scand 13, 257-74

Farach-Carson MC, Carson DD (2007):

Perlecan--a multifunctional extracellular proteoglycan scaffold.

Glycobiology $\underline{17}, 897-905$

\section{Fischel EE:}

The erythrocyte sedimentation rate. In: Cohen, A. S. (ed.) Laboratory diagnostic procedures in the rheumatic diseases.

2nd ed. Little, Brown \& Co., Boston 1975, 65-81

Francomano CA, Liberfarb RM, Hirose T, Maumenee IH, Streeten EA, Meyers DA, Pyeritz RE (1987):

The Stickler syndrome: evidence for close linkage to the structural gene for type II collagen.

Genomics 1 , 293-6

\section{Freeman MAR:}

The pathogenesis of osteoarthritis: an hypothesis. In: Appley, A. G.(ed.) Modern trends in orthopaedics. Vol.6, Butterworths, London 1972, 40

\section{Freeman MAR, Kempson GE:}

Load carriage. In: Freemann,M.A.R. (ed.) Adult articular cartilage.

Pitman Medical, Alden Press, Oxford 1973, 228-246. 
French MM, Smith SE, Akanbi K, Sanford T, Hecht J, Farach-Carson MC, Carson DD (1999):

Expression of the heparan sulfate proteoglycan, perlecan, during mouse embryogenesis and perlecan chondrogenic activity in vitro.

J Cell Biol 145, 1103-15

Fujisawa T, Kuboki T, Kasai T, Sonoyama W, Kojima S, Uehara J, Komori C, Yatani H, Hattori T, Takigawa M (2003):

A repetitive, steady mouth opening induced an osteoarthritis-like lesion in the rabbit temporomandibular joint.

J Dent Res $\underline{82}, 731-5$

\section{Gardner DL:}

Pathology of the connective tissues diseases.

Edward Arnold, London 1965, 296

Gersdorff N, Müller M, Otto S, Poschadel R, Hübner S, Miosge N (2005):

Basement membrane composition in the early mouse embryo day 7.

Dev Dyn 233, 1140-8

Giedion A, Boltshauser E, Briner J, Eich G, Exner G, Fendel H, Kaufmann L,

Steinmann B, Spranger J, Superti-Furga A (1997):

Heterogeneity in Schwartz-Jampel chondrodystrophic myotonia.

Eur J Pediatr $\underline{156}, 214-23$

Gomes R, Kirn-Safran C, Farach-Carson MC, Carson DD (2002):

Perlecan: an important component of the cartilage pericellular matrix.

J Musculoskelet Neuronal Interact 2, 511-6 


\section{Gomes RR Jr, Farach-Carson MC, Carson DD (2004):}

Perlecan functions in chondrogenesis: insights from in vitro and in vivo models.

Cells Tissues Organs $\underline{176}, 79-86$

\section{Gühring W, Barth J:}

Anatomie: Spezielle Biologie des Kausystems.

Grundwissen für Zahntechniker. Band 3. Verlag Neuer Merkur GmbH, München 1992, 110

\section{Hansson T, Oberg T, Carlsson GE, Kopp S (1977):}

Thickness of the soft tissue layers and the articular disk in the temporomandibular joint. Acta Odontol Scand $\underline{35}, 77-83$

\section{Harper RP, Kerins CA, McIntosh JE, Spears R, Bellinger LL (2001):}

Modulation of the inflammatory response in the rat TMJ with increasing doses of complete Freund's adjuvant.

Osteoarthritis Cartilage $\underline{9}, 619-24$

\section{Hassell JR, Robey PG, Barrach HJ, Wilczek J, Rennard SI, Martin GR (1980):}

Isolation of a heparan sulfate-containing proteoglycan from basement membrane.

Proc Natl Acad Sci U S A $\underline{77}, 4494-8$

\section{Helfet A:}

Disorders of the knee.

J. B. Lippincott Co., Philadelphia 1974, 1-335

\section{Helkimo E, Carlsson GE, Carmeli Y (1975):}

Bite force in patients with functional disturbances of the masticatory system.

J Oral Rehabil 2, 397

\section{Hesse I, Mohr W, Hesse W (1990):}

Morphologic changes in the early stages of arthrosis.

Orthopade $\underline{19}, 16-27$ 


\section{Hocking AM, Shinomura T, McQuillan DJ (1998):}

Leucine-rich repeat glycoproteins of the extracellular matrix.

Matrix Biol 17, 1-19

\section{Hopf M, Göhring W, Ries A, Timpl R, Hohenester E (2001):}

Crystal structure and mutational analysis of a perlecan-binding fragment of nidogen-1.

Nat Struct Biol $\underline{8}, 634-40$

Hu K, Xu L, Cao L, Flahiff CM, Brussiau J, Ho K, Setton LA, Youn I, Guilak F, Olsen

BR (2006):

Pathogenesis of osteoarthritis-like changes in the joints of mice deficient in type IX collagen.

Arthritis Rheum 54, 2891-900

\section{Huth F, Bellmann LU (1976):}

The synovial membrane of the temporomandibular joint. Histological and morphometric studies on 106 temporomandibular joints.

Zahn Mund Kieferheilkd Zentralbl 64, 827-35

\section{Inerot S, Heinegård D, Audell L, Olsson SE (1978):}

Articular-cartilage proteoglycans in aging and osteoarthritis.

Biochem J 169, 143-56

\section{Iozzo RV (1997):}

The family of the small leucine-rich proteoglycans: key regulators of matrix assembly and cellular growth.

Crit Rev Biochem Mol Biol 32, 141-74

\section{Iozzo RV (1998):}

Matrix proteoglycans: from molecular design to cellular function.

Annu Rev Biochem 67, 609-52 


\section{Iozzo RV (2005):}

Basement membrane proteoglycans: from cellar to ceiling.

Nat Rev Mol Cell Biol $\underline{6}, 646-56$

\section{Iozzo RV, Cohen IR, Grässel S, Murdoch AD (1994):}

The biology of perlecan: the multifaceted heparan sulphate proteoglycan of basement membranesand pericellular matrices.

Biochem J $\underline{15}, 625-39$

\section{Ireland VE (1951):}

The problem of "the clicking jaw".

Proc R Soc Med 44, 363-74

\section{Jeffery AK (1973):}

Osteogenesis in the osteoarthritic femoral head. A study using radioactive $32 \mathrm{P}$ and tetracycline bone markers.

J Bone Joint Surg Br $\underline{55}, 262-72$

\section{Johansson AS, Isberg A (1991):}

The anterosuperior insertion of the temporomandibular joint capsule and condylar mobility in joints with and without internal derangement: a double-contrast arthrotomographic investigation.

J Oral Maxillofac Surg 49, 1142-8

\section{Kalluri R (2003):}

Basement membranes: structure, assembly and role in tumour angiogenesis.

Nat Rev Cancer $\underline{3}, 422-33$

\section{Karaharju-Suvanto T, Peltonen J, Laitinen O, Kahri A (1996):}

The effect of gradual distraction of the mandible on the sheep temporomandibular joint. Int J Oral Maxillofac Surg 25, 152-6 


\section{Kefalides NA, Alper R, Clark CC (1979):}

Biochemistry and metabolism of basement membranes.

Int Rev Cytol $\underline{61}, 167-228$

\section{Kellgren JH, Lawrence JS (1957):}

Radiological assessment of osteo-arthrosis.

Ann Rheum Dis $\underline{16}, 494-502$

\section{Kempson GE, Muir H, Swanson SA, Freeman MA (1970):}

Correlations between stiffness and the chemical constituents of cartilage on the human femoral head.

Biochim Biophys Acta 215, 70-7

\section{Knahr K, Pinggera O (2001):}

Gelenke: Konservative und operative Behandlungsmöglichkeiten.

J Mineralstoffwechsel $\underline{8}, 7-14$

\section{Kohfeldt E, Sasaki T, Göhring W, Timpl R (1998):}

Nidogen-2: a new basement membrane protein with diverse binding properties.

J Mol Biol 282, 99-109

\section{Kopp S (1978):}

Topographical distribution of sulfated glycosaminoglycans in the surface layers of the human temporomandibular joint. A histochemical study of an autopsy material.

J Oral Pathol ㄱ, 283-94

\section{Kopp S, Rockler B (1978):}

Variation in interpretation of radiographs of temporomandibular and hand joints.

Dentomaxillofac Radiol 7, 95-102 


\section{Koritzer RT, Schwartz AH, Harris RR, St Hoyme LE (1992):}

Previously undescribed disk-capsule innervation: some speculative thoughts for TMD clinicians.

Am J Orthod Dentofacial Orthop 102, 109-12

\section{Kouri JB, Jiménez SA, Quintero M, Chico A (1996):}

Ultrastructural study of chondrocytes from fibrillated and non-fibrillated human osteoarthritic cartilage.

Osteoarthritis Cartilage $\underline{4}, 111-25$

\section{Kruegel J, Sadowski B, Miosge N (2008):}

Nidogen-1 and nidogen-2 in healthy human cartilage and in late-stage osteoarthritis cartilage. Arthritis Rheum $\underline{58}, 1422-32$

\section{Kuettner KE (1992):}

Biochemistry of articular cartilage in health and disease.

Clin Biochem 25, 155-63

\section{Kvist AJ, Nyström A, Hultenby K, Sasaki T, Talts JF, Aspberg A (2008):}

The major basement membrane components localize to the chondrocyte pericellular matrix--a cartilage basement membrane equivalent?

Matrix Biol 27, 22-33

\section{Lamberty Y, Gower AJ (1992):}

Age-related changes in spontaneous behavior and learning in NMRI mice from middle to old age.

Physiol Behav $\underline{51}, 81-8$

\section{Lang P, Yoshioka H, Steines D, Nöbauer-Huhmann IM, Imhof H (2000):}

Magnetic resonance tomography (MRI) of joint cartilage. Current status of knowledge and new developments.

Radiologe $\underline{40}, 1141-8$ 


\section{Lereim P, Goldie I, Dahlberg E (1974):}

Hardness of the subchondral bone of the tibial condyles in the normal state and in osteoarthritis and rheumatoid arthritis.

Acta Orthop Scand $\underline{45}$, 614-27

\section{Li Y, Lacerda DA, Warman ML, Beier DR, Yoshioka H, Ninomiya Y, Oxford JT, Morris} NP, Andrikopoulos K, Ramirez F, et al (1995):

A fibrillar collagen gene, Col11a1, is essential for skeletal morphogenesis.

Cell $\underline{80}, 423-30$

\section{Limbdom G (1960):}

On the anatomy and funktion of the temporomandibular joint.

Acta Odontol Scand 17, 23-51

\section{Lindvall AM, Helkimo E, Hollender L, Carlsson GE (1976):}

Radiographic examination of the temporomandibular joint. A comparison between radiographic findings and gross and microscopic morphologic observations.

Dentomaxillofac Radiol $\underline{5}$, 24-32

\section{Little CB, Smith MM:}

Animal Models of Osteoarthritis. Current Rheumatology Reviews, Vol. 4, No. 3

Bentham Science Publishers Ltd., Sydney 2008, 1-8

\section{Livne E, Schmidt J, Closs EI, Silbermann M, Erfle V (1989):}

Effects of leukemogenic retroviruses on condylar cartilage in vitro: an ultrastructural study.

Calcif Tissue Int $\underline{44}, 25-35$

\section{Livne E, Weiss A, Silbermann M (1990):}

Changes in growth patterns in mouse condylar cartilage associated with skeletal maturation and senescence.

Growth Dev Aging 54, 183-93 


\section{Livne E, Laufer D, Blumenfeld I (1997):}

Osteoarthritis in the temporo-mandibular joint (TMJ) of aged mice and the in vitro effect of TGF-beta 1 on cell proliferation, matrix synthesis, and alkaline phosphatase activity.

Microsc Res Tech 37, 314-23

\section{Madsen B (1966):}

Normal variations in anatomy, condylar movements, and arthrosis frequency of the temporomandibular joints.

Acta Radiol Diagn (Stockh) 또 273-88

\section{Mahan PE:}

Normale und Anormale Funktion des Kiefergelenkes.

In: Solberg WK, Clark GT.: Das Kiefergelenk. Quintessenz, Berlin 1983, 33-43

\section{Mankin HJ (1982):}

Current concepts review: The response of articular cartilage to injury.

J Bone Joint Surg $\underline{62}, 460-466$

\section{Mankin HJ, Brandt K:}

Biochemistry and metabolism of articular cartilage in osteoarthritis. In: Moskowitz RW, Howe DS, Goldberg VM, Mankin HJ, editors. Osteoarthritis: diagnosis and medical/surgical management. Saunders, Philadelphia 1992, 109-54

\section{Mankin HJ, Dorfman H, Lippiello L, Zarins A (1971):}

Biochemical and metabolic abnormalities in articular cartilage from osteo-arthritic human hips. II. Correlation of morphology with biochemical and metabolic data.

J Bone Joint Surg Am 53, 523-37

\section{Maroudas A, Evans H, Almeida L (1973):}

Cartilage of the hip joint. Topographical variation of glycosaminoglycan content in normal and fibrillated tissue.

Ann Rheum Dis $\underline{32}, 1-9$ 
Martel W (1973):

Radiology of the rheumatic diseases.

JAMA $\underline{224}, 791-8$

Mateescu RG, Todhunter RJ, Lust G, Burton-Wurster N (2005):

Increased MIG-6 mRNA transcripts in osteoarthritic cartilage.

Biochem Biophys Res Commun $\underline{32}$, 482-6

Meachim G, Emery IH (1974):

Quantitative aspects of patello-femoral cartilage fibrillation in Liverpool necropsies.

Ann Rheum Dis $\underline{33}, 39-47$

\section{Melrose J, Roughley P, Knox S, Smith S, Lord M, Whitelock J (2006):}

The structure, location, and function of perlecan, a prominent pericellular proteoglycan of fetal, postnatal, and mature hyaline cartilages.

J Biol Chem 281, 36905-14

\section{Melrose J, Hayes AJ, Whitelock JM, Little CB (2008):}

Perlecan, the "jack of all trades" proteoglycan of cartilaginous weight-bearing connective tissues.

Bioessays $\underline{30}$, 457-69

\section{Meyenberg K, Kubik S, Palla S (1986):}

Relationships of the muscles of mastication to the articular disc of the temporomandibular joint.

Schweiz Monatsschr Zahnmed 96, 815-34

\section{Miller R, Kettelkamp DB, Laubenthal KN, Karagiorgos A, Smidt GL (1973):}

Quantitative correlations in degenerative arthritis of the knee.

J Bone Joint Surg Am 55, 956-62 


\section{Mills DK, Daniel JC, Herzog S, Scapino RP(1994a):}

An animal model for studying mechanisms in human temporomandibular joint disc derangement.

J Oral Maxillofac Surg 르, 1279-92

\section{Mills DK, Fiandaca DJ, Scapino RP (1994b):}

Morphologic, microscopic, and immunohistochemical investigations into the function of the primate TMJ disc.

J Orofac Pain $\underline{8}, 136-54$

\section{Miosge N, Sasaki T, Timpl R (2002):}

Evidence of nidogen-2 compensation for nidogen-1 deficiency in transgenic mice.

Matrix Biol 21, 611-21

\section{Mizoguchi I, Nakamura M, Takahashi I, Kagayama M, Mitani H (1990):}

An immunohistochemical study of localization of type I and type II collagens in mandibular condylar cartilage compared with tibial growth plate.

Histochemistry $\underline{93}, 593-9$

\section{Mizoguchi I, Nakamura M, Takahashi I, Kagayama M, Mitani H (1992):}

A comparison of the immunohistochemical localization of type I and type II collagens in craniofacial cartilages of the rat.

Acta Anat 144, 59-64

Moffett BC Jr, Johnson LC, Mccabe JB, Askew HC (1964):

Articular remodelling in the adult human temporomandibular joint.

Am J Anat $\underline{115}$, 119-41

\section{Moskowitz RW, Altman RD, Hochberg MC, Goldberg VM:}

Osteoarthritis, Fourth Edition. Diagnosis and Medical/Surgical Management.

Lippincott Williams \& Wilkins Wolters Kluwer, Philadelphia 2007, 3-253 
Mow VC, Ratcliffe A, Poole AR (1992):

Cartilage and diarthrodial joints as paradigms for hierarchical materials and structures.

Biomaterials $\underline{13}, 67-97$

Murray AB, Schmidt J, Rieke L (1986):

Retrovirus-induced osteopetrosis in mice. Ultrastructural evidence of early virus production in osteoblasts and osteocytes.

Am J Pathol 124, 319-23

Murshed M, Smyth N, Miosge N, Karolat J, Krieg T, Paulsson M, Nischt R (2000):

The absence of nidogen 1 does not affect murine basement membrane formation.

Mol Cell Biol 20, 7007-12

Nicole S, Davoine CS, Topaloglu H, Cattolico L, Barral D, Beighton P, Hamida CB,

Hammouda H, Cruaud C, White PS (2000):

Perlecan, the major proteoglycan of basement membranes, is altered in patients with

Schwartz-Jampel syndrome (chondrodystrophic myotonia).

Nat Genet $\underline{26}, 480-3$

\section{Noonan DM, Hassell JR (1993):}

Perlecan, the large low-density proteoglycan of basement membranes: structure and variant forms.

Kidney Int $\underline{43}, 53-60$

\section{Noonan DM, Fulle A, Valente P, Cai S, Horigan E, Sasaki M, Yamada Y, Hassell JR} (1991):

The complete sequence of perlecan, a basement membrane heparan sulfate proteoglycan, reveals extensive similarity with laminin A chain, low density lipoprotein-receptor, and the neural cell adhesion molecule.

J Biol Chem 266, 22939-47 


\section{Öberg T (1964):}

Morphology, growth and matrinx formation of the mandibular joint of the guinea pig.

Diss. Trans Royal Schools of Dent Stockholm/Umeå 2, 10.

\section{Öberg T:}

Käleder. In: Bidfunktion/Bettfysiologi I.

eds. Krogh-Poulsen, W. Und Carlsen, O., Munksgaard/Copenhagen 1977

\section{Öberg T, Fajers CM, Lohmander S, Friberg U (1967):}

Autoradiographic studies with H3-thymidine on cell proliferation and differentiation in the mandibular joint of young guinea pigs.

Odontol Revy $\underline{18}, 327-44$

\section{Öberg T, Carlsson GE, Fajers CM (1971):}

The temporomandibular joint. A morphologic study on a human autopsy material.

Acta Odontol Scand 29, 349-84

\section{Okabe T (1989):}

Experimental studies on the spontaneous osteoarthritis in C57black mice.

J Tokyo Med Univ $\underline{47}, 546-57$

Palotie A, Väisänen P, Ott J, Ryhänen L, Elima K, Vikkula M, Cheah K, Vuorio E, Peltonen L (1989):

Predisposition to familial osteoarthrosis linked to type II collagen gene.

Lancet $\underline{1989,1}$, 924-7

\section{Paulsson M, Aumailley M, Deutzmann R, Timpl R, Beck K, Engel J (1987):}

Laminin-nidogen complex. Extraction with chelating agents and structural characterization.

Eur J Biochem 166, 11-9 


\section{Poole CA, Matsuoka A, Schofield JR (1991):}

Chondrons from articular cartilage. III. Morphologic changes in the cellular microenvironment of chondrons isolated from osteoarthritic cartilage.

Arthritis Rheum $\underline{34}, 22-35$

\section{Pugh JW, Radin EL, Rose RM (1974):}

Quantitative studies of human subchondral cancellous bone. Its relationship to the state of its overlying cartilage.

J Bone Joint Surg Am 56, 313-21

\section{Putz R, Pabst R:}

Sobotta-Atlas der Anatomie des Menschen.

Band 1. 22. Auflage, Elsevier Urban\&Fischer Verlag, München-Wien-Baltimore 2006, 63

\section{Radin EL, Paul IL, Rose RM (1972):}

Role of mechanical factors in pathogenesis of primary osteoarthritis.

Lancet $1972,1,519-22$

\section{Radin EL, Parker HG, Pugh JW, Steinberg RS, Paul IL, Rose RM (1973):}

Response of joints to impact loading. III. Relationship between trabecular microfractures and cartilage degeneration.

J Biomech $\underline{6}$, 51-7

\section{Rees LA (1954):}

The structure and function of the mandibular joint.

Br Dent J 96, 125-133

\section{Rintala M, Metsäranta M, Säämänen AM, Vuorio E, Rönning O (1997):}

Abnormal craniofacial growth and early mandibular osteoarthritis in mice harbouring a mutant type II collagen transgene.

J Anat 190, 201-8 


\section{Romeis B:}

Mikroskopische Technik.

P. Böck (Hrsg) 17., Urban \& Schwarzenberg, München, Wien, Baltimore 1989

\section{Salmivirta K, Talts JF, Olsson M, Sasaki T, Timpl R, Ekblom P (2002):}

Binding of mouse nidogen-2 to basement membrane components and cells and its expression in embryonic and adult tissues suggest complementary functions of the two nidogens.

Exp Cell Res $\underline{279}, 188-201$

\section{Sandell LJ, Aigner T (2001):}

Articular cartilage and changes in arthritis. An introduction: cell biology of osteoarthritis.

Arthritis Res $\underline{3}, 107-13$

\section{Sarnat BG:}

Craniofacial growth, postnatal.

In: Encyclopedia of Human Biology, vol. 2 (ed. Dulbecco R)

Academic Press, New York 1991, 697-708

\section{Savalle WP (1988):}

Some aspects of the morphology of the human temporomandibular joint capsule.

Acta Anat 131, 292-6

\section{Scapino RP (1991):}

The posterior attachment:

Its structure, function, and appearance in TMJ imaging studies. Part 1.

J Craniomandib Disord $\underline{5}, 83-95$

\section{Schmidt J, Casser-Bette M, Murray AB, Luz A, Erfle V (1987):}

Retrovirus-induced osteopetrosis in mice. Effects of viral infection on osteogenic differentiation in skeletoblast cell cultures.

Am J Pathol 129, 503-10 
Schymeinsky J, Nedbal S, Miosge N, Pöschl E, Rao C, Beier DR, Skarnes WC, Timpl R, Bader BL (2002):

Gene structure and functional analysis of the mouse nidogen-2 gene: nidogen-2 is not essential for basement membrane formation in mice.

Mol Cell Biol 22, 6820-30

\section{Sicher H (1949):}

Oral Anatomy. C.V. Mosby Co., St. Louis 1949

\section{Sicher H:}

Funktional anatomy of the temporomandibular joint, in: Sarat B.G. (ed): The

Temporomandibular Joint. Charles C Thomas, Publisher, Springfield/IL 1951, 3-40

\section{Silberberg M, Silberberg R (1960):}

Osteoarthrosis in mice fed diets enriched with animal or vegetable fat.

Arch Pathol 70, 385-90

\section{Silbermann M (1976):}

Experimentally induced osteoarthrosis in the temporomandibular joint of the mouse.

Acta Anat 96, 9-24

Silbermann M, Livne E (1979):

Age-related degenerative changes in the mouse mandibular joint.

J Anat $\underline{129}$, 507-20

\section{Sokoloff L (1959):}

Osteoarthritis in laboratory animals.

Lab Invest $\underline{8}, 1209-17$

\section{Sokoloff L (1977):}

The biology of degenerative joint disease.

Acta Rhumatol Belg 1, 155-6 


\section{Sokoloff L, Habermann RT (1958):}

Idiopathic necrosis of bone in small laboratory animals.

Arch Pathol 65, 322-30

\section{Sokoloff L, Crittenden LB, Yamamoto RS, Jay GE Jr (1962):}

The genetics of degenerative joint disease in mice.

Arthritis Rheum $\underline{5}, 531-46$

Spranger J, Hall BD, Häne B, Srivastava A, Stevenson RE (2000):

Spectrum of Schwartz-Jampel syndrome includes micromelic chondrodysplasia, kyphomelic dysplasia, and Burton disease.

Am J Med Genet 94, 287-95

\section{Stanson AW, Baker HL Jr (1976):}

Routine tomography of the temporomandibular joint.

Radiol Clin North Am $\underline{14}, 105-27$

\section{SundarRaj N, Fite D, Ledbetter S, Chakravarti S, Hassell JR (1995):}

Perlecan is a component of cartilage matrix and promotes chondrocyte attachment.

J Cell Sci 108, 2663-72

\section{Takisawa A, Ihara K, Jinguji Y (1982):}

Fibro-architectonics of human temporomandibular joint.

Okajimas Folia Anat Jpn 59, 141-66

\section{Telhag H:}

Studies in degenerative joint disease.

Thesis. University of Lund, Sweden 1973

\section{Tesche F, Miosge N (2004):}

Perlecan in late stages of osteoarthritis of the human knee joint.

Osteoarthritis Cartilage 12, 852-62 


\section{Tesche F, Miosge N (2005):}

New aspects of the pathogenesis of osteoarthritis: the role of fibroblast-like chondrocytes in

late stages of the disease.

Histol Histopathol 20, 329-37

\section{Tillmann B:}

Kauapparat-Kiefergelenk, Artikulatio temporomandibularis.

In: Rauber A, Kopsch, F: Anatomie des Menschen, Bewegungsapparat.

Band 1, Thieme, Stuttgart 1987, 730-744

\section{Timpl R, Brown JC (1996):}

Supramolecular assembly of basement membranes.

Bioessays $\underline{18}, 123-32$

\section{Toller PA (1974):}

Temporomandibular arthropathy.

Proc R Soc Med 67, 153-9

\section{Tominaga K, Hirashima S, Fukuda J (2002):}

An experimental model of osteoarthrosis of the temporomandibular joint in monkeys.

Br J Oral Maxillofac Surg 40, 232-7

Vikkula M, Metsäranta M, Ala-Kokko L (1994):

Type II collagen mutations in rare and common cartilage diseases.

Ann Med 26, 107-14

\section{Vinkka H (1982):}

Secondary cartilages in the facial skeleton of the rat.

Proc Finn Dent Soc ㄱ, 1-137 


\section{Wadhwa S, Embree MC, Bi Y, Young MF (2004):}

Regulation, regulatory activities, and function of biglycan.

Crit Rev Eukaryot Gene Expr 14, 301-15

\section{Wadhwa S, Embree M, Ameye L, Young MF (2005):}

Mice deficient in biglycan and fibromodulin as a model for temporomandibular joint osteoarthritis.

Cells Tissues Organs $\underline{181}, 136-43$

\section{Walton M (1977):}

Degenerative joint disease in the mouse knee; radiological and morphological observations. J Pathol 123, 97-107

\section{Wigren A, Wik O, Falk J (1975):}

Repeated intraarticular implantation of hyaluronic acid. An experimental study in normal and immobilized adult rabbit knee joints.

Ups J Med Sci Suppl 17, 1-20

\section{Xu L, Flahiff CM, Waldman BA, Wu D, Olsen BR, Setton LA, Li Y (2003):}

Osteoarthritis-like changes and decreased mechanical function of articular cartilage in the joints of mice with the chondrodysplasia gene (cho).

Arthritis Rheum $\underline{48}, 2509-18$

\section{Yamamoto K, Shishido T, Masaoka T, Imakiire A (2005):}

Morphological studies on the ageing and osteoarthritis of the articular cartilage in C57 black mice.

J Orthop Surg $\underline{13}$, 8-18 
Yang W, Gomes RR, Brown AJ, Burdett AR, Alicknavitch M, Farach-Carson MC, Carson DD (2006):

Chondrogenic differentiation on perlecan domain I, collagen II, and bone morphogenetic protein-2-based matrices.

Tissue Eng $\underline{12}$, 2009-24

\section{Zarb GA, Carlsson EG:}

In: Physiologie und Pathologie des Kiefergelenks, Grundlagen und Praxis von Diagnose und Therapie.

Quintessenz Verlag-Gmbh, Berlin, Chicago, Rio de Janeiro und Tokio 1985, 14-426

\section{Zenker W (1956):}

Retroarticular plastic pad of the temporomandibular joint and its mechanic significance. Z Anat Entwicklungsgesch $\underline{119}, 375-88$

\section{Zhang YW, Su Y, Lanning N, Swiatek PJ, Bronson RT, Sigler R, Martin RW, Vande Woude GF (2005):}

Targeted disruption of Mig-6 in the mouse genome leads to early onset degenerative joint disease.

Proc Natl Acad Sci U S A $\underline{102}, 11740-5$ 


\section{Danksagung}

Ich möchte mich herzlich beim damaligen Abteilungsleiter Herrn Prof. Dr. med. Dr. med. dent. Alfons Hüls bedanken, der mir unmittelbar nach der Physikumsprüfung angeboten hat, bei ihm in der Abteilung zu promovieren. Es freut mich sehr, dass ich bei ihm in der Prüfung einen positiven Eindruck hinterlassen konnte. Leider ist Herr Prof. Dr. med. Dr. med. dent. Alfons Hüls im August 2010 plötzlich und unerwartet verstorben. Weiterhin möchte ich mich bedanken bei dem heutigen kommissarischen Leiter der Abteilung Prothetik, PD Dr. med. dent. Nikolaus Gersdorff, für die Bereitstellung aller Einrichtungen seines Instituts, die zur Erstellung dieser Arbeit notwendig waren.

Insbesondere möchte ich mich sehr herzlich bei Herrn Prof. Dr. med. Nicolai Miosge, Leiter der AG für orale Geweberegeneration in seiner Funktion als Doktorvater sowie für die Vergabe des Themas dieser Arbeit bedanken. Er ermöglichte mir meine Arbeit frei und selbstständig zu gestalten. Dank seiner investierten Zeit und seiner geduldigen Unterstützung konnte ich die Fertigstellung zeitnah absolvieren.

Besonderer Dank gilt auch meinem Betreuer PD Dr. med. dent. Nikolaus Gersdorff, der mich in das Thema und in alle für diese Arbeit notwendigen Methoden eingelernt hat. Für seine große Hilfsbereitschaft, Unterstützung und Freundschaft bin ich ihm sehr dankbar.

Ich möchte dem gesamten Labor der AG für Orale Rehabilitation dafür danken, dass ich bei allen praktischen Fragen kompetente Hilfestellungen bekommen habe. 